University of Redlands

\title{
HAZUS-MH Analysis of Earthquake Risk at the Census Block Level
}

\author{
A Major Individual Project submitted in partial satisfaction of the requirements \\ for the degree of Master of Science in Geographic Information Systems \\ by \\ Brittany Kelley \\ Mark Kumler, Ph.D., Committee Chair \\ Douglas Flewelling, Ph.D.
}

December 2009 
HAZUS-MH Analysis of Earthquake Risk at the Census Block Level

Copyright (C) 2009

by

Brittany Kelley 
The report of Brittany Kelley is approved.

Douglas Flewelling, Ph.D.

Mark Kumler, Ph.D., Committee Chair

December 2009 



\begin{abstract}
HAZUS-MH Analysis of Earthquake Risk at the Census Block Level

by

Brittany Kelley
\end{abstract}

Southern California is at risk of a severe earthquake occurring in the near future. In order to be as prepared as possible for the impending natural disaster, the City of Redlands utilized FEMA's Hazards U.S. Multi-Hazard (HAZUS-MH) software to estimate social, economic, and physical impacts a potential earthquake could have on the area. The finest aggregation level allowed in HAZUS-MH was the census tract level, but this was not fine enough for the study area because some census tracts are too large to accurately reflect population distribution. In this project, the HAZUS-MH geodatabases were manipulated to use census blocks instead. The census block data used to replace the tracts within HAZUS-MH was first updated using ESRI's Business Analyst 2008 population estimates. Multiple potential earthquakes with varying magnitudes were modeled using the software. A model was created to determine the most suitable schools to act as shelters in the event of an earthquake based on their locations within the neighborhoods with the most need. The results allow disaster management officials to better plan for mitigation and preparedness within the communities. 



\section{Table of Contents}

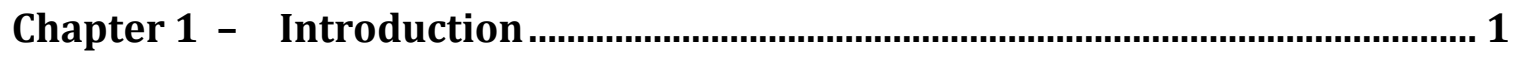

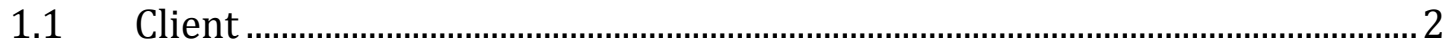

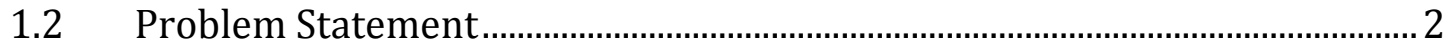

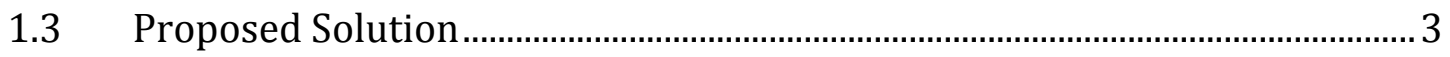

1.3.1 Goals and Objectives ……………………………………………………….

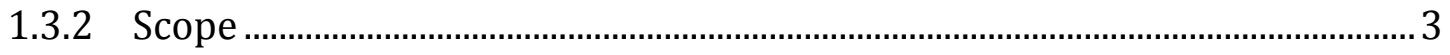

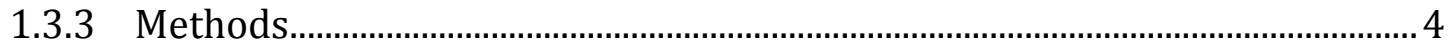

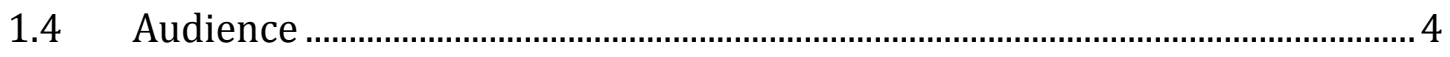

1.5 Overview of the Rest of this Report .................................................................... 4

Chapter 2 - Background and Literature Review................................................. 5

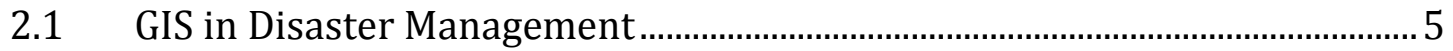

2.2 HAZUS-MH: A Risk Assessment Tool............................................................ 6

2.3 Suitability of Emergency Shelters ....................................................................... 8

2.4 Summary

Chapter 3 - Systems Analysis and Design ….....................................................11

3.1 Problem Statement......................................................................................... 11

3.2 Requirements Analysis ..................................................................................... 11

3.2.1 Functional Requirements................................................................................ 12

3.2.2 Non-Functional Requirements.................................................................... 12

3.3 System Design .................................................................................................. 15

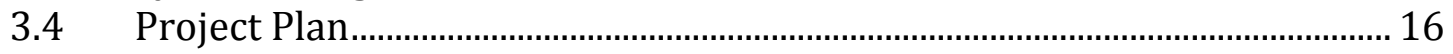

3.4.1 Define and Document Client's Final Requirements ....................................... 17

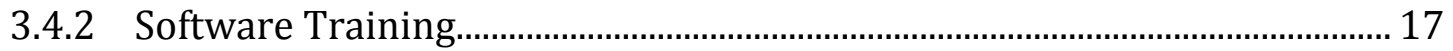

3.4.3 Examine Default Databases Provided with HAZUS-MH ................................. 17

3.4.4 Acquire and Prepare Data................................................................................ 17

3.4.5 Run HAZUS-MH Model ................................................................................ 18

3.4.6 Use ModelBuilder for Further Spatial Analyses ............................................ 18

3.4.7 Prepare Final Documents............................................................................... 18

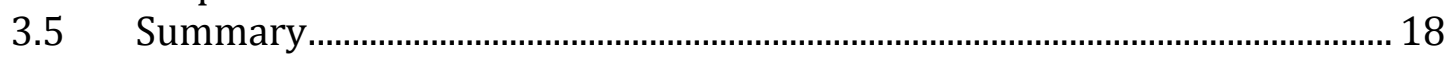

Chapter 4 - Database Design ............................................................................21

4.1 Conceptual Data Model .................................................................................... 21

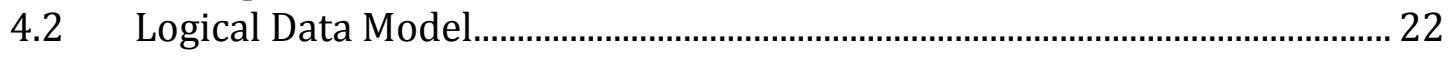

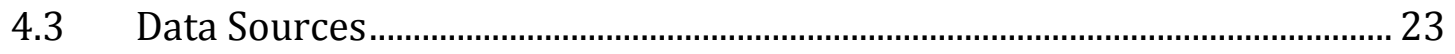

4.3.1 ESRI Business Analyst ..................................................................................... 23

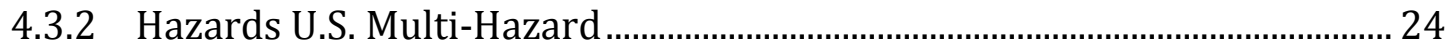

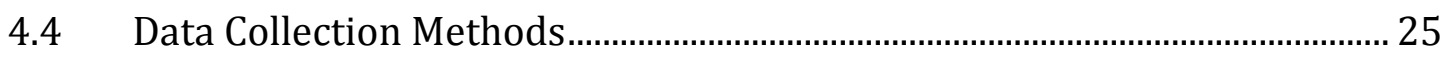

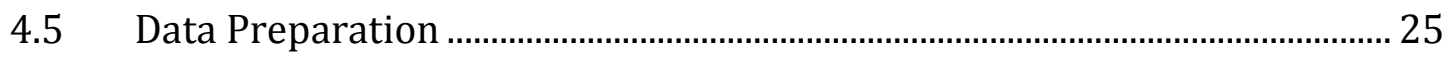

4.6 Summary ………………………………………………………………... 26

Chapter 5 - Implementation ..........................................................................27

5.1 Census Disaggregation .................................................................................. 27

$5.2 \quad$ HAZUS-MH Tract Replacement.......................................................................... 34 


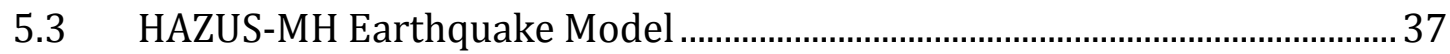

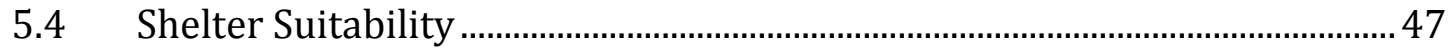

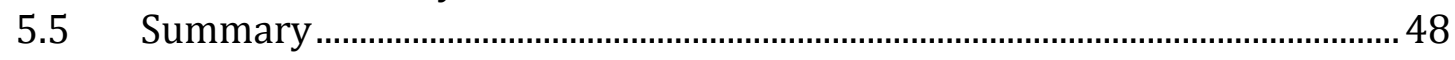

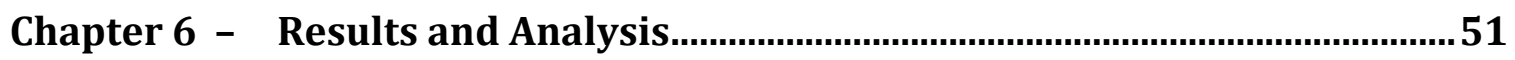

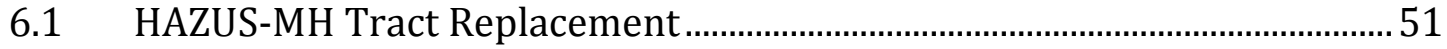

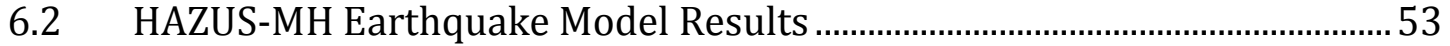

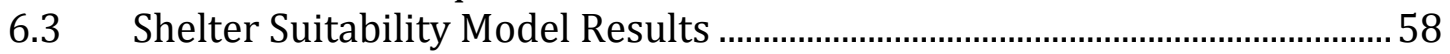

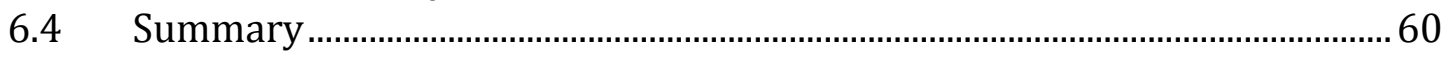

Chapter 7 - Conclusions and Future Work .......................................................61

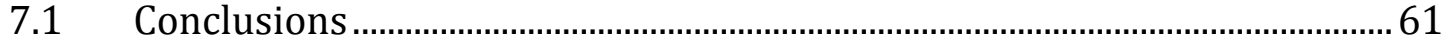

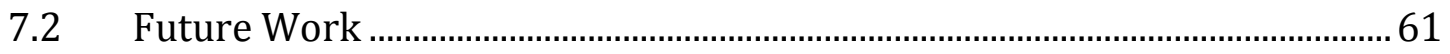

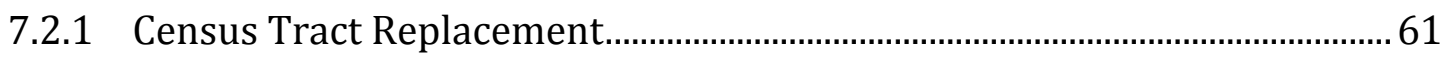

7.2.2 Enhancing HAZUS-MH with User-Supplied Data ............................................. 61

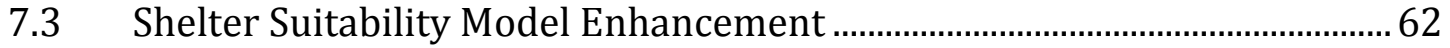

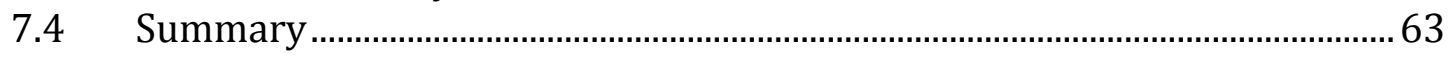

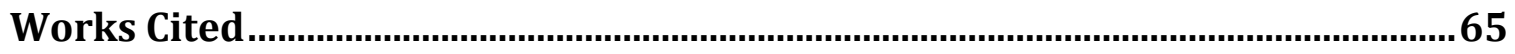

Appendix A. Summary of HAZUS-MH Inventory Databases (Earthquake

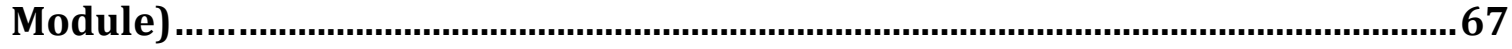

Appendix B. ESRI Business Analyst Demographics Fields ...............................69

Appendix C. Census Disaggregation Field Map and Calculations.....................71 


\section{Table of Figures}

Figure 1.1: Project Study Area and San Andreas Fault ......................................... 1

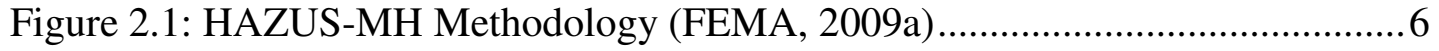

Figure 2.2: HAZUS-MH Analysis Levels (FEMA, 2009a)...................................... 7

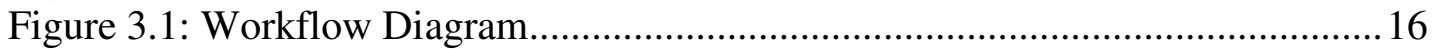

Figure 4.1: Census Disaggregation Conceptual Model .........................................21

Figure 4.2: HAZUS-MH Tract Replacement Conceptual Model ............................22

Figure 5.1: Project Custom Toolbox........................................................................2

Figure 5.2: Clip Census and Delete Fields Model ............................................28

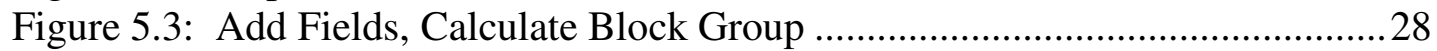

Figure 5.4: Join Census Block Groups to Census Blocks.......................................29

Figure 5.5: Calculate 2008 Demographics Fields ............................................... 31

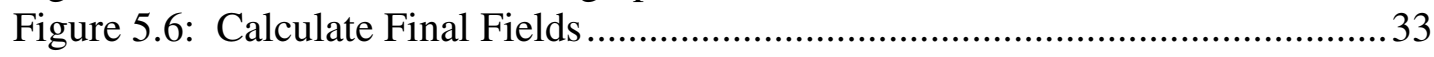

Figure 5.7: Update to HAZUS-MH Geodatabases Using CDMS ........................... 34

Figure 5.8: hzTract and hzCensusBlock Clip .................................................... 35

Figure 5.9: Calculate Tract Fields for Boundary and Building Stock Tables........... 36

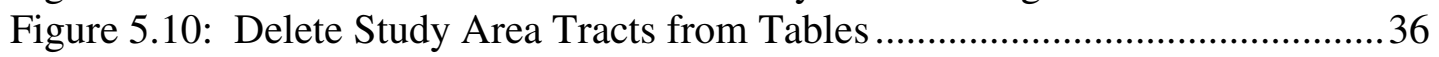

Figure 5.11: Facilities Tract Number Update ...................................................... 37

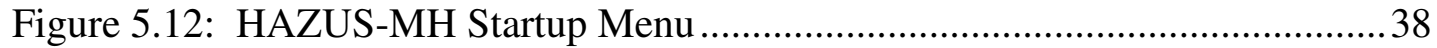

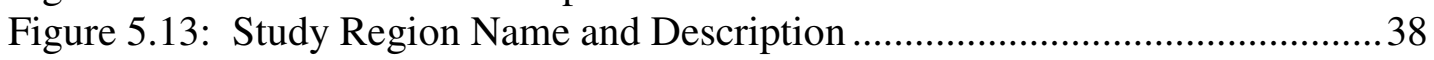

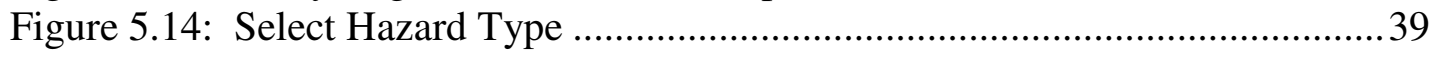

Figure 5.15: Aggregation Level ........................................................................ 40

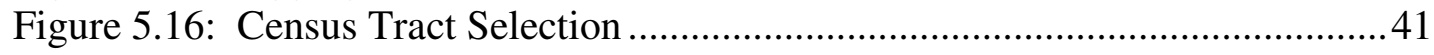

Figure 5.17: Select Census Tracts from Map........................................................4

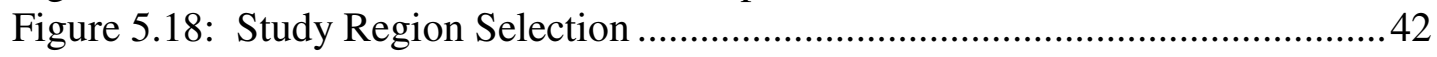

Figure 5.19: Seismic Hazard Type Selection.................................................... 43

Figure 5.20: Fault Selection from Source Event Database ..................................... 44

Figure 5.21: Fault Selection from Map................................................................... 44

Figure 5.22: Define Source Event Parameters ........................................................ 45

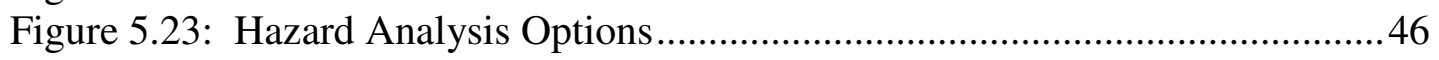

Figure 5.24: Results Menu Options ................................................................ 47

Figure 5.25: School Selection Based on Fire Zones and Major Roads ....................48

Figure 5.26: Selecting Public Schools near High Shelter Requirements ................. 48

Figure 6.1: Study Area Differences ......................................................................51

Figure 6.2: Comparison of Shelter Requirements by Census Tracts and Blocks .....52

Figure 6.3: Shelter Requirements for Specific Tract ...........................................53

Figure 6.4: Total Building Economic Losses per Census Block for Three Scenario

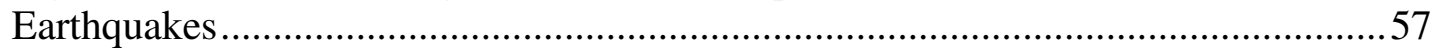

Figure 6.5: Schools Functionality on Day One of Three Earthquake Scenarios ......59 



\section{List of Tables}

Table 1. Functional Requirements ..................................................................... 12

Table 2. Technical Requirements for HAZUS-MH 3 (FEMA, 2009b) ..................... 13

Table 3. Technical Requirements for CDMS (FEMA, 2009b) ................................ 14

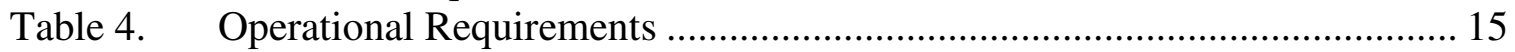

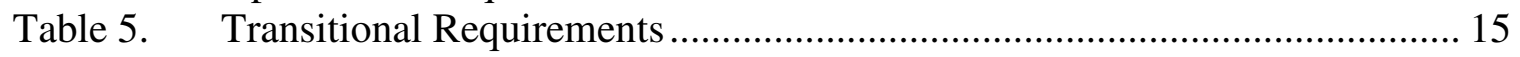

Table 6. Planned Project Tasks and Hours of Effort.............................................. 18

Table 7. Census Disaggregation Logical Model .................................................. 23

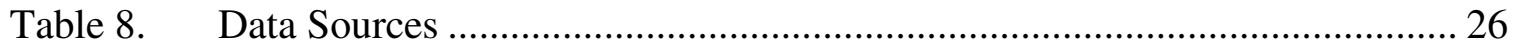

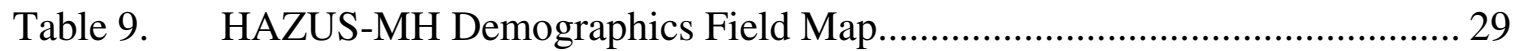

Table 10. Census Disaggregation Ratio Fields ........................................................ 31

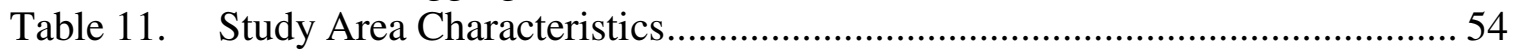

Table 12. Damage Comparisons for 7.5 Earthquake Across Tracts and Blocks ......... 54

Table 13. Damage Comparison for Three Different Earthquakes Across Blocks ........ 55 



\section{List of Acronyms and Definitions}

CDMS

FEMA

HAZUS-MH

NIBS

ORNL

USGS
Comprehensive Data Management System

Federal Emergency Management Agency

Hazards U.S. Multi Hazard

National Institute of Building Sciences

Oak Ridge National Laboratory

United States Geological Survey 



\section{Chapter 1 - Introduction}

Due to its proximity to the San Andreas Fault, the City of Redlands and the surrounding area is expected to be deeply impacted when a major earthquake hits Southern California. The fault runs from the Salton Sea to the north of San Francisco. Redlands is in the southwest corner of San Bernardino County and parts of it are within one mile of the south branch of the fault (Figure 1.1). A recent study (Chong, 2009) indicated that earthquakes with a magnitude greater than 6.7 on the San Andreas Fault occur with an average interval of 137 years, rather than every 150 to 200 years. A portion of the fault just north of Los Angeles has not experienced a severe earthquake since the 1857 Fort Tejon Temblor, and part of the fault near the Salton Sea has not slipped in over 300 years (Jones, et al., 2008). This leads many experts to believe that Southern California is long overdue for a major earthquake.

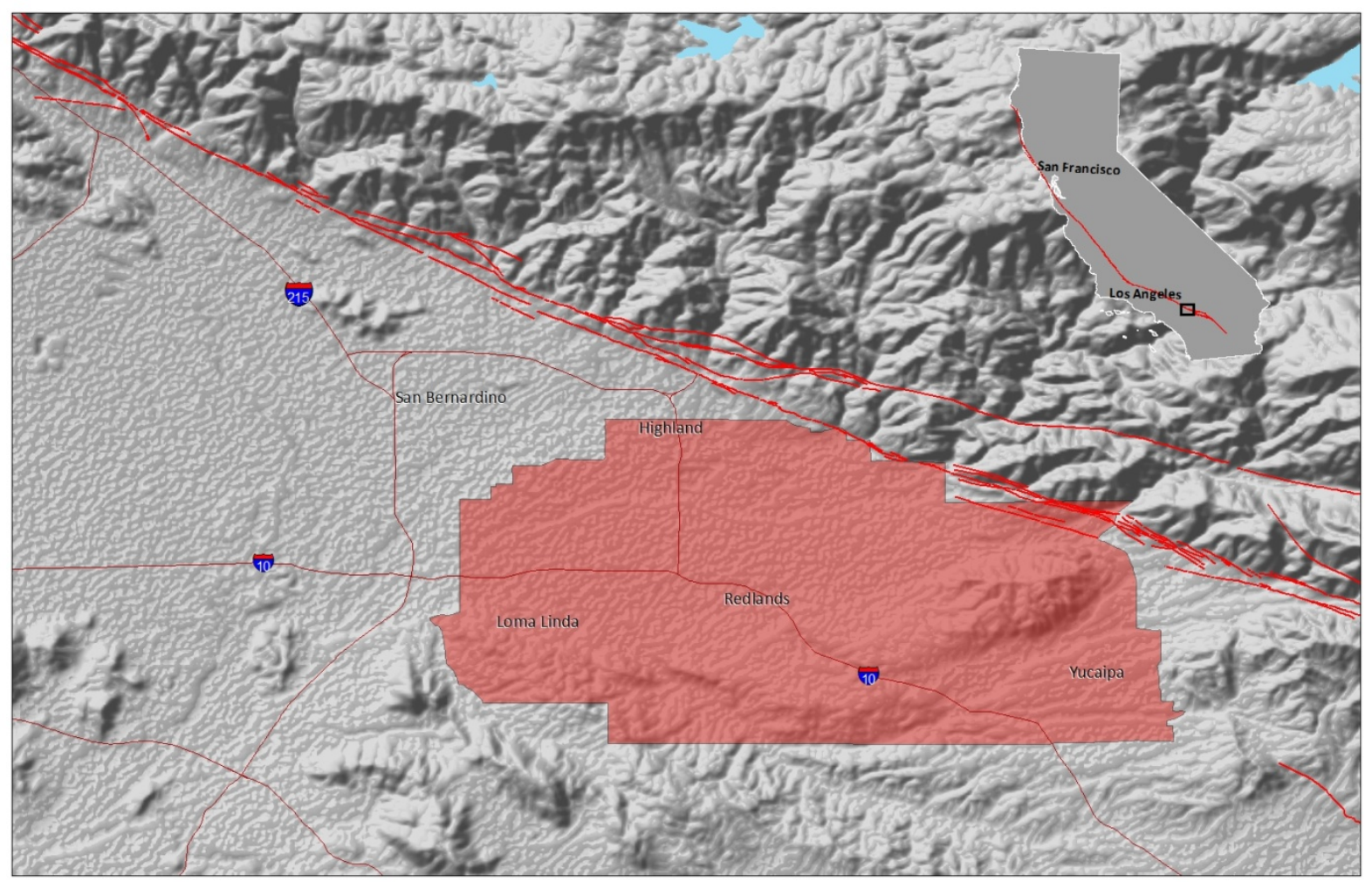

Figure 1.1: Project Study Area and San Andreas Fault

The number of people seeking help from the Red Cross after an earthquake increased from less than half a million to more than five and a half million between the years 1993 and 1999 (Amdahl, 2001). The City of Redlands needs to understand how a severe earthquake will affect the area so that it can be better prepared to deal with it. Redlands currently uses geographic information systems (GIS) for many aspects of its disaster mitigation plan, but would like to incorporate the Hazards U.S. Multi Hazard (HAZUS- 
$\mathrm{MH)}$ software. HAZUS-MH is a powerful risk assessment tool created by the Federal Emergency Management Agency (FEMA) under contract with the National Institute of Building Sciences (NIBS). It estimates economic and physical losses from natural disasters, such as earthquakes, floods, and hurricanes. This project focuses on using the earthquake model to estimate risk in the study area. Redlands needed a localized version of HAZUS-MH to better understand how it will be affected and to prepare for the needs of the residents, such as shelter requirements after an earthquake occurs.

\subsection{Client}

The client for this project was the City of Redlands. The point of contact in the city was Mr. Phil Mielke, the GIS Administrator. Mr. Mielke wants to use GIS to develop a better understanding of where the population of the City of Redlands will be most affected by a severe earthquake. In order to simulate an earthquake occurring in the general Redlands area, he intends to use FEMA's HAZUS-MH Earthquake Model, a risk assessment tool used by communities all over the country to identify potential economic, physical, and social losses suffered after an earthquake occurs.

\subsection{Problem Statement}

The City of Redlands was in need of a more localized version of the HAZUS-MH Earthquake model to better determine the after-effects a major earthquake will have on the city. The geodatabases bundled with the HAZUS-MH software include data aggregated at the state, county, census tract, and census block levels for the entire country. However, the earthquake model does not allow the user to define a study region or utilize the data aggregated at the census block level.

A census tract is defined as "a small, relatively permanent statistical subdivision of a county...designed to be relatively homogenous units with respect to population characteristics, economic status, and living conditions at the time of establishment, census tracts average about 4,000 inhabitants" (U.S. Census Bureau, 2009). In the City of Redlands' case, this was not a fine enough level of analysis to most accurately assess the damage incurred throughout the city. Some census tracts in Redlands are very heterogeneous, including both large areas of commercial real estate and high density residential areas. This may cause a user to misinterpret the losses estimated by HAZUS$\mathrm{MH}$, such as population displacement and building damage.

A census block is defined as "a subdivision of a census tract, a block is the smallest geographic unit for which the Census Bureau tabulates 100-percent data. Many blocks correspond to individual city blocks bounded by streets..." (U.S. Census Bureau, 2009). This definition more closely represents the level of analysis the City of Redlands disaster management officials hoped to achieve using the HAZUS-MH earthquake model.

Further analysis can be done with the model results, such as locating shelters in areas where there will be the most demand for such assistance. This detailed analysis aids the City of Redlands in becoming more prepared for an earthquake, as well as plan for response and recovery when one occurs. 


\subsection{Proposed Solution}

In order to run the earthquake model using census blocks instead of census tracts, the geodatabases included with the HAZUS software were manipulated to use the block attributes as opposed to the tract attributes. Before running the model, the census block data was updated with the 2008 population estimates provided in ESRI Business Analyst. The results generated from the earthquake model, such as estimated population displacement and damage to essential facilities allowed for further analysis to determine suitable shelters for the residents of Redlands.

\subsubsection{Goals and Objectives}

The goal of this project was to modify the HAZUS-MH earthquake model to run using census blocks instead of census tracts. The City of Redlands officials wanted a more detailed analysis level to better plan for an earthquake. The HAZUS-MH software was also used to help determine which schools would make suitable emergency shelters after an earthquake. Schools are often used as shelters for the public but only if they are structurally sound. Other characteristics, like the locations of the shelters in relation to population displacement, helped in determining where shelters will be needed most. Suitable schools will be structurally sound and located in the areas of the community that will need it most.

The objective of this project for the City of Redlands was the opportunity to improve the safety of its residents after an earthquake by determining the areas in the city that will be most affected by an earthquake and identifying safe shelters for displaced population. The disaster management team can also use the results to become better prepared before an earthquake ever occurs.

\subsubsection{Scope}

HAZUS-MH has the potential to be an all-encompassing loss estimation tool; however, the scope was reduced to a level that can be accomplished in the time available. The use of the software was limited to the earthquake model to estimate the damages to the vicinity of Redlands. The majority of the data for this project was included with the HAZUS-MH software. The 2008 population estimates were acquired from ESRI's Business Analyst dataset. After the initial overall analysis was complete for the city, the results were extracted from HAZUS-MH and used to determine suitable shelters for the displaced residents.

The technical components of this project included the Federal Emergency Management Agency's (FEMA) HAZUS-MH software, the accompanying Comprehensive Data Management System (CDMS), and the national dataset that is included with the software. The most recent release of this software, HAZUS-MH MR 3, runs on ArcGIS 9.2 and Windows 2000 or XP. A new release, HAZUS-MH MR4, is now available and runs on ArcGIS 9.3 and Windows XP but was not used for this project due to a backlog of software requests at FEMA.

The deliverables for this project were the result of the earthquake model run with 2008 census block data as well as the updated geodatabases. Several scenario earthquakes were run to assess the damage across the city after earthquakes of varying magnitudes. 
There was sufficient documentation of the progression through this project so that it may be duplicated when there are updates to the data. The documentation can also be used as a reference for future projects that may deploy the same methods to different study areas.

\subsubsection{Methods}

The methods used in this project included requirements analysis, software training, implementation, and final analysis. The requirements analysis was completed by meeting with the client to determine the objectives of the project. This resulted in the decision to use HAZUS-MH to study potential earthquake damage at the census block level. This lead to software training for HAZUS-MH before the implementation stages took place. The implementation stages included disaggregation of 2008 population estimates, manipulating HAZUS-MH geodatabases to use census blocks, running the HAZUS-MH earthquake model, and finally creating a model to determine shelter suitability. The results of the earthquake model with the successful addition of census blocks to the HAZUS-MH geodatabases were reviewed in the final analysis stage.

\subsection{Audience}

This paper is intended for an audience with a basic understanding of disaster management practices and ArcGIS, and assumes a fundamental understanding of FEMA's HAZUSMH software as well. Vocabulary will be used that is specific to the GIS field and the HAZUS-MH software.

\subsection{Overview of the Rest of this Report}

The rest of this report consists of six chapters. Chapter Two provides a background of GIS being used in the disaster management field, as well as a literature review and previous work completed using the HAZUS-MH software as a risk assessment tool. Chapter Three will cover the functional and non-functional requirements and the system design. Chapter Four discusses the database design, the conceptual and logical model, and data sources. Chapter Five describes the process undertaken to modify the HAZUSMH geodatabases. Chapter Six discusses the results and the level of success of the project. Chapter Seven summarizes the project and possibilities for future works. 


\section{Chapter 2 - Background and Literature Review}

Jack Dangermond says in Confronting Catastrophe "GIS works effectively in all four phases of the disaster management cycle: preparedness, mitigation, response, and recovery. Whether analyzing consequences; projecting and predicting; disseminating information; allocating personnel, equipment, and resources; getting from A to B; or picking up the pieces in ways that help rather than hinder stricken families, businesses, and regions, GIS is the tool of choice" (Amdahl, 2001, p. 1). This chapter will research the role of GIS in the disaster management field, how the HAZUS-MH software fits into the disaster management cycle, and how HAZUS-MH can help to determine the suitability of structures to act as shelters after a disaster occurs.

\subsection{GIS in Disaster Management}

All phases in the disaster management cycle depend on data that can be better organized and accessed by utilizing a GIS. These data are usually spatial and can be mapped (ESRI, 1999). There are five phases in the cycle: planning and initiation, mitigation, preparedness, response, and recovery (Greene, 2002). The first three phases take place before a disaster occurs, while the last two take place afterwards. The first questions that need to be answered in the planning and initiation phase are "What is at risk?" and "What will put these assets at risk?" Assets can include a wide range of entities, from structures to people. GIS is an ideal tool for answering these questions. It can map the attributes of these assets against the disasters that will put them at risk in a way that can help disaster management teams understand what to do and where to do it (Greene, 2002). This phase must be completed thoroughly, as it is the building block for following phases. Answers found in the first phase allow disaster management officials to determine where to focus efforts in the subsequent phases (ESRI, 1999).

Governments all over the world and at all levels use GIS in their disaster management plans. A GIS was used in Marin County, CA, to map wildfire risks so county officials could prevent fires where possible, and respond efficiently when necessary (Amdahl, 2001). The Los Angeles County Fire Department used a GIS to study emergency medical response times after a major hospital was shut down. After the Northridge earthquake, measuring 6.7 on the Richter scale, hit downtown Los Angeles in 1994, a GIS was used extensively to keep track of emergency housing grant requests by ZIP code, to map levels of structural damage, and to monitor the available water supply (Amdahl, 2001). These are just a few examples of how a GIS has been used to enhance disaster management planning.

HAZUS-MH falls into the first phase of disaster management because it identifies what is at risk and simulates natural disasters that put those assets in harm's way. "Once information is mapped and data is linked to the map, emergency management planning can begin. Once life, property, and environmental values are combined with hazards, emergency management personnel can begin to formulate mitigation, preparedness, response, and recovery program needs" (ESRI, 1999). HAZUS-MH combines those values with the hazards and allows personnel to move forward with the next phases in the cycle. 


\subsection{HAZUS-MH: A Risk Assessment Tool}

HAZUS-MH is a powerful risk assessment tool that uses a standardized methodology (Figure 2.1) to estimate losses that could occur from earthquakes, hurricane winds, or floods (Bausch, 2003). The losses covered by HAZUS-MH include physical damage to building stock, essential facilities, and infrastructure; economic losses such as lost jobs and reconstruction costs; and social impacts such as displaced household and shelter requirements (FEMA, 2009b).

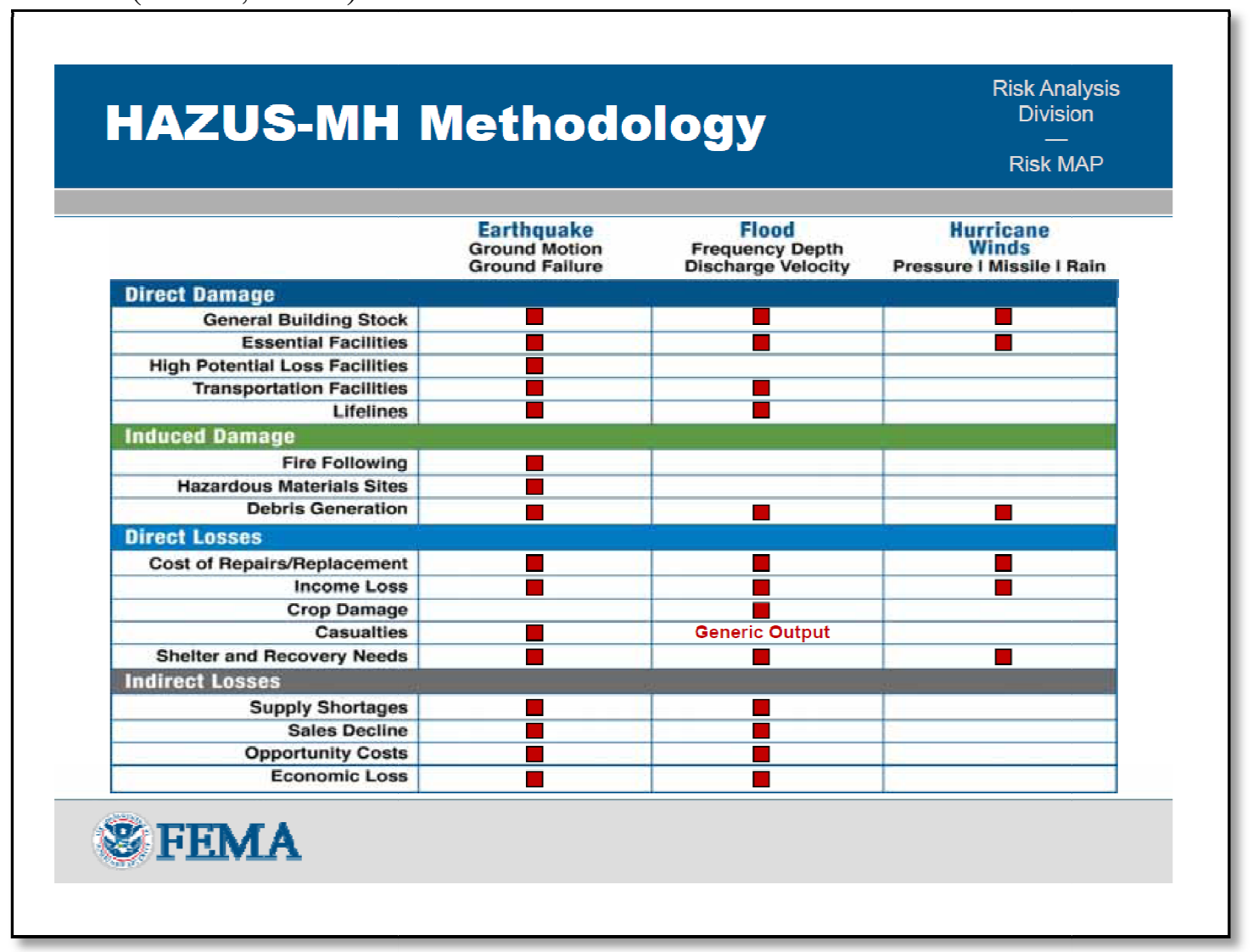

Figure 2.1: HAZUS-MH Methodology (FEMA, 2009a)

There are three different analysis levels in HAZUS-MH depending on the degree of accuracy of the data input (Figure 2.2). Level 1 uses the default data provided with the software to estimate losses. A HAZUS-MH validation study was conducted to determine how reliable and realistic predicted losses from default data were by comparing them to the actual losses of five earthquakes that have occurred in California. The findings of this study showed:

1. Overall estimates of direct economic losses to buildings were typically within $50 \%$ of the documented reports.

2. HAZUS-MH generally predicted that damage to essential facilities (hospitals and schools) would be light and that most would be functional within a day after the event. This estimation was supported with the limited (mainly anecdotal) evidence (National Institute of Building Sciences, 2001). 
Level 2 analyses are implemented by modifying the default data or by adding more accurate city data (Schneider, 1999) and analyses can significantly enhance the estimates of Level 1. According to the validation study, "the use of site specific ground motion and soils information and refined inventory data improved loss predictions" (National Institute of Building Sciences, 2001). Level 3 includes all data from the Level 2 analysis but also has user input from technical experts such as structural engineers or earth scientists (FEMA, 2009b).

\section{HAZUS-MHz Analysis Levels}

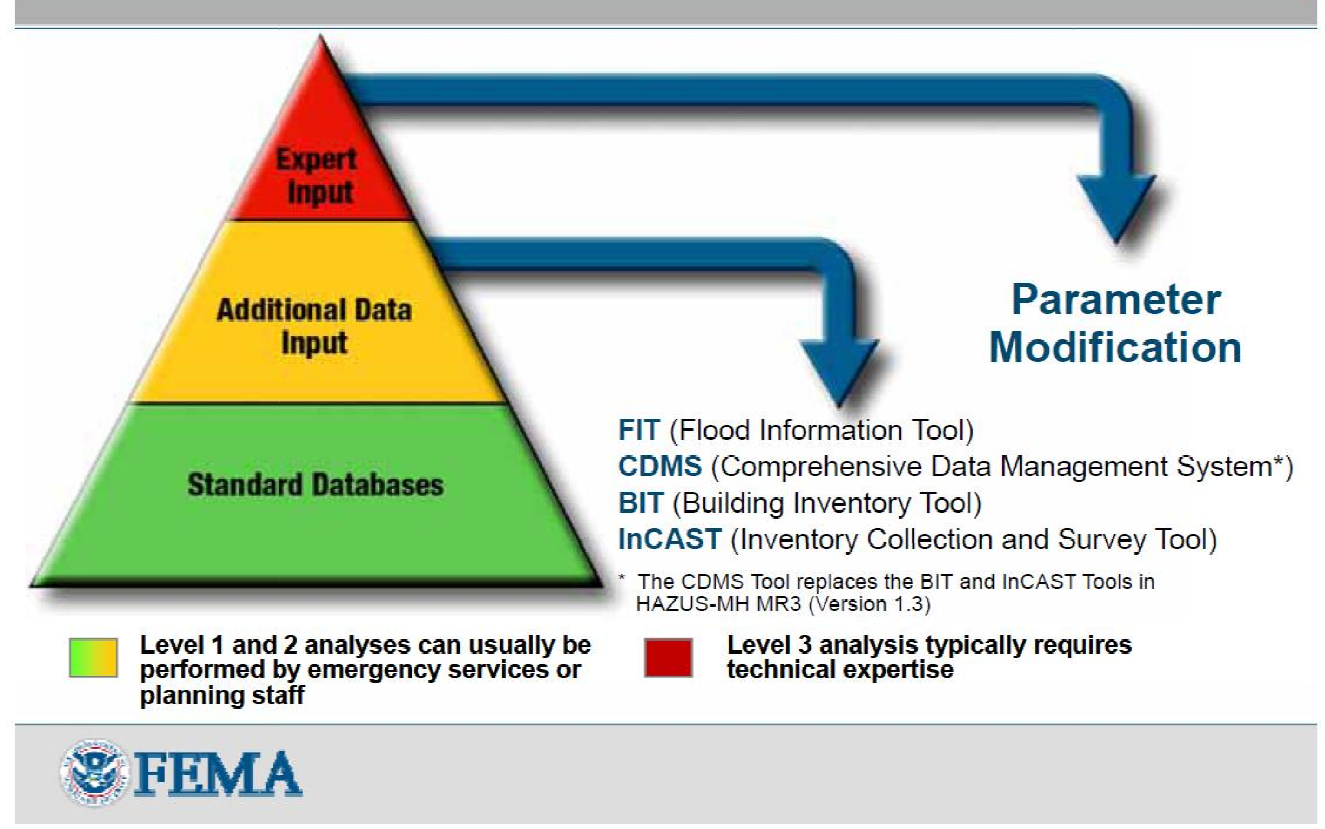

Figure 2.2: HAZUS-MH Analysis Levels (FEMA, 2009a)

HAZUS-MH has been used across the country at every level of government. The Sugar House Community, a historic district in Salt Lake City, Utah, used HAZUS-MH analysis to get a resolution passed in the Utah General Assembly which encouraged the Utah Seismic Safety Commission to compose a list of buildings that were structurally vulnerable to earthquakes and to recommend actions to deal with the problem (FEMA, 2008). It was used by the Pala Band of Mission Indians in northern San Diego to assess the damage they may incur during a major earthquake. Their fears of potential damage after a severe earthquake were confirmed when HAZUS-MH predicted, using a 7.1 magnitude scenario earthquake, that 5,262 buildings would be moderately damaged and 382 buildings could possibly suffer total destruction (FEMA, 2009c). The Golden Guardian exercise was conducted in San Francisco using a scenario earthquake matching that of the great 1906 earthquake. The earthquake had a 7.8 magnitude and HAZUS-MH predicted over 3,000 deaths and up to 120,000 people needing short term shelters 
(FEMA, 2009b). Federal, state, and local governments were involved in this exercise to better prepare themselves for an actual event.

The ShakeOut Scenario, similar to Golden Guardian, was a project conducted in late 2008 to study the physical, social, and economic effects of a 7.8 magnitude earthquake on eight counties in southern California, including San Bernardino County. Los Angeles

County had local building inventory data available and was therefore able to increase the accuracy of the loss assessment in that area. The HAZUS-MH default building inventory had $40 \%$ less square footage than the tax assessor's data from the county (Jones, et al., 2008) and would have underestimated losses if this data had not been used. San Bernardino and Riverside Counties did not have countywide inventory data available so the default data was used. According to the ShakeOut Scenario, a publication documenting the results of the project, "The losses estimated in Riverside and San Bernardino Counties should therefore be considered lower bound estimates and with inventory enhancement, they might increase on the order of $20-30 \%$ " (Jones, et al., 2008, p. 109). The ShakeOut Scenario also anticipates that the need for shelters in San Bernardino and Riverside Counties will be greater than other impacted areas (Jones, et al., 2008). These findings make it even more important to determine the effect of an earthquake on specific buildings to act as shelters in the City of Redlands. While HAZUS-MH is a great risk assessment tool for broad estimates, Redlands needs a more site specific analysis.

These examples use the aggregation levels provided within the HAZUS-MH earthquake model, which only allows the user to define a study region at the census tract level. Redlands needs to perform the analysis at the census block level. FEMA says that the census tract is the smallest aggregation unit used by the earthquake model but the "open architecture allows sophisticated users to modify the appropriate files in order to permit analysis by census block or grid cell" (FEMA, 2009b). The State of Wyoming was able to do this through a contract with PBS\&J, the consulting firm awarded the contract to develop the HAZUS-MH applications and update the hazard and inventory databases under supervision from the National Institute of Buildings Sciences. The original census tract boundary features were replace with census blocks. They did this in areas with low population and building density (FEMA, 2005). It can also be done to compare analysis results from the earthquake model to analysis results at the block level from the flood model. In an international approach, LandScan data from the Oak Ridge National Laboratory (ORNL) was used to create an urban and rural grid based on population estimates for Sicily (Bausch \& Hansen, 2009). The geodatabases in HAZUS$\mathrm{MH}$ were then modified to represent the new grid as the boundary file, and allowed the user to define a study area in Sicily.

\subsection{Suitability of Emergency Shelters}

A vital part of disaster preparation is identifying shelters for the public before an earthquake occurs. Having suitable shelters will also aid in response and recovery after an earthquake. Emergency shelters are often primarily used as some other public structure, such as schools or hospitals. These buildings are identified as "essential facilities" (National Institute of Building Sciences, 2002). While HAZUS-MH is a powerful tool, there have also been studies on the suitability of facilities without the use of this software. 
GIS have been widely used for site suitability studies for facilities ranging from steam plants to nuclear dumping sites, but there is a lack of documentation of GIS being used for emergency shelter site suitability (Kar \& Hodgson, 2008). Kar and Hodgson explored using a GIS model to determine site suitability of hurricane shelters in 17 counties in southern Florida. Factors such as flood zones, proximity to highways, evacuation routes, hazard sites, hospitals, and population were used to evaluate suitability of existing shelters and buildings that could potentially be used as shelters. This study was primarily concerned with the physical location of shelters, as opposed to the structural suitability of a building (Kar \& Hodgson, 2008).

The State Civil Defense of the County of Hawaii created customized data for HAZUS-MH "to account for Hawaii seismicity and ground motion studies from past earthquakes, the spatial distribution of soil types and volcanic ash deposits, Hawaii and Maui building construction types and their numbers and distribution" (Hawaii State Department of Defense, 2005, p. 5). This data greatly increased the possibility for HAZUS-MH to return more accurate estimates of the damage to buildings by including details that the national database did not have, such as detailed construction types, code adoption, and enforcement policy. They were able to determine that out of 93 schools, 51-60 would be moderately damaged after the most severe earthquake (Hawaii State Department of Defense, 2005).

In a study similar to determining the performance of schools in an earthquake, California is using HAZUS-MH to determine the structural vulnerability of hospitals to ensure that patients being treated during and after an earthquake will be protected. After several hospitals were damaged in the 1994 Northridge earthquake, a bill was passed requiring all hospitals to be "seismically evaluated and retrofitted, if needed" (FEMA, 2009b). Using HAZUS-MH has aided the state in accurately identifying hospitals that need retrofitting while saving the state billions of dollars at the same time (FEMA, 2009b). Both of these studies are at a much larger scale than the one required by the City of Redlands, but the data was still successfully localized to the appropriate level to determine building damage.

\subsection{Summary}

Southern California is a great risk for a severe earthquake in the near future. The City of Redlands needs to be prepared when catastrophic event occurs. GIS has long been used in disaster management to analyze spatial data and display it usefully on maps. HAZUS$\mathrm{MH}$ is a software program that simply builds on this concept. It has been used all over the country and in all levels of government to solve different problems. The HAZUS-MH earthquake model only allows users to define a study region at the census tract aggregation level. HAZUS-MH allows for users to modify the databases in order to use census blocks or create a user-defined grid. HAZUS-MH can also help the city determine which schools will be suitable to act as shelters after an earthquake and where the residents who might require shelter will most likely be located. The next chapter will discuss the functional and non-functional requirements, as well as review the system design and project plan. 



\section{Chapter 3 - Systems Analysis and Design}

This chapter discusses the functional and non-functional requirements to successfully implement HAZUS-MH at the block level for the study area. It covers hardware and software requirements, as well as operational and transitional requirements. This chapter also discusses the original project plan and how changes to the project were handled to ensure completion.

\subsection{Problem Statement}

The City of Redlands was in need of a more localized version of the HAZUS-MH Earthquake model to better determine the after-effects a major earthquake will have on the city. The geodatabases bundled with the HAZUS-MH software include data aggregated at the state, county, census tract, and census block levels for the entire country. However, the earthquake model does not allow the user to define a study region or utilize the data aggregated at the census block level.

A census tract is defined as "a small, relatively permanent statistical subdivision of a county...designed to be relatively homogenous units with respect to population characteristics, economic status, and living conditions at the time of establishment, census tracts average about 4,000 inhabitants" (U.S. Census Bureau, 2009). In the City of Redlands' case, this was not a fine enough level of analysis to most accurately assess the damage incurred throughout the city. Some census tracts in Redlands are very heterogeneous, including both large areas of commercial real estate and high density residential areas. This may cause a user to misinterpret the losses estimated by HAZUS$\mathrm{MH}$, such as population displacement and building damage.

A census block is defined as "a subdivision of a census tract, a block is the smallest geographic unit for which the Census Bureau tabulates 100-percent data. Many blocks correspond to individual city blocks bounded by streets..." (U.S. Census Bureau, 2009). This definition more closely represents the level of analysis the City of Redlands disaster management officials hoped to achieve using the HAZUS-MH earthquake model.

Further analysis can be done with the model results, such as locating shelters in areas where there will be the most demand for such assistance. This detailed analysis aids the City of Redlands in becoming more prepared for an earthquake, as well as plan for response and recovery when one occurs.

\subsection{Requirements Analysis}

The requirements analysis includes functional and non-functional requirements. Functional requirements are specific behaviors or actions that the system should accomplish. Non-functional requirements refer to how the system will meet the functional requirements. These can be divided into three categories: technical, operational, and transitional. The requirements analysis for this project focuses on what is needed to manipulate the geodatabases for delivery to the client, rather than the development of a system that will perform specific actions for the client. The functional requirements for this project center on the development of the necessary data for input 
into the HAZUS-MH geodatabases and how the client utilizes the data in the final product. The non-functional requirements include software, hardware, data updates, archiving, training, and documentation.

\subsubsection{Functional Requirements}

The analyst needs to be able to edit and manipulate geodatabases in order to update the demographics data with the most recent estimates from ESRI Business Analyst. The data was disaggregated from the block group level to the block level using ModelBuilder and geoprocessing tools. Comprehensive Data Management System (CDMS) is used to update the HAZUS-MH geodatabases with the most current demographics data, as well as any data the client supplied that could supplement the default geodatabases. After the most current data is in the HAZUS-MH geodatabases, the analyst needs to modify the geodatabases in order to use the census blocks instead of the census tracts.

A critical requirement of the client is that the HAZUS-MH geodatabases remain complete and do not alter the functionality of the HAZUS-MH software. The earthquake simulations can still be run as originally intended, with the exception of the aggregation level. The aggregation level is now at the block level for the study area defined by the client. The client is also able to duplicate the analyst's efforts, should they choose to do so. This may be needed if there are updates to the data, or they wish to expand the study area. The functional requirements for this project are summarized in Table1.

Table 1. Functional Requirements

\begin{tabular}{|l|l|}
\hline Function & Description \\
\hline $\begin{array}{l}\text { The system allows the user to view, edit, } \\
\text { and save geodatabases. }\end{array}$ & $\begin{array}{l}\text { The analyst needs to be able to edit } \\
\text { geodatabases in order to update } \\
\text { demographics data and manipulate } \\
\text { HAZUS-MH geodatabases. }\end{array}$ \\
\hline $\begin{array}{l}\text { The system allows the user to update } \\
\text { HAZUS-MH geodatabases via CDMS. }\end{array}$ & $\begin{array}{l}\text { The analyst needs to be able to input } \\
\text { current demographics data and any client- } \\
\text { supplied data into HAZUS-MH. }\end{array}$ \\
\hline $\begin{array}{l}\text { HAZUS-MH will be fully functional after } \\
\text { modifications are made to the } \\
\text { geodatabases. }\end{array}$ & $\begin{array}{l}\text { The client should be able to run HAZUS- } \\
\text { MH earthquake simulations using the new } \\
\text { geodatabases without error. }\end{array}$ \\
\hline $\begin{array}{l}\text { Client will be able to duplicate analyst's } \\
\text { efforts by means of extensive } \\
\text { documentation. }\end{array}$ & $\begin{array}{l}\text { There will be sufficient documentation to } \\
\text { allow the client, to duplicate or build upon } \\
\text { previous work. }\end{array}$ \\
\hline
\end{tabular}

\subsubsection{Non-Functional Requirements}

The non-functional requirements can be divided into three categories. The technical requirements specify the pertinent software, and the hardware required to most efficiently run that software. The operational requirements detail what should be done by the client to maintain the most accurate risk assessments possible. The transitional requirements discuss how the final product will be delivered to the client with the most ease. 


\subsubsection{Technical Requirements}

The technical requirements are directed towards the analyst's requirements to complete the necessary work, as well as the client's ability to access and use the data and software. The major technical component of this project is the HAZUS-MH software and the accompanying CDMS. The technical requirements for these two pieces of software encompass practically everything needed for all aspects of the project. The HAZUS-MH software requires ArcGIS 9.2, Windows XP, and sufficient disk space to allow for several earthquake scenarios to be saved (Table 2).

Table 2. Technical Requirements for HAZUS-MH 3 (FEMA, 2009b)

\begin{tabular}{|c|c|c|c|}
\hline Hardware & $\begin{array}{l}\text { Minimum } \\
\text { Pentium }{ }^{\circledR} \text { III } \\
1 \text { GHz core speed } \\
512 \text { MB RAM } \\
\text { Note: Allows } \\
\text { moderately fast } \\
\text { analysis of small } \\
\text { communities only. }\end{array}$ & $\begin{array}{l}\text { Moderate } \\
\text { Pentium }{ }^{\circledR} \mathrm{IV} \\
2 \mathrm{GHz} \text { core speed } \\
1 \mathrm{~GB} \text { RAM } \\
\text { Note: Allows fast } \\
\text { analysis of medium- } \\
\text { sized communities } \\
\text { or real-time } \\
\text { analysis for small } \\
\text { communities. }\end{array}$ & $\begin{array}{l}\text { Preferred } \\
\text { Pentium }{ }^{\circledR} \mathrm{IV} \\
3 \mathrm{GHz} \text { (or better) } \\
\text { core speed } \\
2 \mathrm{~GB} \text { RAM } \\
\text { Note: Allows fast } \\
\text { analysis of large } \\
\text { urban areas and } \\
\text { real-time analysis } \\
\text { for all communities. }\end{array}$ \\
\hline $\begin{array}{l}\text { Computer Storage: } \\
\text { Free Hard Disk } \\
\text { Space }\end{array}$ & $\begin{array}{l}10 \text { GB } \\
\text { Allows installation } \\
\text { of HAZUS-MH and } \\
\text { storage of three } \\
\text { scenarios for a } \\
\text { medium-sized } \\
\text { community. }\end{array}$ & $\begin{array}{l}40 \mathrm{~GB} \\
\text { Allows installation } \\
\text { of HAZUS-MH and } \\
\text { storage of three } \\
\text { scenarios for large } \\
\text { urban areas. }\end{array}$ & $\begin{array}{l}120 \mathrm{~GB} \\
\text { Allows installation } \\
\text { of HAZUS-MH and } \\
\text { storage of } 25 \text { or } \\
\text { more scenarios for } \\
\text { large urban areas. }\end{array}$ \\
\hline $\begin{array}{l}\text { Hardware } \\
\text { Accessories }\end{array}$ & \multicolumn{3}{|c|}{$\begin{array}{l}\text { DVD-ROM reader with } 12 \times \text { minimum read speed } \\
\text { Graphics Card with } 1024 \text { x } 768 \text { minimum resolution } \\
\text { Mouse, Keyboard and } 19 " \text { Monitor }\end{array}$} \\
\hline $\begin{array}{l}\text { Supporting } \\
\text { Software }\end{array}$ & \multicolumn{3}{|c|}{$\begin{array}{l}\text { Microsoft Windows } 2000 \text { SP2, SP3, and SP4 } \\
\text { Microsoft Windows XP SP1 and SP2 (U.S. English Version) } \\
\text { ArcGIS } 9.2 \text { SP5 } \\
\text { ArcGIS Spatial Analyst extension required for Flood Model } \\
\text { Note: Will not run on Windows Vista } 64 \text { bit. HAZUS-MH running } \\
\text { on Windows Vista is not yet supported. }\end{array}$} \\
\hline
\end{tabular}

CDMS runs independently of ArcGIS but requires sufficient disk space and several other pieces of software, which are included in the installation (Table 3). The analyst needs access to ArcGIS, ModelBuilder, and geoprocessing tools in order to disaggregate the population estimates to the block level, as well as edit the HAZUS-MH geodatabases. If the client wishes to duplicate this process, they too will need access to ModelBuilder and certain geoprocessing tools. 
Table 3. Technical Requirements for CDMS (FEMA, 2009b)

\begin{tabular}{|c|c|}
\hline Hardware & $\begin{array}{l}\text { Pentium® IV with } 800 \mathrm{MHz} \text { system bus and } 2.6 \mathrm{GHz} \text { (or better) } \\
\text { core speed } \\
1 \text { GB RAM } \\
\text { Note: Allows for fast import, export, and query for large areas. }\end{array}$ \\
\hline $\begin{array}{l}\text { Computer Storage: } \\
\text { Free Hard Disk } \\
\text { Space }\end{array}$ & $\begin{array}{l}80 \mathrm{MB} \text { Moderate } \\
\text { Allows for base Statewide data and temporary storage for file } \\
\text { imports. }\end{array}$ \\
\hline $\begin{array}{l}\text { Hardware } \\
\text { Accessories }\end{array}$ & $\begin{array}{l}\text { CD-ROM reader with } 12 \times \text { minimum read speed for software } \\
\text { installation } \\
\text { Graphics Card with } 1024 \text { x } 768 \text { minimum resolution } \\
\text { Mouse, Keyboard, and 19" Monitor }\end{array}$ \\
\hline $\begin{array}{l}\text { Software } \\
\text { Requirements }\end{array}$ & $\begin{array}{l}\text { The CDMS application requires that the following programs be } \\
\text { loaded: } \\
\text { - Microsoft Visual FoxPro Driver 9.0* } \\
\text { - Microsoft .NET } 2.0 \text { Framework* } \\
\text { - MS SQL Server } 2005 \text { Express Edition* } \\
\text { - Microsoft Data Access Components } 2.8 \text { Service Pack } 1 * \\
\text { - Microsoft J\# Distributable File* } \\
\text { - ESRI ArcGIS 9.2 Service Pack } 5 \text { or higher (Engine, } \\
\text { - ArcView, ArcEditor, or ArcMap) } \\
\text { ESRI ArcGIS, ArcView 9.2, Service Pack 5, .NET } \\
\text { Those programs highlighted by an asterisk (*) in the above list will } \\
\text { be installed by CDMS. Please consult the CDMS instructions } \\
\text { document for full details concerning CDMS installation. }\end{array}$ \\
\hline
\end{tabular}

\subsubsection{Operational Requirements}

The operational requirements (Table 4) are solely at the client's discretion and are only required if deemed necessary. As new data become available, the databases should be updated with the most current demographic data for the most accurate analysis results. Software updates are very important with regard to the HAZUS-MH software. Every time there is a new release, the default databases are updated and the methodologies used to predict direct and indirect damages are improved. The HAZUS-MH software is constantly evolving; updates are a must if the client wishes to use the risk assessment software to its full potential. Archiving is optional, and will only be needed if the databases are updated and the client wishes to save past versions, or if the client does not have enough disk space to save the desired number of earthquake scenarios. 
Table 4. Operational Requirements

\begin{tabular}{|l|l|}
\hline Function & Description \\
\hline Database Updates & $\begin{array}{l}\text { Databases will need to be updated when } \\
\text { more current data is available. }\end{array}$ \\
\hline Software Updates & $\begin{array}{l}\text { HAZUS-MH software updates are } \\
\text { necessary to have the most current } \\
\text { methodologies and default data. }\end{array}$ \\
\hline Archiving & $\begin{array}{l}\text { Archiving may be needed if the client } \\
\text { wishes to save older data or earthquake } \\
\text { scenarios. }\end{array}$ \\
\hline
\end{tabular}

\subsubsection{Transitional Requirements}

The transitional requirements (Table 5) address what needs to happen for the deployment of the HAZUS-MH software with the modified geodatabases at the client's site to be successful. If the client does not already have the software installed, then they will need to do so. This is a free software program available from the Federal Emergency Management Agency (FEMA). The employees who deal directly with the software will need basic training to understand the geodatabases and the methodologies used. ESRI offers several free online training courses and the Emergency Management Institute provides more in-depth training free of charge to government employees. The default geodatabases will be replaced with the modified geodatabases and tested to ensure proper installation. Extensive documentation was provided to the client so they understand how the final geodatabase was created. This included the steps taken to disaggregate the 2008 population estimates to the block level, as well as the model used to automate this process. It also included the methods used to replace the census tracts in the HAZUSMH geodatabase with the census blocks for the defined study area. Metadata will be maintained so the client will know where the data came from and how it was changed.

Table 5. Transitional Requirements

\begin{tabular}{|l|l|}
\hline Function & Description \\
\hline Training & $\begin{array}{l}\text { Training will be necessary for employees } \\
\text { who are not familiar with the HAZUS-MH } \\
\text { software. }\end{array}$ \\
\hline Deployment & $\begin{array}{l}\text { Deployment will involve software } \\
\text { installation and database replacement. }\end{array}$ \\
\hline Documentation & $\begin{array}{l}\text { Sufficient documentation will be provided } \\
\text { so the client understands how the final } \\
\text { product was produced. }\end{array}$ \\
\hline
\end{tabular}

\subsection{System Design}

The system design for this project consisted of multiple geodatabases, geoprocessing models, the software used to maintain and edit the geodatabases and models, and the software to run earthquake risk assessment scenarios. Eight geodatabases, which were 
bundled with the HAZUS-MH software, provided the default data used to run the earthquake model. One file geodatabase was created by the analyst to facilitate the disaggregation of the 2008 population estimates to the block level. Another geodatabase was created to facilitate the manipulation of the HAZUS-MH default geodatabases to use blocks instead of tracts. Models were created in both cases to automate the process and the results were then copied into the default HAZUS-MH databases for use in the HAZUS-MH earthquake model. The models were developed using ModelBuilder and geoprocessing tools accessed through ArcMap; the geodatabases were maintained using ArcCatalog. The HAZUS-MH software was used to analyze potential losses from earthquake, and CDMS was used to update the default databases with user-supplied data.

\subsection{Project Plan}

This section discusses the original approach for meeting the goals and objectives of this project and how this approach evolved as the project did. Finalizing the needs and requirements of the client was the first and most important task in starting this project. Once the requirements were established, training on the software and other skills was completed so the subsequent tasks could be carried out. The data were then acquired and reviewed, the analyses were performed, and the final documents created. Figure 3.1 summarizes the major tasks and workflow identified at the beginning of the project. These tasks and how they were modified to fit the project are detailed below. The hours planned to complete each task can be found in Table 6 .

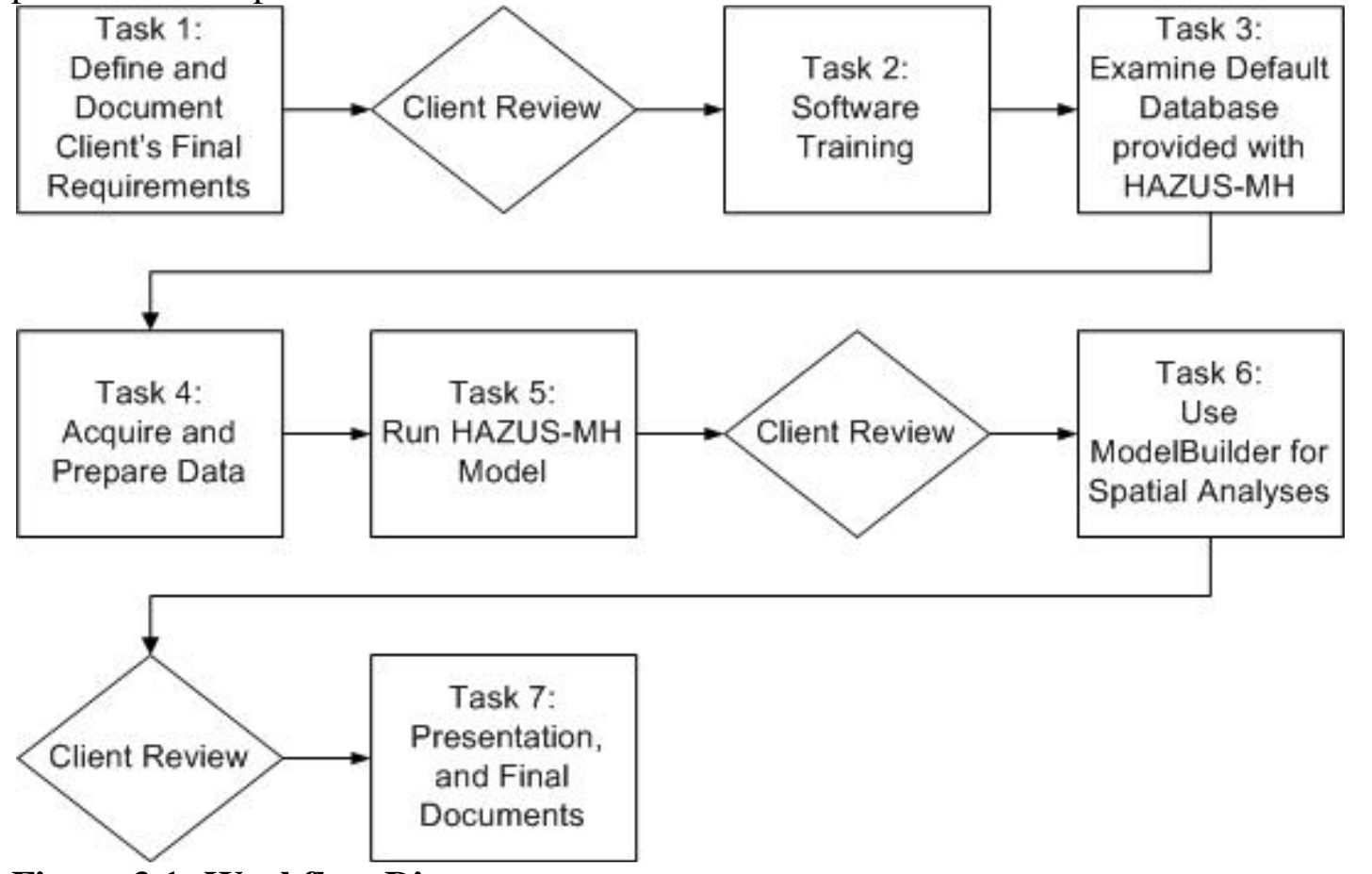

Figure 3.1: Workflow Diagram 


\subsubsection{Define and Document Client's Final Requirements}

Defining the project's final requirements became the most difficult task. The project was originally focused solely on supplementing the default databases with more accurate local data and identifying schools that would be suitable shelters after an earthquake. The project eventually evolved into being most concerned with running HAZUS-MH at the census block level and the suitability of shelters became a secondary component. After reviewing a preliminary HAZUS-MH earthquake scenario, the client determined that the census tract aggregation level was too broad, and did not accurately reflect the distribution of damage across the study area. It was therefore decided that HAZUS-MH would need to be manipulated to run at the census block level for better results.

\subsubsection{Software Training}

Training was the most time consuming task and occurred throughout the course of the project. HAZUS-MH is very complex software with many modules based on data from eight geodatabases. The introductory software training course available through the ESRI virtual campus barely scratched the surface. Further training was needed in order to successfully edit the geodatabases that drive the HAZUS-MH model. The user manual and technical manual for the software proved to be the most effective method for learning the specifics of the software and geodatabases. The online resources available through the FEMA website were also extremely helpful.

\subsubsection{Examine Default Databases Provided with HAZUS-MH}

The default geodatabases provided with the software were examined to determine how complete and accurate they were for the City of Redlands. This was meant to determine where supplementing local data would be beneficial to the accuracy of the assessment. However, it was found that the default data were actually more complete than the city data. It was decided in consultation with the client that the default databases would be used, with the exception of the 2008 demographic updates.

\subsubsection{Acquire and Prepare Data}

All of the data required for this project were readily available. The data used to update the demographics were obtained from ESRI Business Analyst. These data are not available at the census block level, so the 2008 population estimates for block groups were disaggregated to blocks for use in HAZUS-MH. The earthquake model only runs using the tract level, so the census blocks were added to the HAZUS-MH tract feature class and assigned unique eleven-digit IDs so they would be compatible with the field requirements. The feature classes and tables in each geodatabase are all linked by tract number, so every tract number in the study area was updated to reflect the new IDs given to the blocks based on spatial joins. The data required to determine shelter suitability were acquired from the client and included schools, roads, and high risk fire zones. 


\subsubsection{Run HAZUS-MH Model}

After the demographics were updated, and the census tracts were replaced with blocks, several HAZUS-MH earthquake models were run. When an earthquake occurs, it is unknown how severe it will be, or where it will originate. Therefore, each scenario earthquake had different magnitudes, depths, and epicenters to better understand the affects a severe earthquake will have on the study area.

\subsubsection{Use ModelBuilder for Further Spatial Analyses}

After a reasonable understanding of how earthquake damage will be distributed across the study area was obtained, further spatial analysis was performed to answer the first question asked by the client. What schools will be most suitable to act as emergency shelters after a severe earthquake?

\subsubsection{Prepare Final Documents}

The process used to update the demographics and manipulate HAZUS-MH into using blocks instead of tracts was thoroughly documented so it can be duplicated in the future. The final documents were completed and a presentation was given to discuss the findings and successful completion of the project.

Table 6. Planned Project Tasks and Hours of Effort

\begin{tabular}{|r|l|r|}
\hline Task & Description & Hours \\
\hline 1 & Define and Document Requirements & 80 \\
\hline 2 & Software Training & 120 \\
\hline 3 & Examine Default HAZUS Database & 40 \\
\hline 4 & Acquire and Prepare Data & 70 \\
\hline 5 & Run HAZUS-MH Model & 50 \\
\hline 6 & Use ModelBuilder for Spatial Analysis & 60 \\
\hline 7 & Final Documents & 100 \\
\hline & & 520 \\
\hline
\end{tabular}

\subsection{Summary}

The preceding sections detailed the major tasks accomplished in this project and how changes to the project were dealt with to ensure successful completion. Defining the requirements took much longer than originally anticipated but the time consumed was 
offset by the lack of local data to be prepared for addition to the HAZUS-MH geodatabases. The next chapter discusses the data sources, methods used to edit the data, and database design. 


\section{Chapter 4 - Database Design}

This chapter discusses the conceptual and logical models of the geodatabases used in this project. The geodatabase that was delivered to the client was already defined by the HAZUS-MH software. The data models apply to the intermediate geodatabases created to facilitate the demographics update and making the blocks compatible with the tract feature class. This chapter also describes the data sources in detail, collection methods, and data scrubbing.

\subsection{Conceptual Data Model}

A conceptual model is a map of important concepts for a project and their relationships to each other. They are a tool to begin building the framework to move on to the logical model. There are two conceptual models for this project: the first is the census disaggregation model and the second is for the HAZUS-MH Tract Replacement.

The main components of the census disaggregation model are the study area block groups, the study area blocks, and the rate of change from 2000 to 2008 (Figure 4.1). A census block group is composed of several census blocks. The 2008 demographics data were available only at the block group level and had to be disaggregated to the block level for this project. Rates of change were derived from the 2000 and 2008 demographics attributes. These rates were then used to convert the 2000 block demographics to match the 2008 block group demographics.

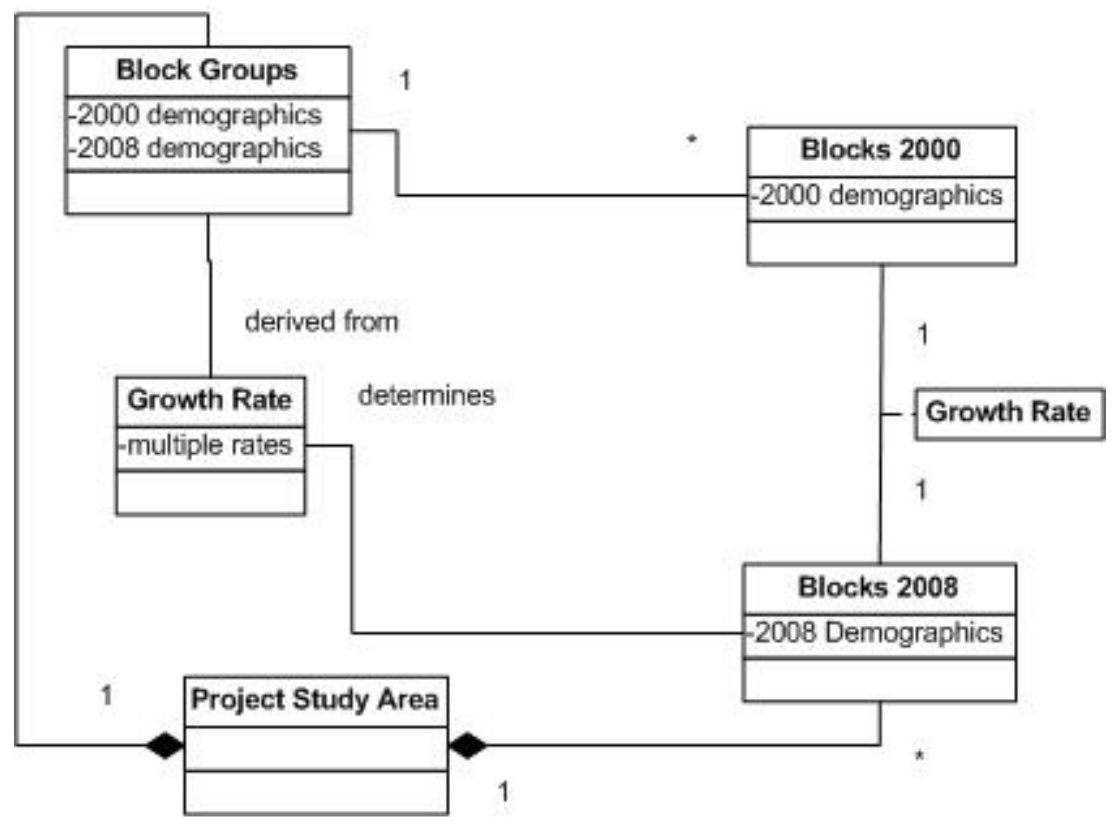

Figure 4.1: Census Disaggregation Conceptual Model

The HAZUS-MH Tract Replacement Conceptual Model main components are the updated 2008 blocks and the 2008 Tracts (Figure 4.2). HAZUS-MH does not allow the earthquake model to run using census blocks. Therefore, the census tracts for the study 
area needed to be replaced by census blocks. After the tracts were replaced, then the other components, such as essential facilities and transportation, could be updated to match the new census tracts. The new tracts and their facilities were then input to the HAZUS-MH earthquake model.

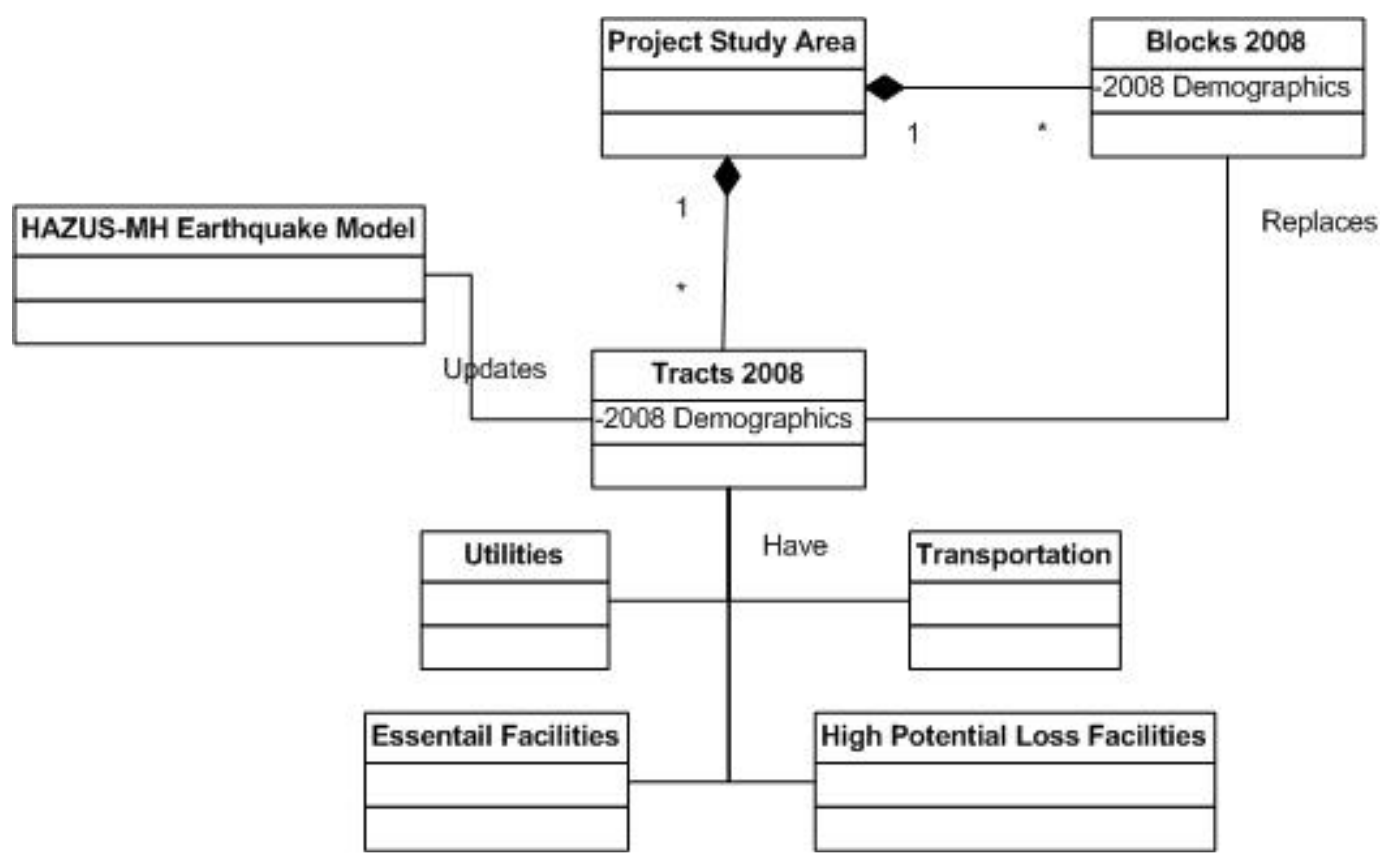

Figure 4.2: HAZUS-MH Tract Replacement Conceptual Model

\subsection{Logical Data Model}

It was fairly easy to move from the conceptual models to the logical models, as all the components were already in the proper GIS format. The census blocks extracted from the HAZUS-MH software were clipped to the study area and a field for the Block Group ID was added. The Block Group ID was derived by taking the first twelve digits of the Block ID. This ID was used to link the blocks to block groups in order to calculate the 2008 block demographics. The Census Disaggregation geodatabases contained six feature classes (Table 7). Three were used to calculate the 2008 demographics for the blocks, and three were used to calculate the 2008 demographics for the tracts. The three feature classes used for blocks were CensusBlockGrps, CensusBlocks2000, and CensusBlocksWorking. CensusBlocksWorking was a workspace used to perform the calculations required to disaggregate the block group demographics. The three feature classes for tracts were CensusTracts, CensusTracts2000, and CensusTractsWorking. Tracts involved very few calculations because the data were already at the tract level, but the workspace was used to update the fields so the 2000 demographics would not be lost. 
Table 7. Census Disaggregation Logical Model

\begin{tabular}{|l|l|}
\hline Feature Class & Description \\
\hline CensusBlockGroups & $\begin{array}{l}\text { Contains 2000 and 2008 demographics, } \\
\text { was used to calculate growth ratios to apply } \\
\text { to Census blocks. }\end{array}$ \\
\hline CensusBlocks2000 & $\begin{array}{l}\text { Original census blocks with 2000 } \\
\text { Demographics. }\end{array}$ \\
\hline CensusBlocksWorking & $\begin{array}{l}\text { Copy of CensusBlocks2000, used as } \\
\text { workspace to add fields and calculate new } \\
\text { 2008 demographics based on } \\
\text { CensusBlockGroups }\end{array}$ \\
\hline CensusTracts & Contains 2000 and 2008 demographics \\
\hline CensusTracts2000 & $\begin{array}{l}\text { Original census tracts with 2000 } \\
\text { demographics }\end{array}$ \\
\hline CensusTractsWorking & $\begin{array}{l}\text { Copy of CensusTracts2000, used as } \\
\text { workspace to update fields with data from } \\
\text { CensusTracts. }\end{array}$ \\
\hline
\end{tabular}

The logical data model for the HAZUS-MH Tract Replacement ended up being a subset of the HAZUS-MH default databases. It did not make sense to change the structure since these were the data that would eventually be used to update the larger default databases. The statewide default boundary database was stripped to include only the tracts and blocks within the project study area, and the facilities in the other HAZUS$\mathrm{MH}$ geodatabases were stripped out by selecting only those within the study area. These geodatabases were used to calculate new eleven-digit IDs for the census blocks so they could be added to the tract feature class, and to update all of the facilities associated tract IDs.

\subsection{Data Sources}

There were two main data sources for this project. The first was the data included with ESRI Business Analyst. The 2008 demographic estimates were extracted from these data. The second data source was the set of default geodatabases included with the HAZUS-MH software. These are the databases that were delivered to the client with the updated demographics and tracts replaced with blocks. The client provided a schools dataset, a roads layer, and high risk fire zones. The Business Analyst and HAZUS-MH data are detailed below.

\subsubsection{ESRI Business Analyst}

Business Analyst is a software package available for purchase from ESRI for use by businesses to better understand their customers and market area. It includes GIS-enabled tools and a data package for either the United States or Canada. The U.S. dataset contains demographic data, segmentation data, business data, major shopping centers, street data, and imagery. The demographics data have more than 2,000 attributes at current year estimates and five year projections, such as population, income, and housing. 
The demographics data used for this project were the 2008/2013 estimates and are available at the state, county, ZIP Code, census tract, block group, Core Based Statistical Area, and Designated Market Area geography levels. ESRI uses a variety of sources to assist in the demographics estimates. They use residential delivery statistics from the U.S. Postal Service, the InfoBase database from Axiom Corporation, and residential construction data from Hanley Wood Market Intelligence to measure the change in population and households within census block groups. Estimates pertaining to the labor force are estimated using the Local Area Unemployment Statistics and Employment Projections from the Bureau of Labor Statistics. ESRI also takes into account current trends such as dropping home prices and higher unemployment rates to derive the most accurate estimates (ESRI, 2008).

These population estimates included in Business Analyst are the most accurate data available and are therefore the ideal choice for this project. Census Tracts and Census Block Groups were extracted from the Business Analyst geodatabase. These data also come with extensive metadata, which will be updated to reflect the minimal changes made to the datasets.

\subsubsection{Hazards U.S. Multi-Hazard}

HAZUS-MH is a powerful risk assessment tool that estimates potential losses from natural disasters such as earthquakes, floods, and hurricane winds. The software is available free of charge from the Federal Emergency Management Agency (FEMA). Extensive databases with data covering the entire U.S. are embedded within the software. These databases include information such as demographics, building stocks, essential facilities, and lifelines. There are two types of databases included. The first is a list of individual facilities that includes essential facilities like schools or hospitals, and important infrastructure features like dams and bridges. The second type of database includes data aggregated at the county or census tract level. Examples of this type are demographics data and building stock square footage by census tract. Both types of databases are developed from publicly available databases and modified for use with HAZUS-MH.

There are eight default geodatabases embedded within HAZUS-MH. Two are specifically for the flood model and will not be modified or utilized in the scope of this project. The most important databases for this project were the Boundary and General Building Stock geodatabase (bndrygbs.mdb) and the Essential Facilities geodatabase (EF.mdb). The other geodatabases were still updated so the census tract numbers matched the new ID numbers, but they were not the focus of the project. A summary of the inventory databases is provided in Appendix A.

The Boundary and General Building Stock geodatabase consists of three feature classes: hzCounty, hzCensusTract, and hzCensusBlock. These are polygon feature classes for the boundaries for the different levels of aggregation available in HAZUS-MH. This geodatabase also includes tables for demographics, building stock square footage by occupancy, building count by occupancy, building exposure by occupancy, and building contents exposure by occupancy. There are two tables for each of these: one aggregated at the census tract level, and one aggregated at the census block level. Although the census block data are available within the HAZUS-MH geodatabases, the earthquake model is not programmed to use the blocks. They are only available for use in the flood 
model. The data from the block level tables were used to replace the study area tracts in the tract level tables. HAZUS uses the census tract or block ID number to link the tables to the feature classes after a study region is defined, thus it is very important that all features and records within the study area are updated to reflect matching IDs.

The Essential Facilities geodatabase consists of five feature classes: hzCareFlty, hzEmergencyCtr, hzFireStation, hzPoliceStation, and hzSchool. These are point feature classes containing the facility ID, census tract, name, address, and other attributes pertinent to essential facilities. The five tables in this geodatabases are eqCareFlty, eqEmergencyCtr, eqFireStation, eqPoliceStation, and eqSchool. These tables contain specific earthquake hazard information for each facility, such as building type and design level, and link back to the feature classes by their facility ID.

The remaining geodatabases include High Potential Loss Facilities (HPLF.mdb), the transportation system (TRN.mdb), and the Utility System (UTIL.mdb). These geodatabases were designed to be similar to the others, with point or line feature classes containing facility information and tables containing hazards specifics. The two link to each other by facility ID. The HAZUS-MH geodatabases have metadata which can be updated to reflect the modifications to the data.

\subsection{Data Collection Methods}

Data collection was minimal for this project. The HAZUS-MH software and data were ordered from the FEMA website. The 2008 demographics from Business Analyst were downloaded from the University servers. The client provided various forms of data, but ultimately the only pieces used for this project were the schools, fire zones, and roads.

\subsection{Data Preparation}

The data obtained for this project were generally in very good condition. The business analyst data have over 2000 attributes, so all attributes unnecessary to this project were deleted from tables, and clipped to the study area. This made the data much easier to manage in the census disaggregation model. The HAZUS-MH geodatabases set the structure for the final geodatabases so all data extracted from these required very little preparation. The tract feature class was joined to the demographics table and clipped to the study area to create a complete feature class for use in the census disaggregation model. The school insurance data were received in an Excel table and were revised to reflect the requirements for input into HAZUS-MH. A HAZUS-ID field was added, and other field names, types, and sizes were changed so that addition to the HAZUS-MH geodatabases through CDMS went smoothly. A summary of the data, their sources, and modifications are summarized in Table 8. 
Table 8. Data Sources

\begin{tabular}{|l|l|l|}
\hline Dataset & Source & Modification \\
\hline baCensusTract & ESRI Business Analyst & $\begin{array}{l}\text { Clip from CensusTract } \\
\text { feature class in business } \\
\text { analyst geodatabase, and } \\
\text { deleted unnecessary fields. }\end{array}$ \\
\hline baCensusBlockGroup & ESRI Business Analyst & $\begin{array}{l}\text { Clip from } \\
\text { CensusBlockGroup feature } \\
\text { class in business analyst } \\
\text { geodatabase, and deleted } \\
\text { unnecessary fields. }\end{array}$ \\
\hline hzCensusTract & HAZUS-MH & $\begin{array}{l}\text { Clip from HAZUS-MH } \\
\text { hzTract feature class in } \\
\text { bndrbys.mdb and joined to } \\
\text { demographics table. }\end{array}$ \\
\hline hzCensusBlock & HAZUS-MH & $\begin{array}{l}\text { Clip from HAZUS-MH } \\
\text { hzCensusBlock feature } \\
\text { class in bndrygbs.mdb and } \\
\text { joined to demographics } \\
\text { table. }\end{array}$ \\
\hline RedlandsSchools & City of Redlands & $\begin{array}{l}\text { Excel table modified to } \\
\text { match HAZUS-MH } \\
\text { requirements. }\end{array}$ \\
\hline
\end{tabular}

\subsection{Summary}

This chapter detailed the conceptual and logical models for this project. The models refer to the geodatabases used to create the data that updated the HAZUS-MH default databases for the client. This chapter also described the data sources in detail, the collection methods, and any data scrubbing that was completed. The next chapter will detail the implementation steps taken to produce the new data and how they were used to update the HAZUS-MH geodatabases. 


\section{Chapter 5 - Implementation}

This chapter discusses the process followed to update the demographics data for input to the HAZUS-MH databases and how those geodatabases were manipulated to use the updated census blocks for the study area instead of census tracts. This chapter will detail how the HAZUS-MH earthquake model was run using the new data. The model created to determine suitable emergency shelters will also be discussed.

\subsection{Census Disaggregation}

A custom toolbox was created for this project to hold the toolsets and models. A new toolbox is created by right clicking in the white area of ArcToolbox and choosing New Toolbox. The toolbox for this project was called MIP (Figure 5.1). A new toolset is created by right clicking the toolbox and selecting New then Toolset. There were three toolsets created: the first was called Blocks2HAZUS, the second was called CensusDisaggregation, and the third was ShelterSuitability. This section will discuss the Census Disaggregation Toolset.

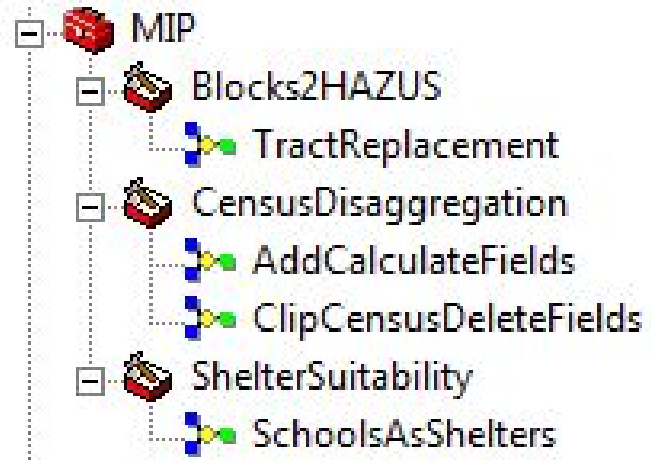

Figure 5.1: Project Custom Toolbox

The Census Disaggregation toolset contains two models. The first model, ClipCensusDeleteFields (Figure 5.2), was created to prepare the data for use. The census data obtained from HAZUS-MH and Business Analyst were clipped to the study area. The population estimates obtained from Business Analyst had more than 2000 attributes. This number of attributes made the data difficult to work with. The attributes that related directly to the demographics required by HAZUS-MH were retained and the extraneous fields were removed. The fields that were retained were associated with population, income and race for the years 2000 and 2008. A table listing these fields and their definitions can be found in Appendix B. This model was also responsible for joining the HAZUS-MH blocks and tracts to the 2000 HAZUS-MH demographics. This model was especially time consuming due to the size of the original Business Analyst dataset and the numerous fields that were deleted. The ClipCensusDeleteFields model was created separately from the AddCalculateFields model because it only needed to be done once and should not affect the performance of the other model. 


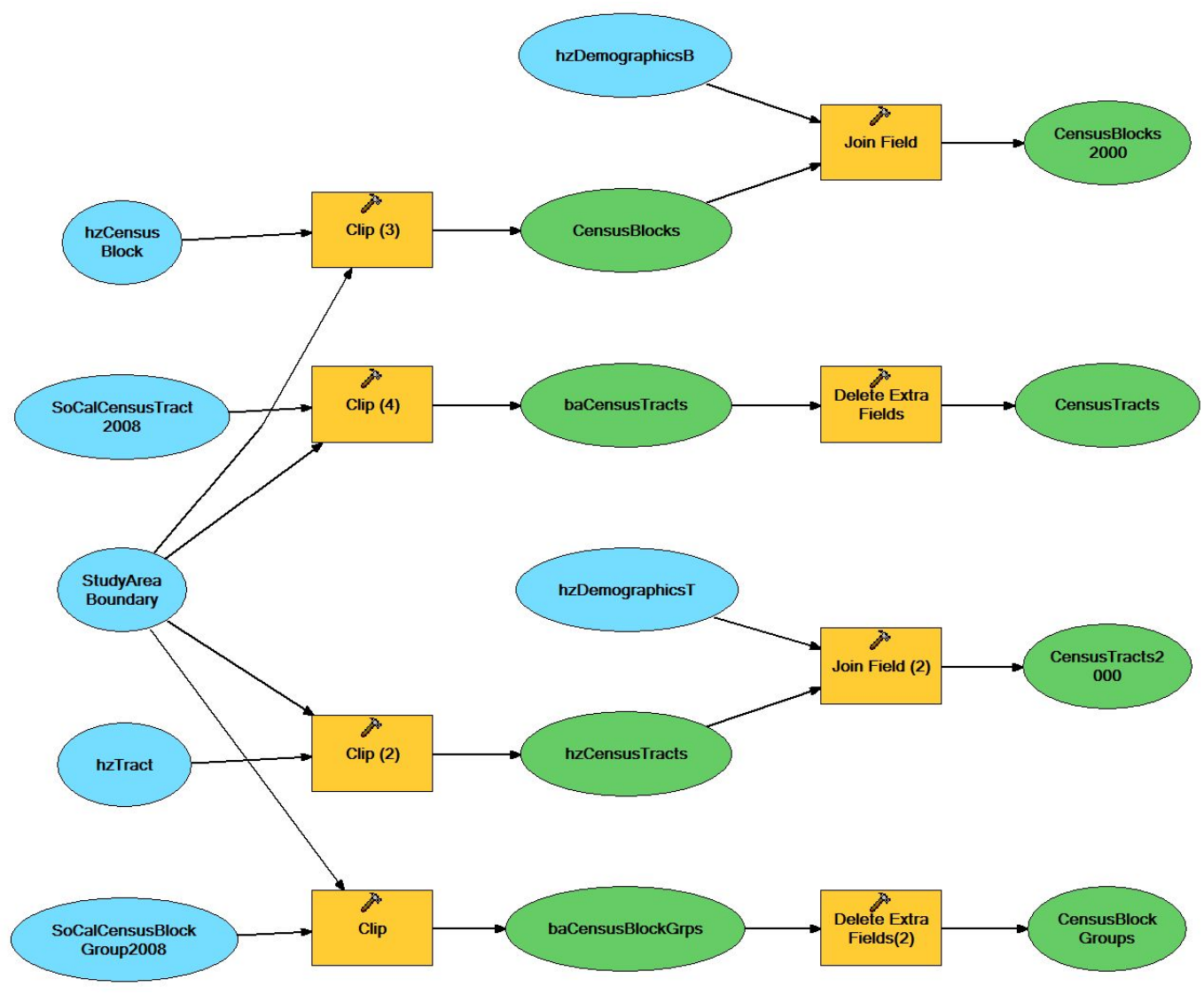

Figure 5.2: Clip Census and Delete Fields Model

The second Model, AddCalculateFields, was created to add and calculate the 2008 demographics. This model has three distinct sections. The first added several fields to hold the 2008 values and several fields to hold intermediate ratio values (Figure 5.3). A field to hold the block group number was added as well. The block group number was calculated by extracting the first twelve digits from the census block numbers. The Visual Basic function Left ([CensusBlock], 12) was used to accomplish this.

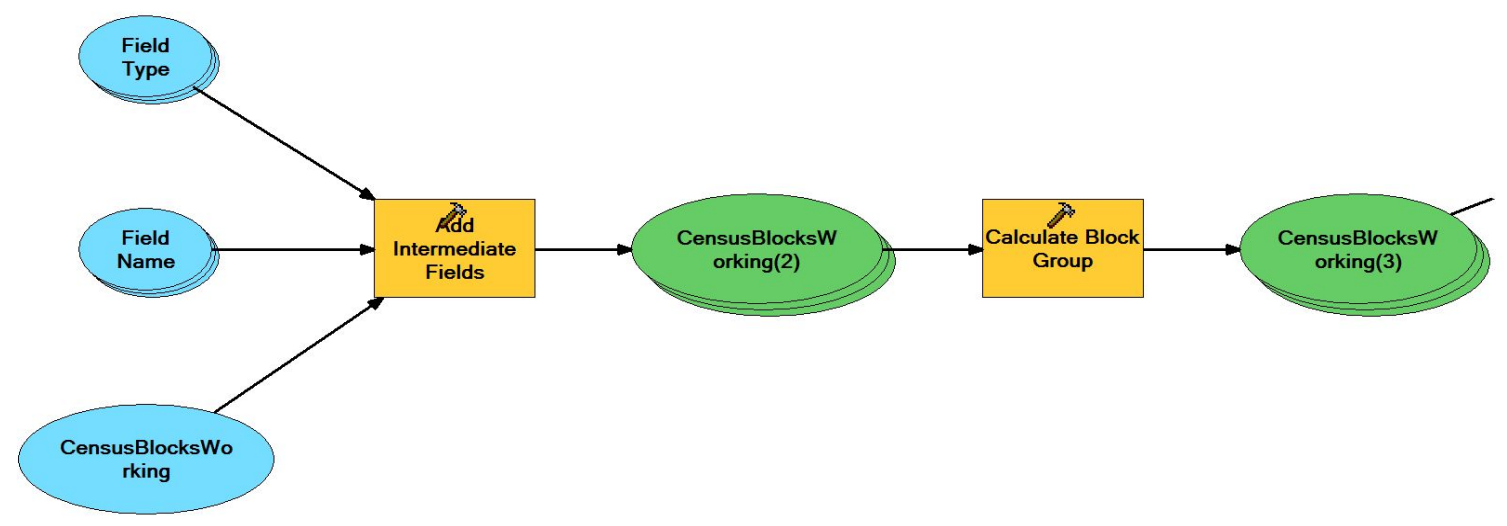

Figure 5.3: Add Fields, Calculate Block Group 
The block group number was needed to join the blocks from HAZUS-MH to the census blocks groups from Business Analyst (Figure 5.4).

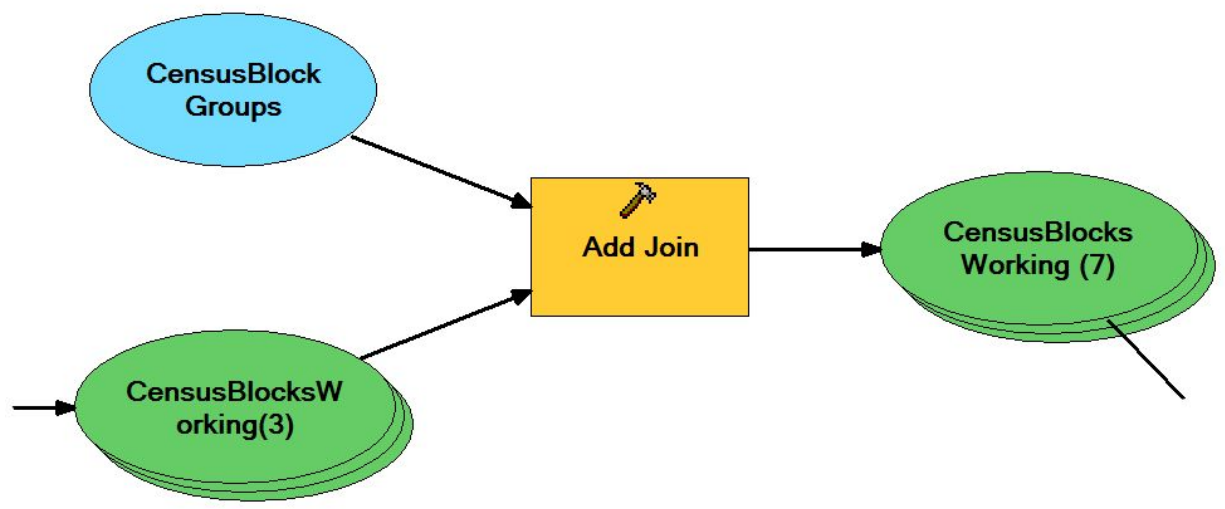

Figure 5.4: Join Census Block Groups to Census Blocks

The 2008 demographic information was extracted from the block groups feature class to calculate the newly added fields. There were 59 fields in the HAZUS-MH 2000 demographics, but 16 were not updated with 2008 values because they were not available in the Business Analyst estimates. The fields from HAZUS-MH and the new fields added for the 2008 values are listed in Table 9. The ratio fields were added to hold values needed for the calculations of the 2008 values.

Table 9. HAZUS-MH Demographics Field Map

\begin{tabular}{|c|c|}
\hline HAZUS-MH Field Names & 2008 Field Names \\
\hline Population & BlockPop2008 \\
\hline Households & BlockHH2008 \\
\hline GroupQuarters & BlockGQ2008 \\
\hline MalesLess16 & MaleLess16_2008 \\
\hline Male16to65 & Male16to65_2008 \\
\hline MaleOver65 & MaleOver65_2008 \\
\hline FemaleLess16 & FemaleLess16_2008 \\
\hline Female16to65 & Female16to65_2008 \\
\hline FemaleOver65 & FemaleOver65_2008 \\
\hline MalePopulation & BlockMale2008 \\
\hline FemalePopulation & BlockFemale2008 \\
\hline White & White2008 \\
\hline Black & Black2008 \\
\hline NativeAmerican & NativeAm2008 \\
\hline Asian & Asian2008 \\
\hline Hispanic & Hispanic2008 \\
\hline Pacificlslander & Paclsland2008 \\
\hline OtherRaceOnly & OtherRace2008 \\
\hline IncLess10 & HHIncLess10_2008 \\
\hline
\end{tabular}




\begin{tabular}{|l|l|}
\hline Inc10to20 & HHInc10to20_2008 \\
\hline Inc20to30 & HHInc20to30_2008 \\
\hline Inc30to40 & HHInc30to40_2008 \\
\hline Inc40to50 & HHInc40to50_2008 \\
\hline Inc50to60 & HHInc50to60_2008 \\
\hline Inc60to75 & HHInc60to75_2008 \\
\hline Inc75to100 & HHInc75to100_2008 \\
\hline IncOver100 & HHIncOver100_2008 \\
\hline ResidDay & ResidDay_2008 \\
\hline ResidNight & ResidNight_2008 \\
\hline WorkingCom & WorkingCom_2008 \\
\hline Hotel & $*$ \\
\hline Visitor & $*$ \\
\hline WorkingInd & WorkingInd_2008 \\
\hline OwnerSingleUnits & OwnerSingleUnits_2008 \\
\hline Commuting5pm & $*$ \\
\hline OwnerMultiUnits & OwnerMultiUnits_2008 \\
\hline OwnerMultiStructs & OwnerMultiStructs_2008 \\
\hline OwnerMHs & OwnerMHs_2008 \\
\hline RenterSingleUnits & RenterSingleUnits_2008 \\
\hline RenterMultiUnits & RenterMultiUnits_2008 \\
\hline RenterMultiStructs & RenterMultiStructs_2008 \\
\hline RenterMHs & RenterMHs_2008 \\
\hline VacantSingleUnits & VacantSingleUnits_2008 \\
\hline VacantMultiUnits & VacantMultiUnits_2008 \\
\hline VacantMultiStructs & VacantMultiStructs_2008 \\
\hline VacantMHs & VacantMHs_2008 \\
\hline BuiltBefore40 & $*$ \\
\hline Built40to49 & $*$ \\
\hline Built50to59 & $*$ \\
\hline Built60to69 & $*$ \\
\hline Built70to79 & $*$ \\
\hline Built80to89 & $*$ \\
\hline Built90to98 & $*$ \\
\hline BuiltAfter98 & $*$ \\
\hline MedianYearBuilt & $*$ \\
\hline AvgRent & $*$ \\
\hline AvgValue & $*$ \\
\hline SchoolEnrollmentKto12 & $*$ \\
\hline SchoolEnrollmentCollege & \\
\hline & \\
\hline
\end{tabular}

*new fields were not added because 2008 values were not available 
The next step in the model was to calculate the values for the 2008 demographics fields (Figure 5.5).

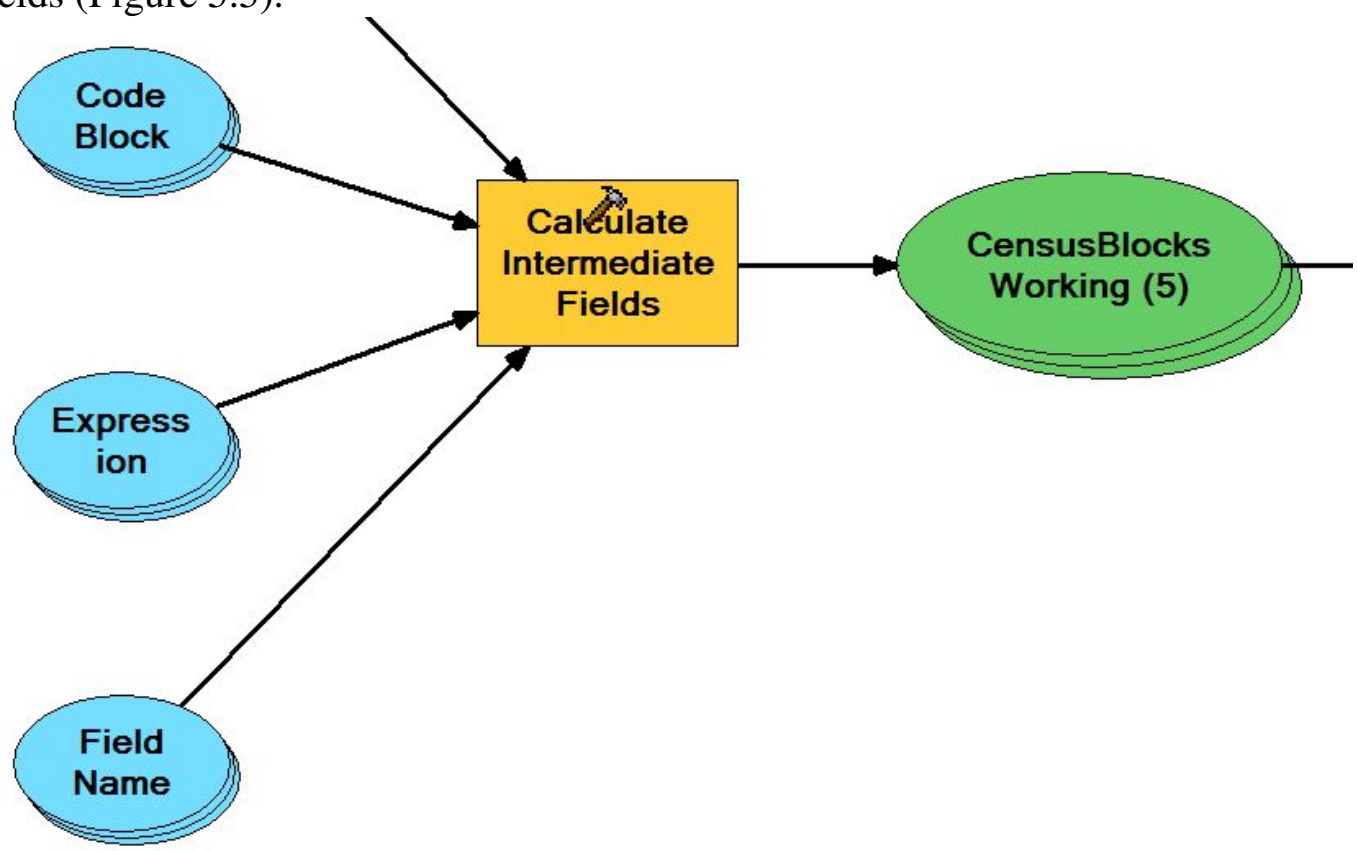

Figure 5.5: Calculate 2008 Demographics Fields

The first fields that needed to be calculated were the ratio fields (Table 10). These were used in subsequent calculations for the actual 2008 values. There were fourteen ratios calculated. The population, households, and group quarters growth ratios were the change in their respective values between 2000 and 2008 by block group. The male and female ratios were the percentage of males and females in the population per census block. The population and households ratios were the percentages each block held within a block group. The day and night residents and commercial and industrial worker ratios were percentages of each respective value out of the block population. Finally, the owner, renter, and vacant ratios were the amount of growth between 2000 and 2008.

Table 10. Census Disaggregation Ratio Fields

\begin{tabular}{|l|l|l|}
\hline Field Name & Calculation & Used to Calculate: \\
\hline PopGrowthRatio & $\begin{array}{l}{[\text { CensusBlockGrps.TOTPOP_CY] } /} \\
{[\text { CensusBlockGrps.TOTPOP00] }}\end{array}$ & BlockPop2008 \\
\hline HHGrowthRatio & $\begin{array}{l}{[\text { CensusBlockGrps.TOTHH_CY] } /} \\
{[\text { CensusBlockGrps.TOTHH00] }}\end{array}$ & BlockHH2008 \\
\hline GQGrowthRatio & $\begin{array}{l}{[\text { CensusBlockGrps.GQPOP_CY] } /} \\
{[\text { CensusBlockGrps.GQPOP00] }}\end{array}$ & BlockGQ2008 \\
\hline BlockMaleRatio & $\begin{array}{l}{[\text { CensusBlocks.Male] / }} \\
{[\text { CensusBlocks.Population }]}\end{array}$ & Male2008 \\
\hline BlockFemaleRatio & $\begin{array}{l}\text { [CensusBlocks.Female] } / \\
{[\text { CensusBlocks.Population }]}\end{array}$ & Female2008 \\
\hline
\end{tabular}




\begin{tabular}{|c|c|c|}
\hline BlkGrpRatio & $\begin{array}{l}\text { [CensusBlocks.BlockPop2008] / } \\
\text { [CensusBlockGrps.TOTPOP_CY] }\end{array}$ & Gender by age, Race \\
\hline BlkGrpHHRatio & $\begin{array}{l}\text { [CensusBlocks.BlockHH2008]/ } \\
\text { [CensusBlockGrps.TOTHH_CY] }\end{array}$ & Household income \\
\hline ResDayRatio & $\begin{array}{l}\text { [CensusBlocks.ResidDay] / } \\
\text { [CensusBlocks.Population] }\end{array}$ & ResidDay_2008 \\
\hline ResNightRatio & $\begin{array}{l}\text { [CensusBlocks.ResidNight] / } \\
\text { [CensusBlocks.Population] }\end{array}$ & ResidNight_2008 \\
\hline WorkingComRatio & $\begin{array}{l}\text { [CensusBlocks.WorkingCom] / } \\
\text { [CensusBlocks.Population] }\end{array}$ & WorkingCom_2008 \\
\hline WorkingIndRatio & $\begin{array}{l}\text { [CensusBlocks.WorkingInd] / } \\
\text { [CensusBlocks.Population] }\end{array}$ & WorkingInd_2008 \\
\hline OwnerBlkGrpRatio & $\begin{array}{l}\text { [CensusBlockGrps.OWNER_CY] / } \\
\text { [CensusBlockGrps.OWNEROCC00] }\end{array}$ & $\begin{array}{l}\text { OwnerSingleUnits_2008, } \\
\text { OwnerMultiUnits_2008, } \\
\text { OwnerMultiStructs_2008, } \\
\text { OwnerMHs_2008, }\end{array}$ \\
\hline RenterBlkGrpRatio & $\begin{array}{l}\text { [CensusBlockGrps.RENTER_CY] / } \\
\text { [CensusBlockGrps.RENTROCC00] }\end{array}$ & \begin{tabular}{|l} 
RenterSingleUnits_2008, \\
RenterMultiUnits_2008, \\
RenterMultiStructs_2008, \\
RenterMHs_2008, \\
\end{tabular} \\
\hline VacantBlkGrpRatio & $\begin{array}{l}\text { [CensusBlockGrps.VACANT_CY] / } \\
\text { [CensusBlockGrps.VACANTHU00] }\end{array}$ & $\begin{array}{l}\text { VacantSingleUnits_2008, } \\
\text { VacantMultiUnits_2008, } \\
\text { VacantMultiStructs_2008, } \\
\text { VacantMHs_2008 } \\
\end{array}$ \\
\hline
\end{tabular}

After the ratio fields were calculated, the rest of the fields could be calculated. The estimated block population was calculated by multiplying the 2000 population by the block group growth ratio. The households and group quarters were calculated using the same concept. The total male and female populations were calculated by applying the 2000 male and female block ratios to the 2008 block population. The gender by age fields involved a little more calculation because the demographics in Business Analyst had these fields split into much smaller age groups. For example, HAZUS-MH has one field for males less than sixteen and Business Analyst has this field separated into three fields. Therefore, to calculate males less than sixteen, the block group fields for males less than five, males ages five to ten, and males ages ten to sixteen were added together, and then multiplied by the block to group population ratio. The value for males over 65 was calculated by subtracting the two younger age groups from the total males, to ensure consistency between the fields. The same process was followed to calculate the female population by age group. The 2008 Race values were determined by multiplying the 2008 block group values by the block to group ratio. The Other Race field was calculated by subtracting the White, Black, Native American, Asian, and Pacific Islander 2008 values from the total 2008 block population. The income fields were derived from the multiple fields in Business Analyst, similar to the gender by age group fields. Business Analyst separated the household incomes into smaller brackets, so households with income from $\$ 10,000$ to $\$ 20,000$ were calculated by adding households with income $\$ 10,000-\$ 15,000$ and $\$ 15,000-\$ 20,000$. These values were then multiplied by the block 
to group household ratio. This method was applied to the rest of the household income fields except for households with income over $\$ 100 \mathrm{~K}$. This value was calculated by subtracting all the households with lower incomes from the total number of households. The day residents, night residents, commercial workers, and industrial workers were all computed by multiplying their respective ratios by the 2008 block population. The owner, renter, and vacant variables were calculated by multiplying the 2000 values for each by the owner, renter, or vacant ratios. A table detailing the equations used for these calculations can be found in Appendix C.

The final step in this model was to replace the original HAZUS-MH fields containing the 2000 demographics data with the newly calculated 2008 demographics (Figure 5.6). This was done using a simple calculate field tool for a direct field to field calculation. The 2000 demographics were maintained in a separate feature class so no data were lost.

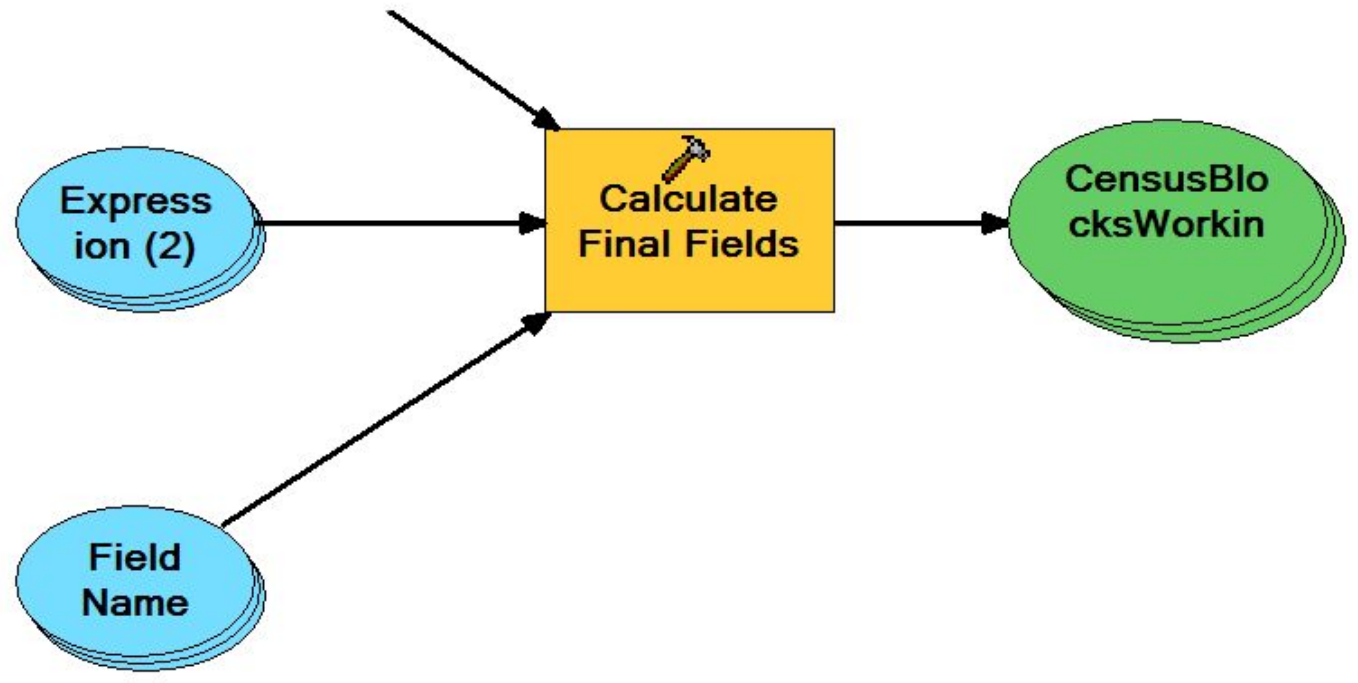

Figure 5.6: Calculate Final Fields

After the HAZUS-MH fields were updated with the 2008 demographics, the table was loaded into HAZUS-MH using the Comprehensive Data Management System (CDMS) (Figure 5.7) so the HAZUS-MH geodatabases would be current for the next step in the implementation. CDMS was also used to load the insurance appraisal data for the schools obtained from the City of Redlands. 


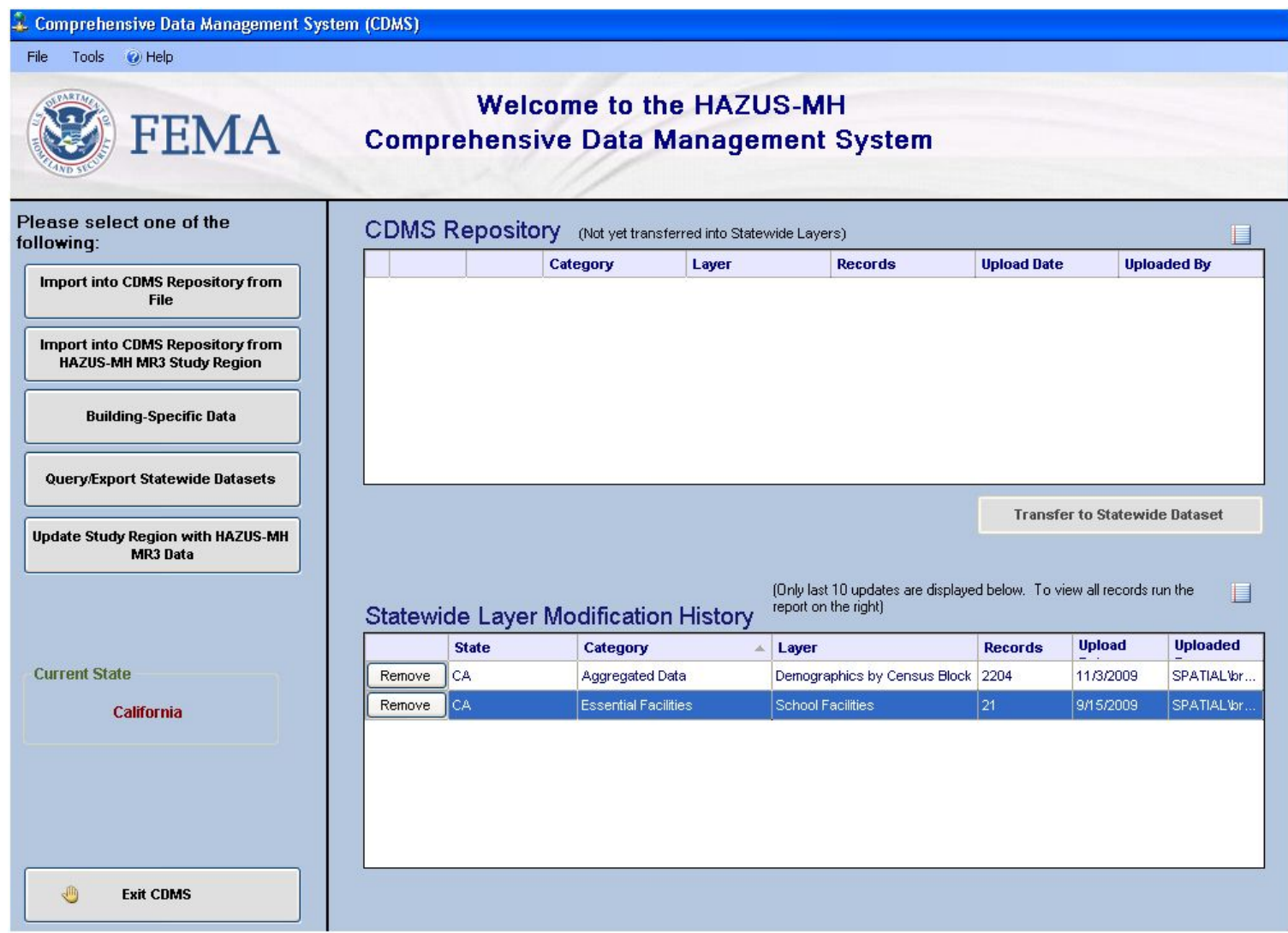

Figure 5.7: Update to HAZUS-MH Geodatabases Using CDMS

\subsection{HAZUS-MH Tract Replacement}

The Tract Replacement model was created to assist in editing the HAZUS-MH geodatabases for use in the earthquake model. A subset of the default geodatabases was used for this model so it would be easier to manage and so no data would be lost. Once the model was complete and all fields had been verified, then the actual default databases were updated with the new data. The first step in this model was to clip the tracts and blocks (Figure 5.8). The blocks were clipped to the study area and the tracts were clipped to the county. The tracts were clipped to the county so that all census tract IDs for the county were available. New eleven-digit IDs were calculated for the census blocks so there would be no duplicates across the county. Duplicate tract numbers would cause errors in HAZUS-MH. 

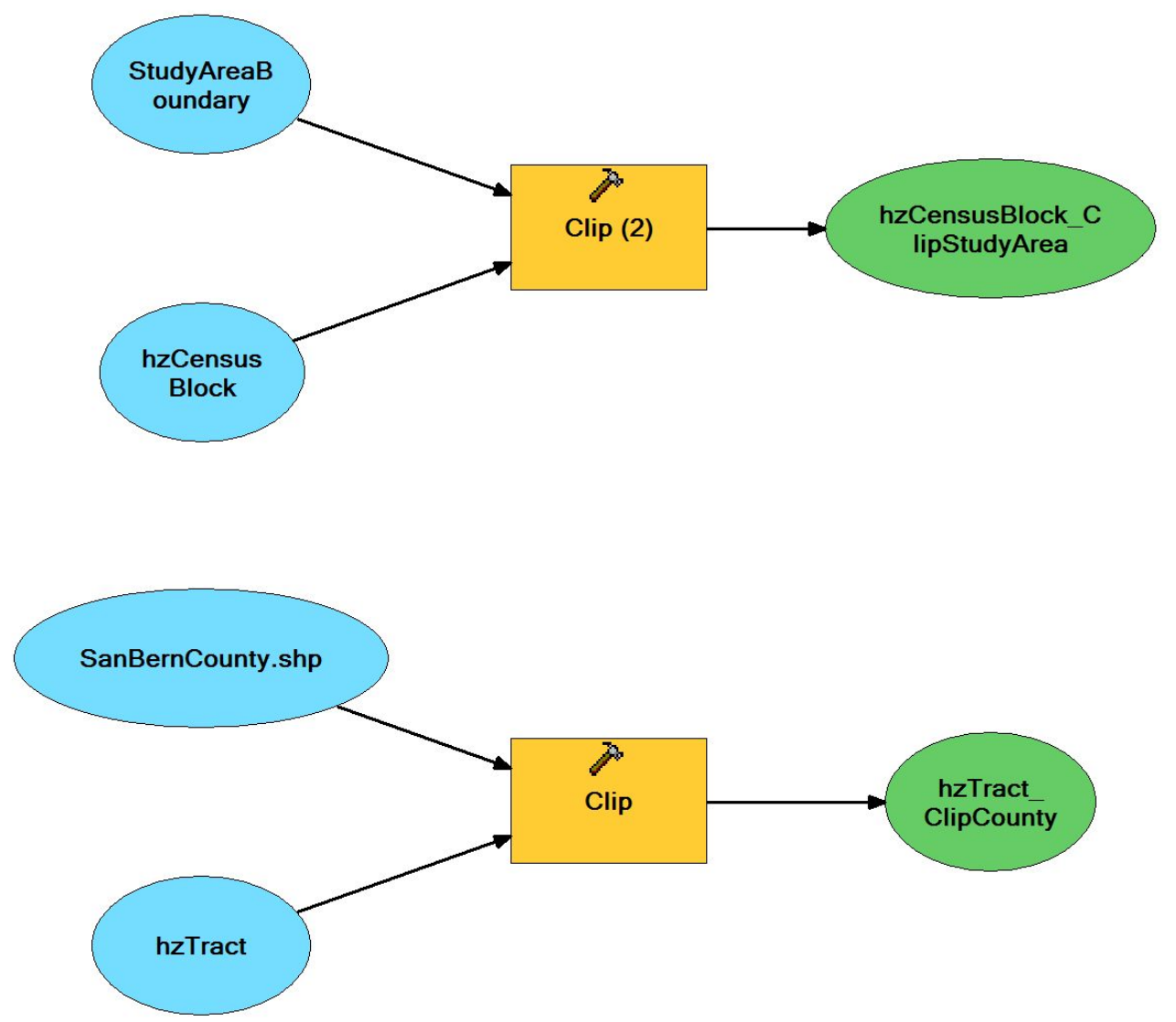

Figure 5.8: hzTract and hzCensusBlock Clip

The next step was to calculate unique eleven-digit numbers for each block to populate the Tract field (Figure 5.9). This number is used in HAZUS-MH to identify the tract, its demographics, and all facilities located within the tract. In order for HAZUSMH to correctly recognize the new IDs, they must start with " 06071 " followed by any combination of six digits. The " 06 " is the code for California, and " 071 " is the code for San Bernardino County. These numbers are important because its links the features to the state and county databases, which HAZUS-MH uses in its analysis. The new IDs were calculated by taking the highest tract number in the county and adding the object ID of each block. This guaranteed that there would not be any duplicate tract numbers. Tract fields were added and calculated to match their respective blocks in each of the block tables in the boundary and building stock geodatabases. 


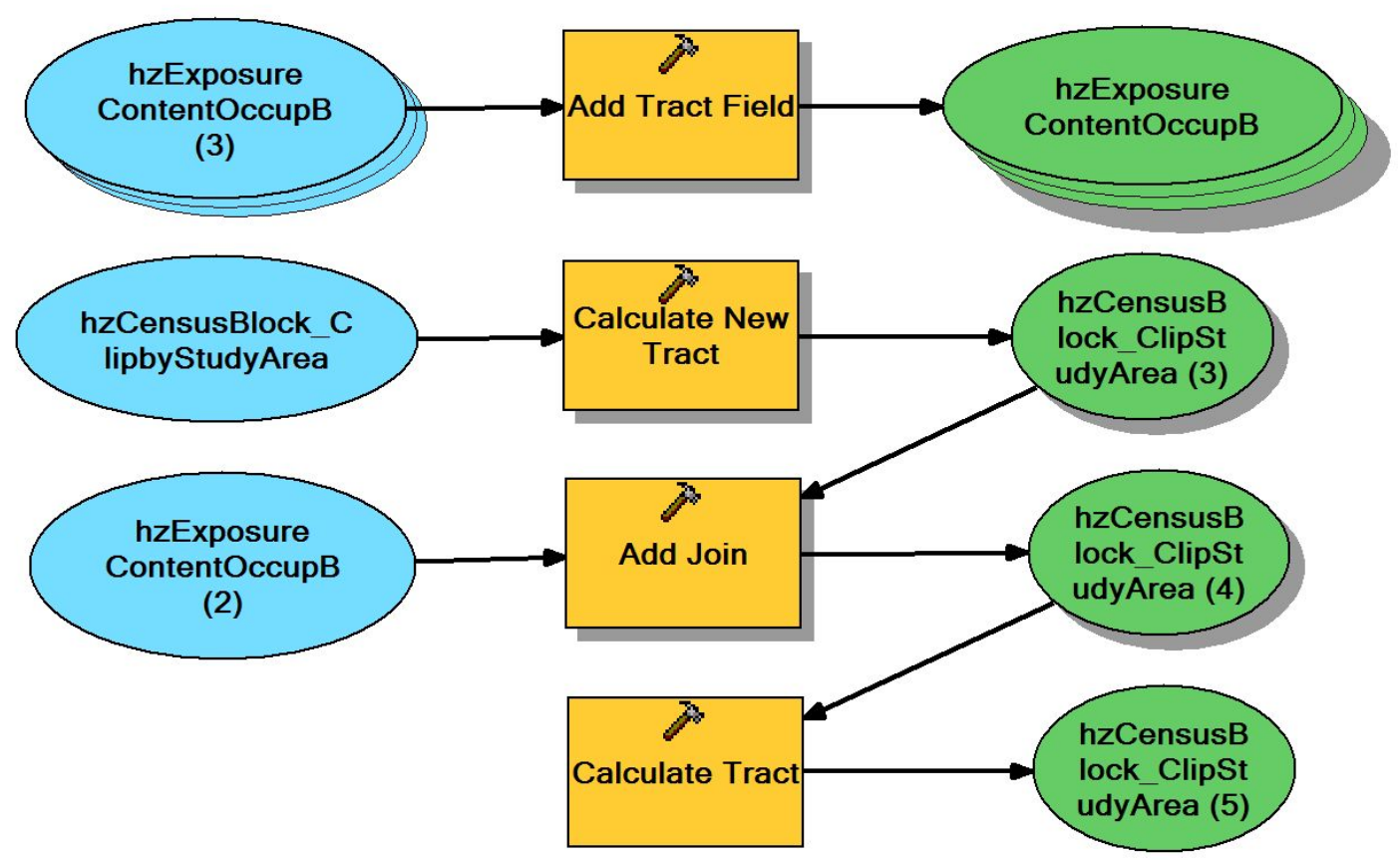

Figure 5.9: Calculate Tract Fields for Boundary and Building Stock Tables

Before these tables with the new IDs could be used to replace the tracts in the study area, the original study area tracts needed to be removed from the tables (Figure 5.10). This was done with a simple delete row tool. The tables were joined to the study area tracts and then the appropriate rows were selected and deleted. The block tables were then loaded into the tract tables in ArcCatalog. This was accomplished by right clicking on a feature class or table in ArcCatalog and choosing load, this allowed for field mapping so the appropriate fields from the block tables could be input to the tract tables.

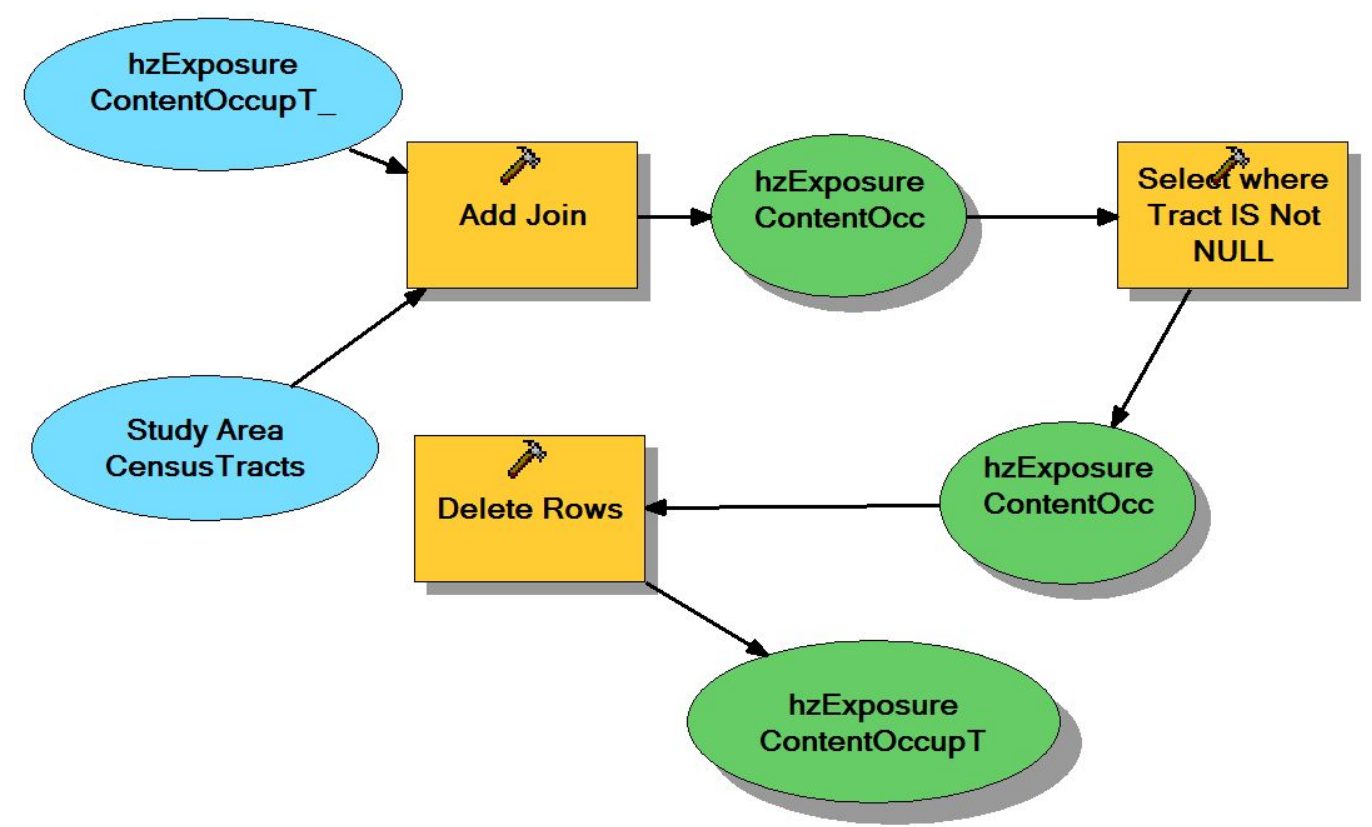

Figure 5.10: Delete Study Area Tracts from Tables 
The facilities geodatabases were the last to be updated (Figure 5.11). Each facility is linked to the census tract it is located in. Because the original census tracts were deleted, the facilities were no longer attached to any specific tract, and therefore were ignored by HAZUS-MH. This was fixed by selecting the facilities within the study area and creating a spatial join between the facilities and the census blocks with the new IDs. Once they were joined, the tract numbers in the facilities tables were calculated to match the new IDs from the census block table.

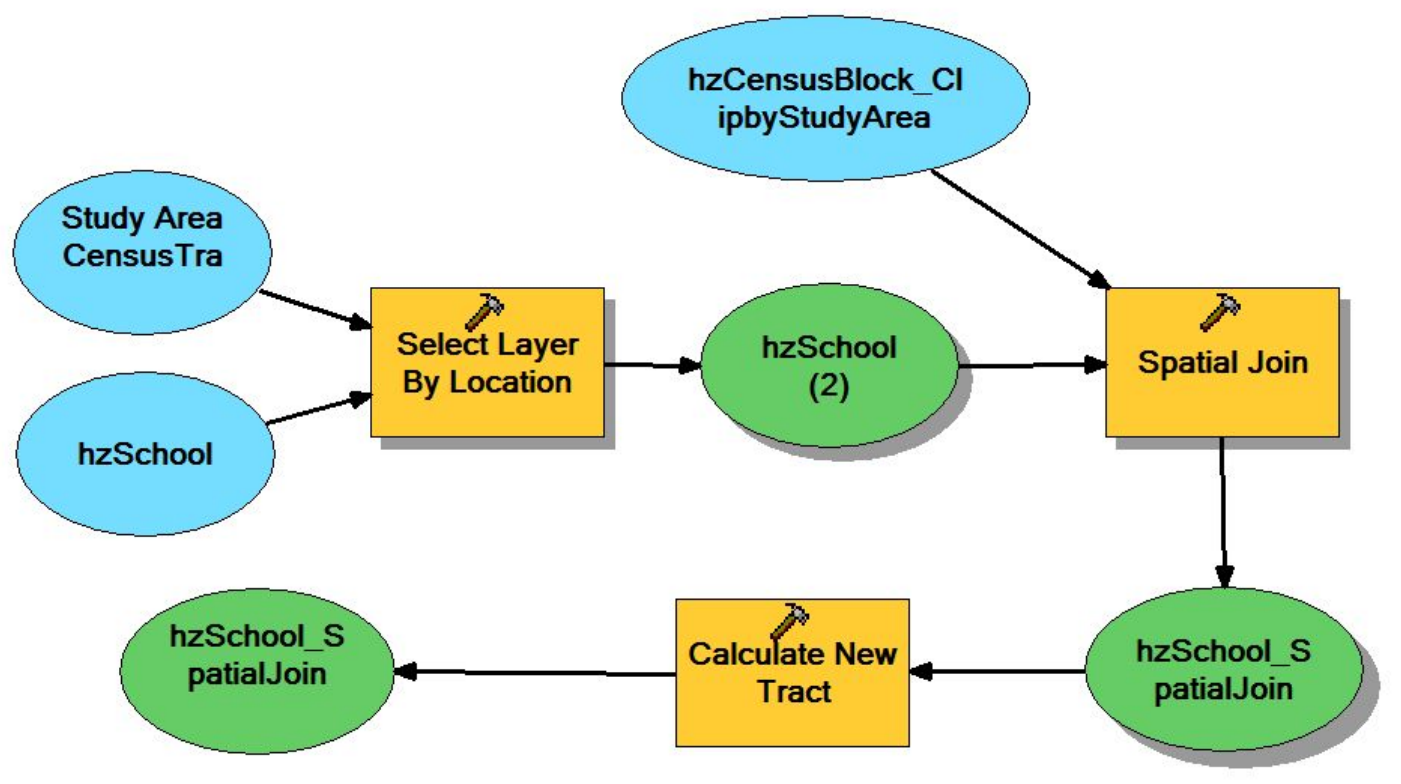

Figure 5.11: Facilities Tract Number Update

Once all the tract numbers were updated, the geodatabases were loaded into the HAZUS-MH default databases. This was done using the same load function mentioned above. The hzTract feature class was also loaded into a HAZUS-MH database called syBoundary.mdb. This geodatabase contains three boundary feature classes (tract, county, state) and is used to define the study regions. The sytract feature class must match the tract feature class contained in the boundary and building stock geodatabase or the software will crash.

\subsection{HAZUS-MH Earthquake Model}

The first step in running an earthquake scenario using HAZUS-MH is to define a study region. This is done by double clicking the HAZUS-MH icon on the desktop and selecting "Create a Study Region" on the startup menu (Figure 5.12). The region is given a name and a description (Figure 5.13) and the earthquake hazard type is selected (Figure 5.14). 


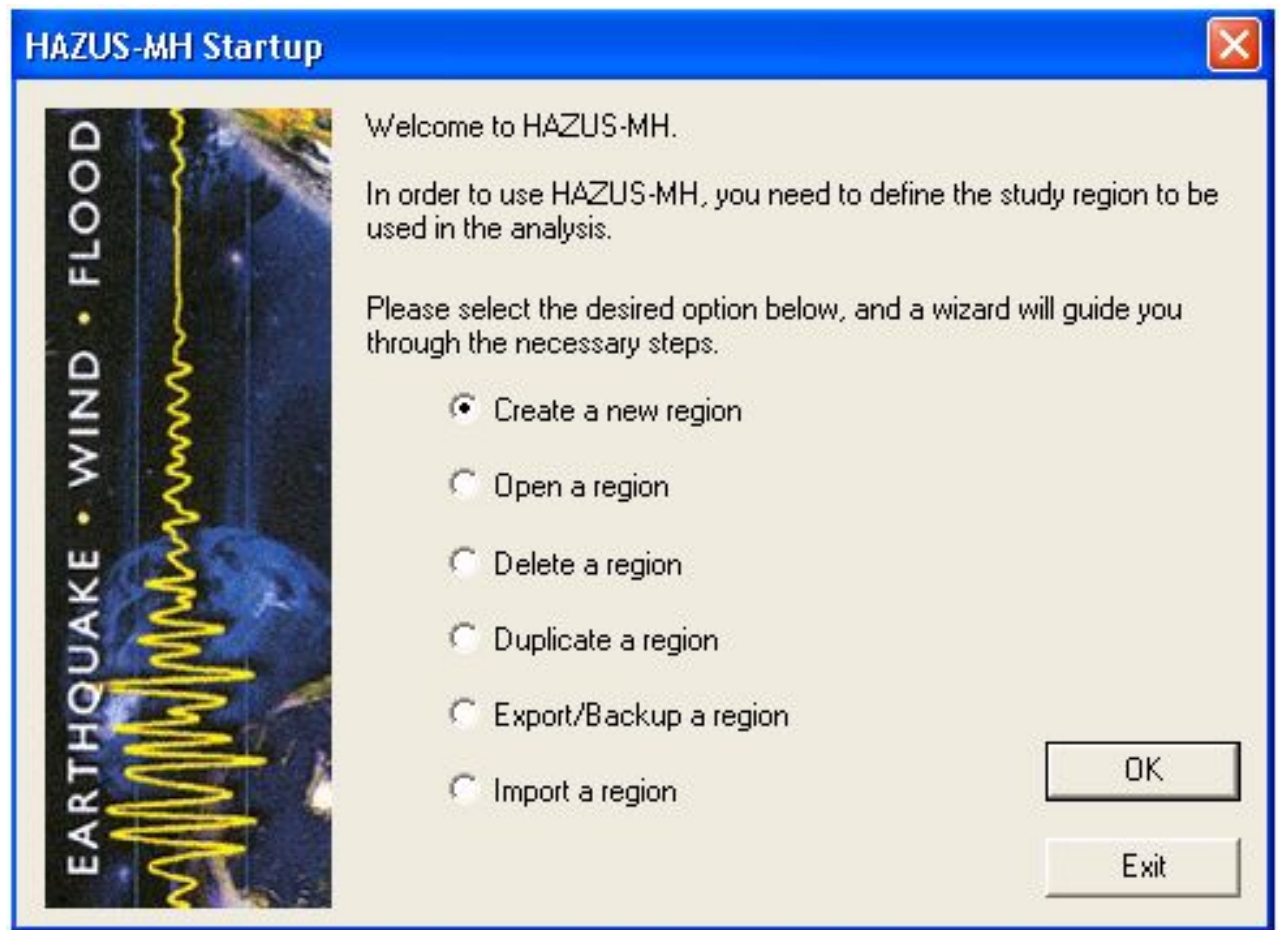

\section{Figure 5.12: HAZUS-MH Startup Menu}

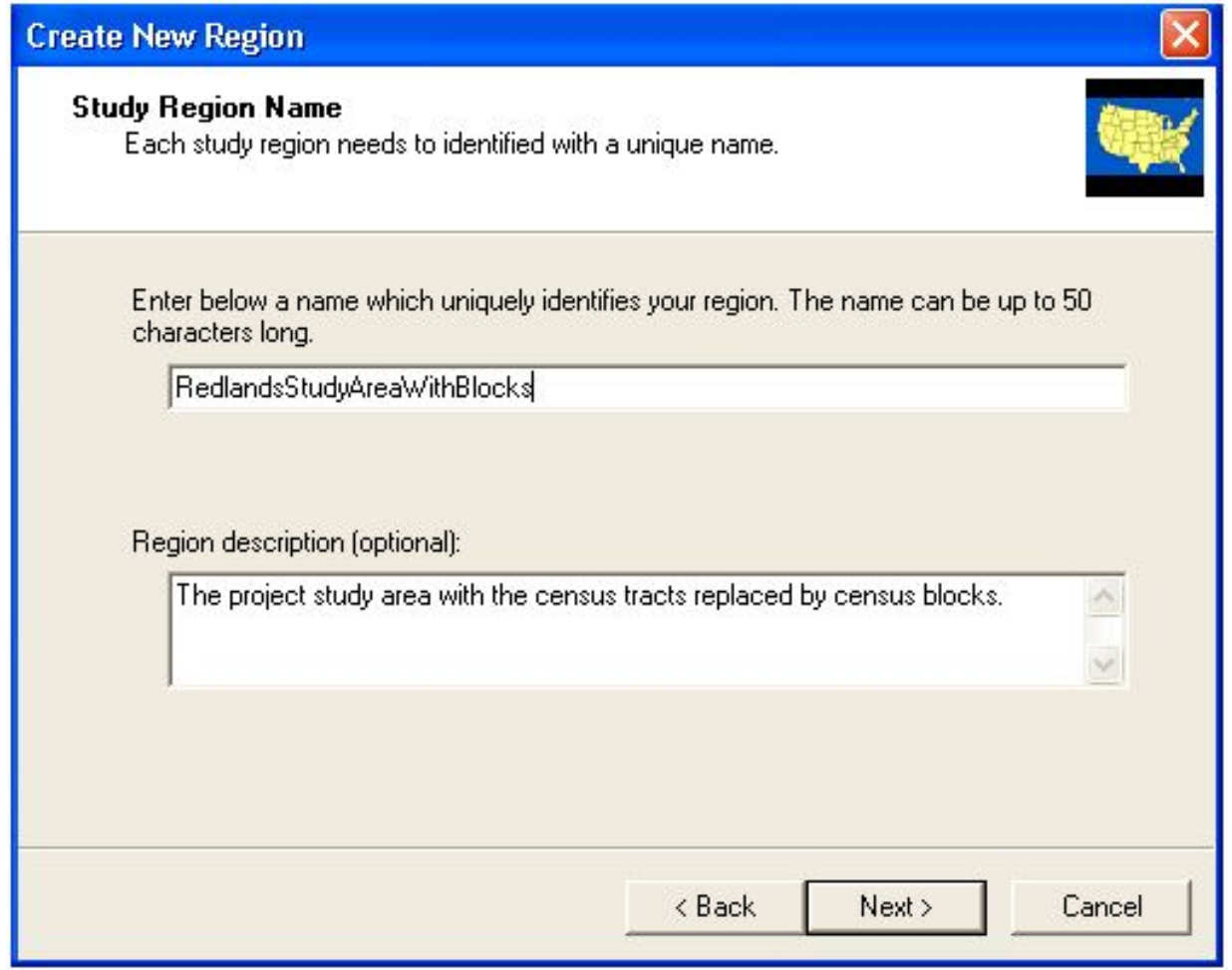

\section{Figure 5.13: Study Region Name and Description}




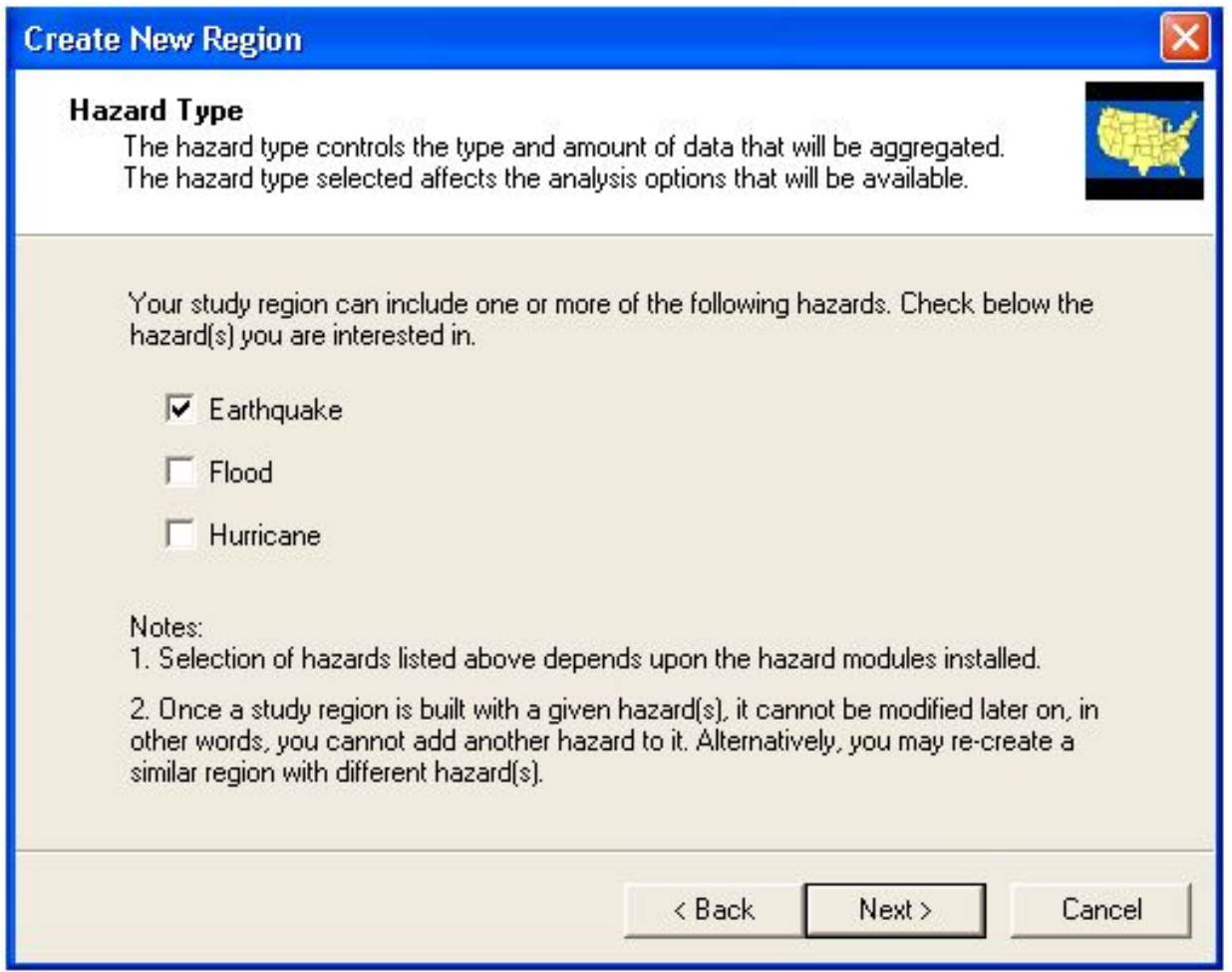

\section{Figure 5.14: Select Hazard Type}

After the hazard is defined, the aggregation level was selected (Figure 5.15). The census tract level is selected because the census block level is not available for the earthquake model. The census block radio button is only available for selection if the flood hazard is selected. 


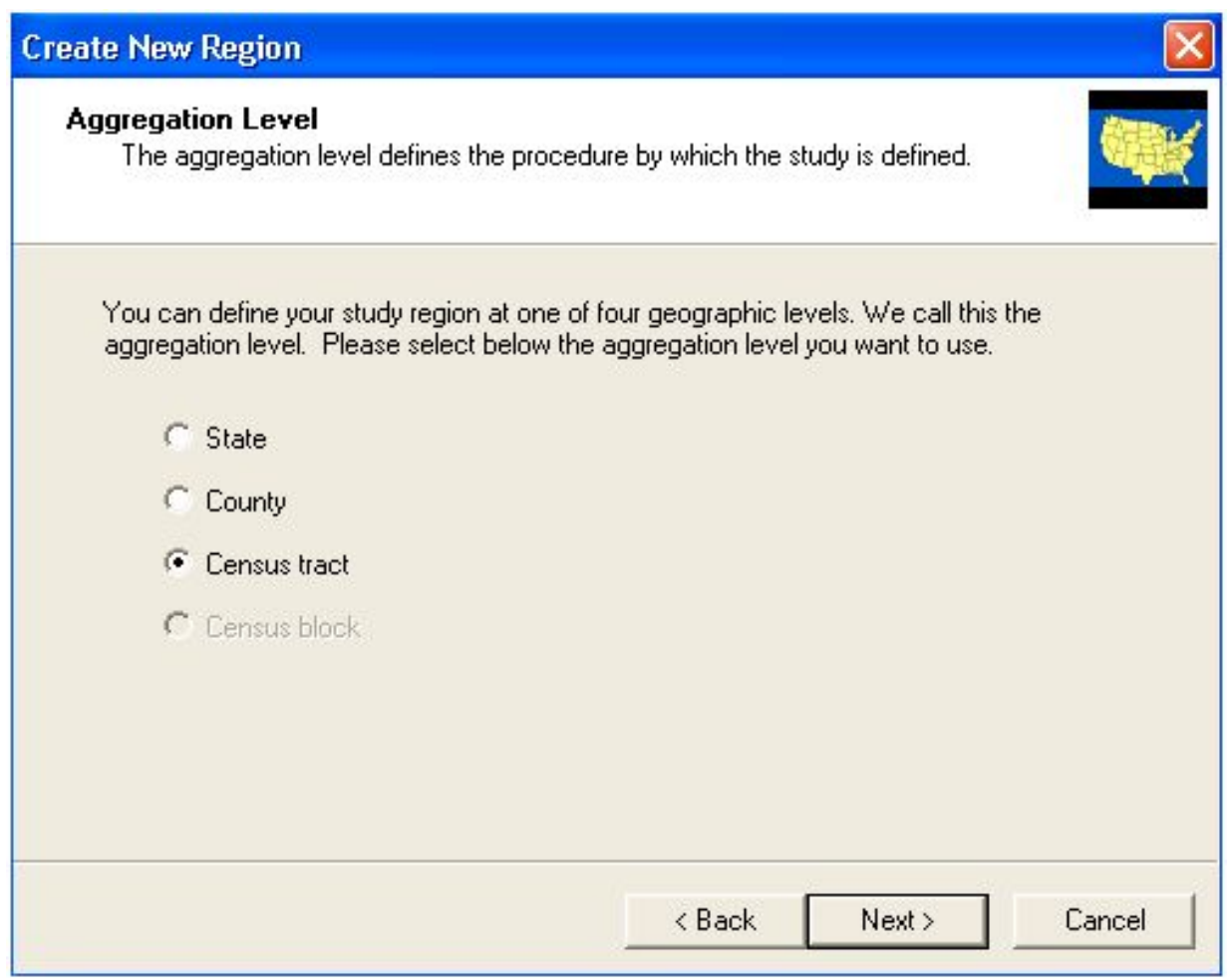

\section{Figure 5.15: Aggregation Level}

The next screen allows for the state to be selected and then the county, in this case it was California (CA) and San Bernardino County. If the state or county was unknown by name, a mapping option is available to select the desired location from a map. The next screen is the census tract selection (Figure 5.16). In this case, because the new IDs for the study area were derived by adding to the highest census tract ID in the county, the last 2204 census tracts were selected from the list. 


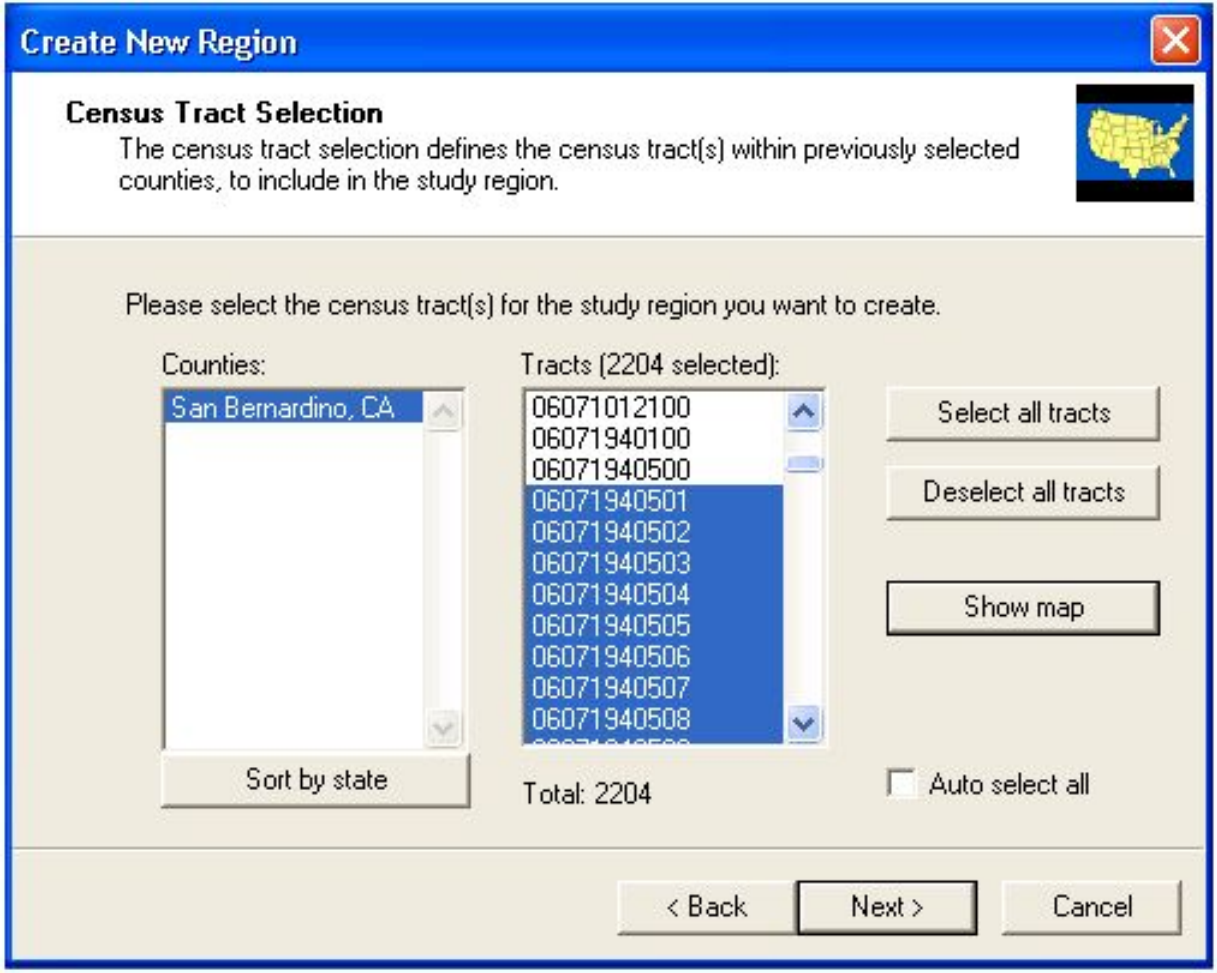

\section{Figure 5.16: Census Tract Selection}

These could have also been selected by using the "Show Map" button (Figure 5.17). While HAZUS-MH believes these are tracts, as seen in the map, they are actually the census blocks for the study area.

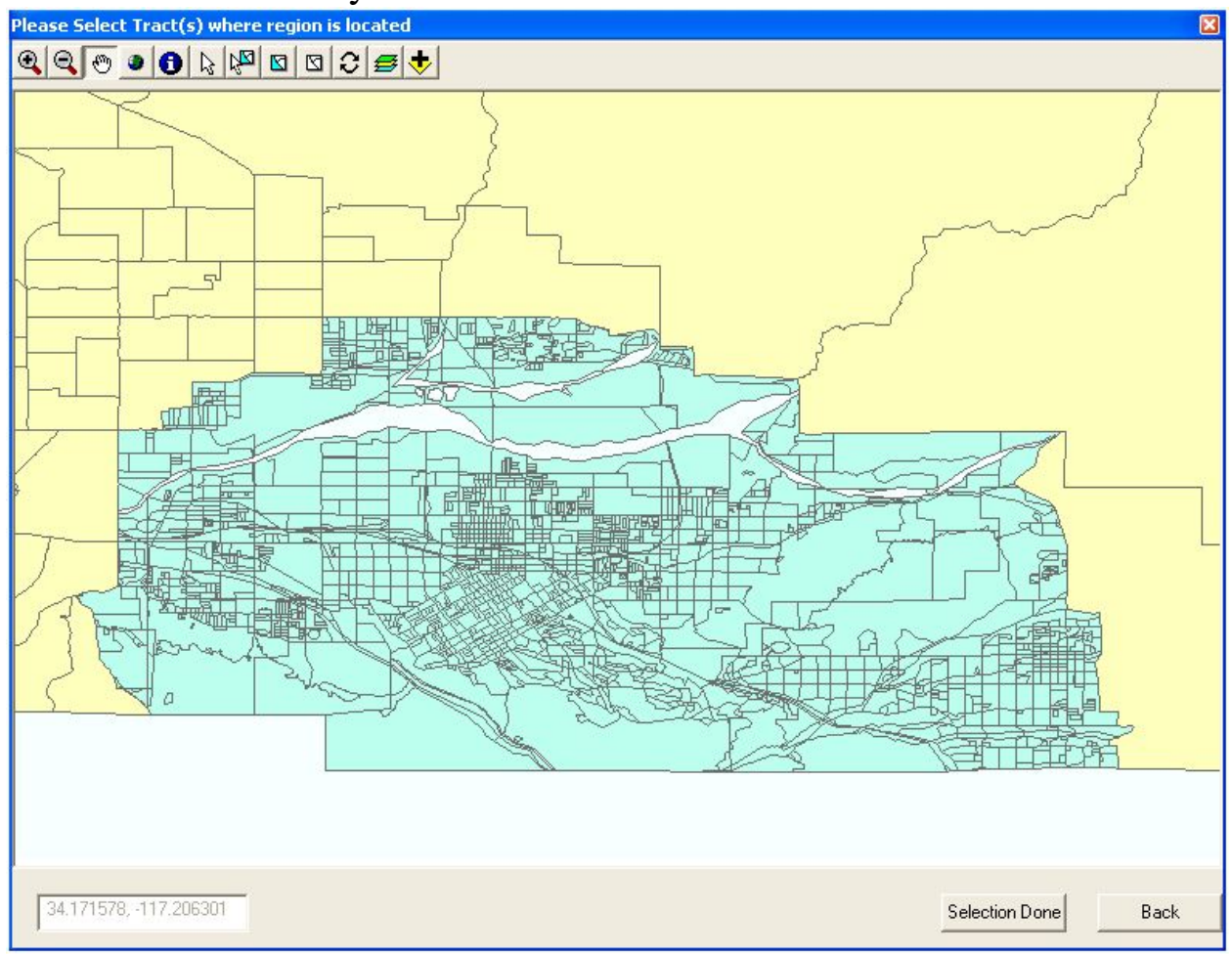

Figure 5.17: Select Census Tracts from Map 
Once the selection is complete, the study region is created. "Open a Region" is selected from the startup screen and the appropriate study region is selected (Figure 5.18). This opened an instance of ArcMap, with two polygon layers. One layer is the study area boundary and the other is the selected census tracts.

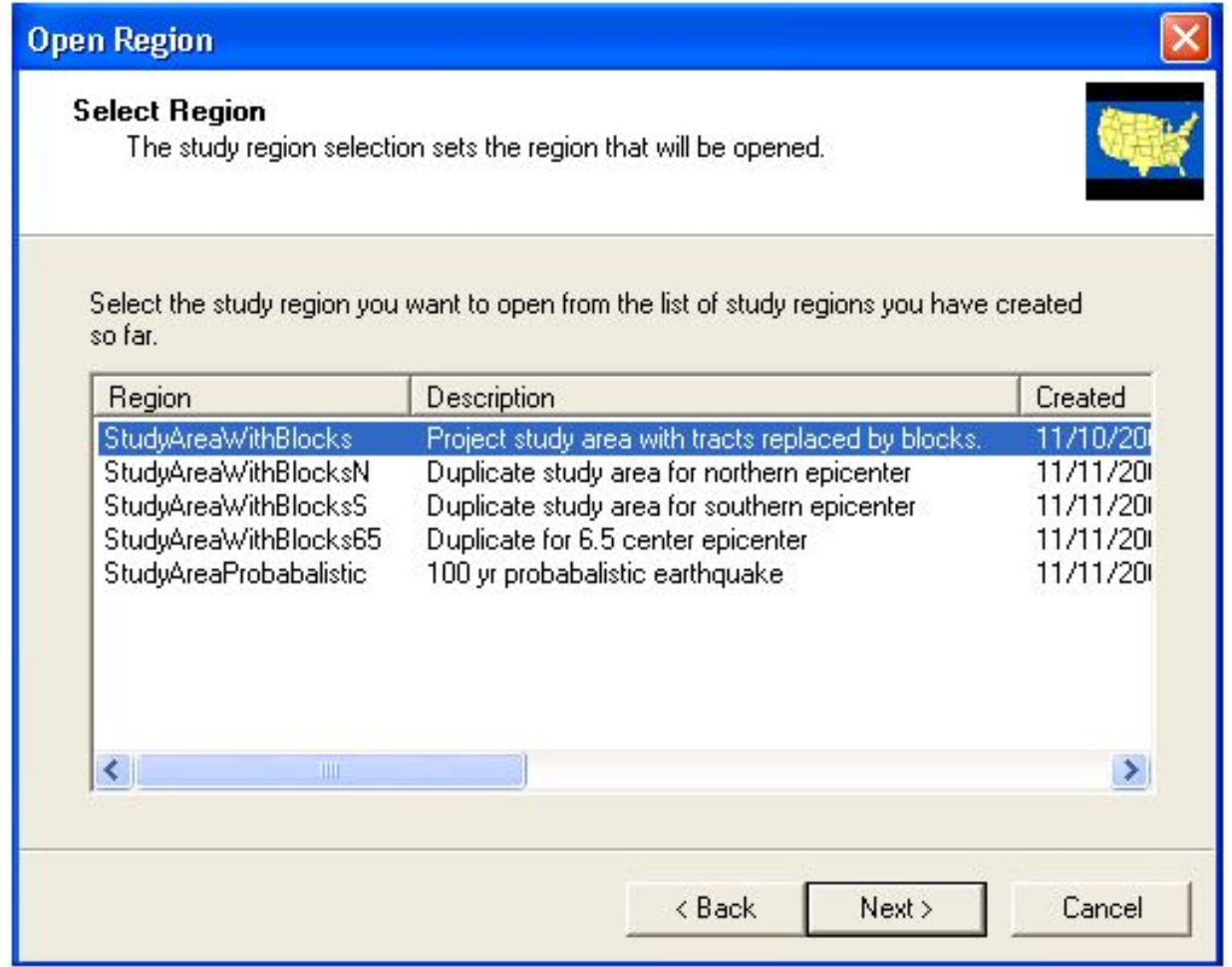

Figure 5.18: Study Region Selection

The next step in HAZUS-MH is to define the earthquake scenario. This is started by selecting "Scenario" from the Hazard menu. This opens the Scenario Definition Wizard (Figure 5.19). There are three ways to define a scenario: a deterministic hazard, and probabilistic hazard, or a user-supplied hazard. 


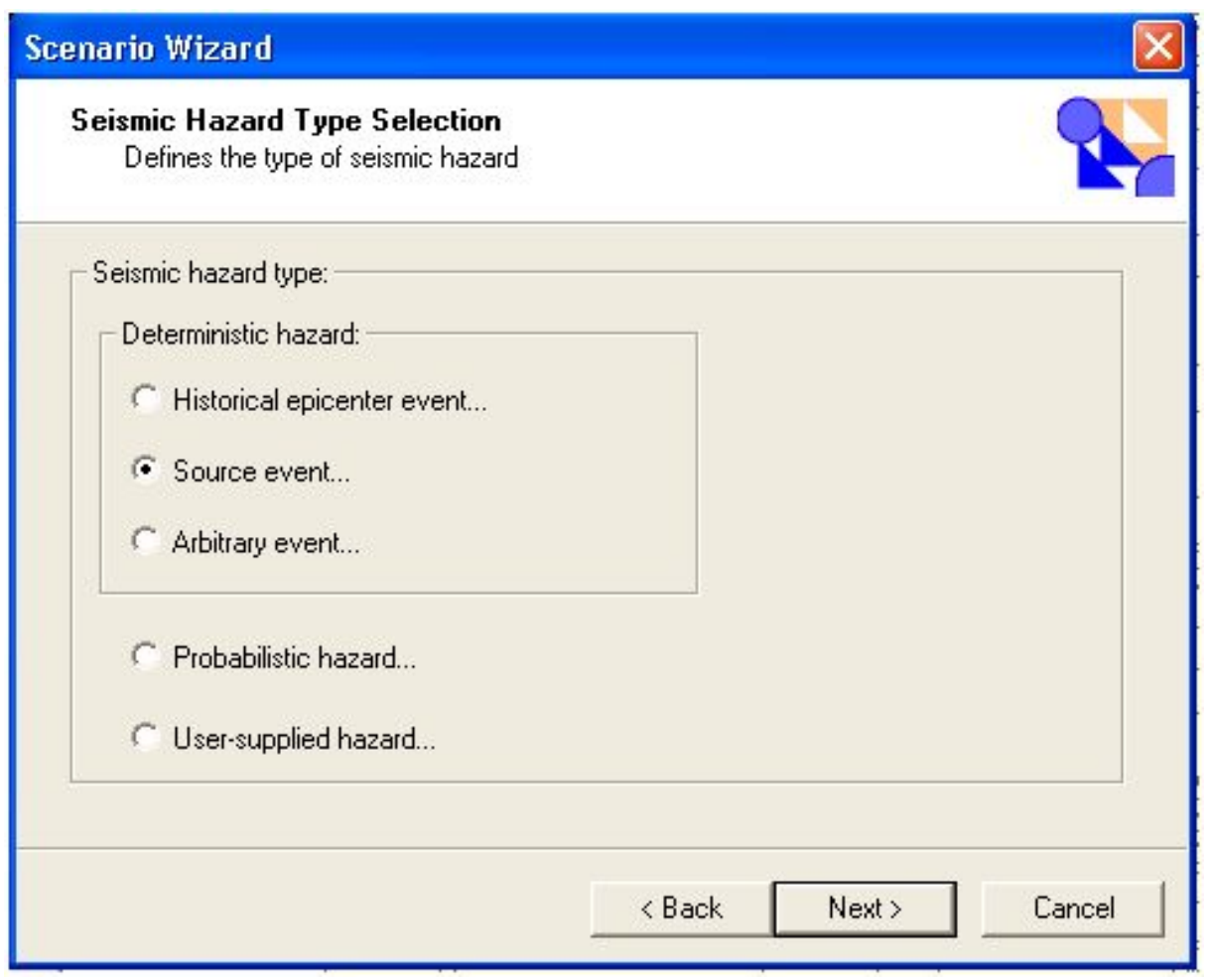

Figure 5.19: Seismic Hazard Type Selection

A deterministic hazard can be a historical epicenter event, a source, or an arbitrary event. A historical epicenter event is chosen from a HAZUS-MH database of over 3,500 historical earthquakes with a magnitude greater than 5.0 (FEMA, 2008a). An arbitrary event is based on a user-defined epicenter, magnitude, depth, type, rupture orientation, and length (FEMA, 2008b). A source event requires selecting a specific fault from a database of seismic sources. This database was developed by the U.S. Geological Survey (USGS), the California Department of Mines and Geology, and the Nevada Bureau of Mines and Geology. The database includes fault type, location, orientation, depth, width, dip angle, and maximum magnitude (FEMA, 2008a). The width, type, magnitude, and rupture length can all be overridden by the user. A probabilistic hazard allows for loss estimates based on probabilistic seismic hazards for eight return periods. They range from ground shaking with a $39 \%$ probability of being exceeded in 50 years (100-year return) to ground shaking with a $2 \%$ probability of being exceeded in 50 years (2500year return) (FEMA, 2008a). The user-supplied hazard requires shake maps to define ground shaking.

This project used the source event option. After selecting the correct radio button and pushing "Next", the source event database appears (Figure 5.20). The fault used for this project was the San Bernardino Mountains section of the San Andreas Fault. 


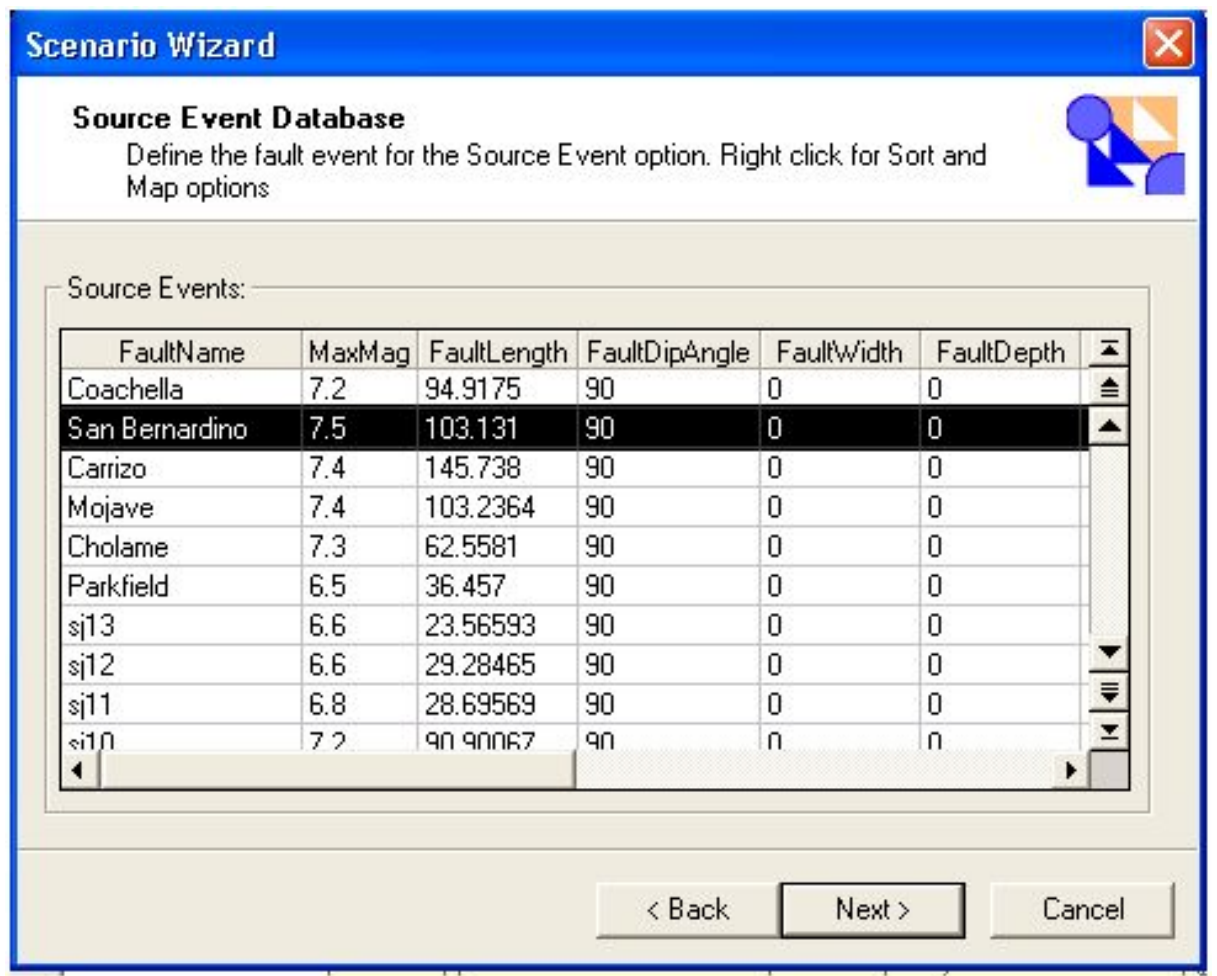

\section{Figure 5.20: Fault Selection from Source Event Database}

This is a strike-slip fault, with a maximum magnitude of 7.5. This section is 103 kilometers long and has a dip angle of 90 degrees. The fault can also be selected graphically (Figure 5.21).

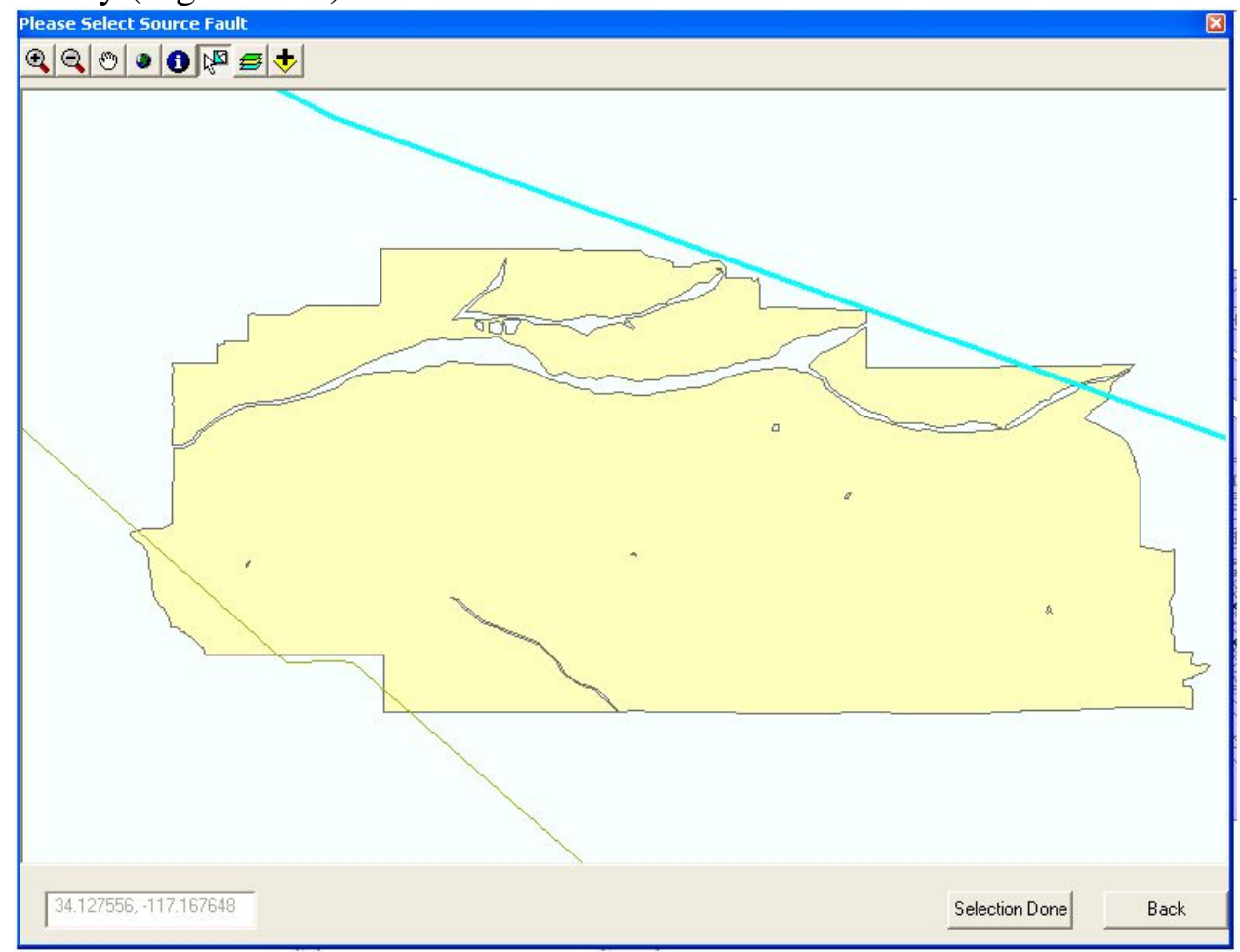

Figure 5.21: Fault Selection from Map 
As seen from the map, the San Andreas Fault runs from the southeast to northwest and just crosses the northeastern corner of the study area. Another fault, the San Jacinto Fault, crosses the southwest corner of the study area.

The source event parameters were defined after the fault section was selected (Figure 5.22). The epicenter was defined graphically by selecting a point on a map similar to Figure 5.21 above.

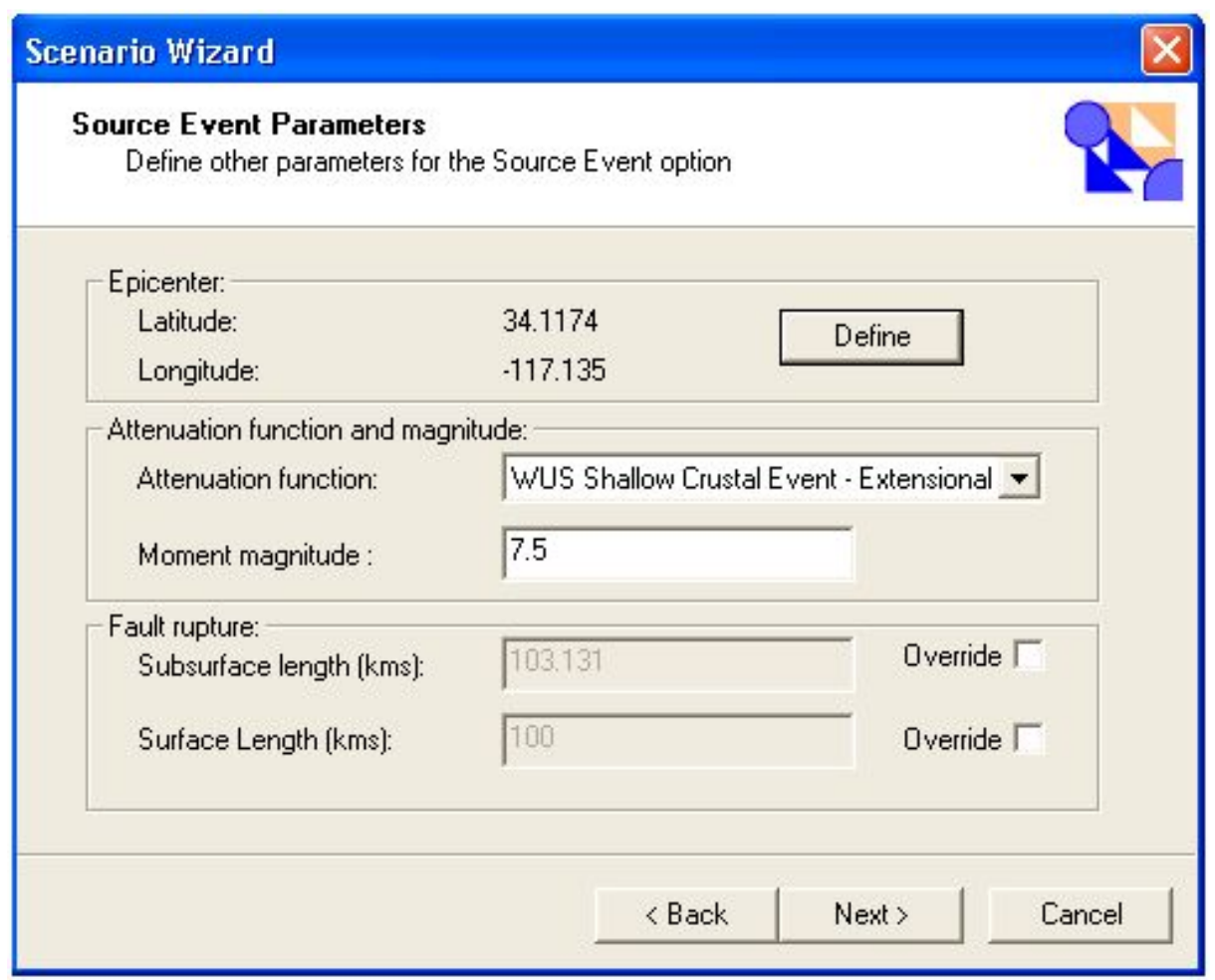

Figure 5.22: Define Source Event Parameters

The point was placed where the fault was closest to the center of the study area. This point was determined by using the Near tool in ArcCatalog. The latitude and longitude of the point were 34.117 and -117.135 . The default attenuation function, WUS Shallow Crustal Event-Extensional, was used because it requires expert input to understand the differences in the available functions well enough to make an educated change. The magnitude for this scenario was defined as 7.5 because that is the maximum magnitude of the fault according to the source event database. After the hazard was defined, the analysis was run by selecting "Run" from the Analysis menu. The analysis options dialog (Figure 5.23) opens to allow the selection of modules. In this case, all modules except for Contour Maps are chosen because this analysis has never been run before. The contour maps can be created for a detailed mapping of the ground motion by census tract and significantly add to the analysis run time. They are for display purposes only and are not used in the damage or loss functions, therefore users may choose not to run that module (FEMA, 2008b). 


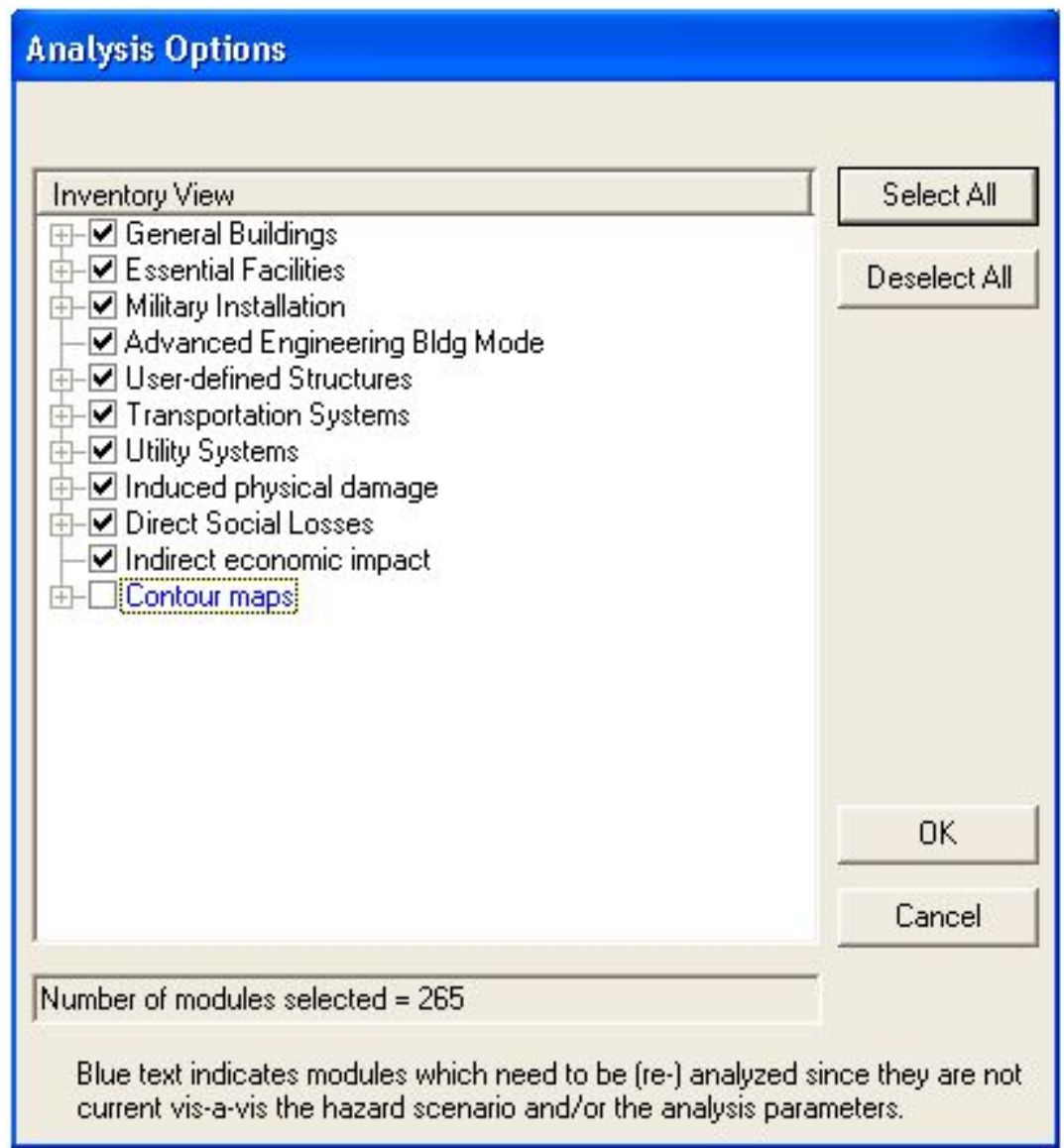

Figure 5.23: Hazard Analysis Options

The process described above was repeated several times in order to simulate different scenarios. Two other source events were created with the same parameters except for the magnitude, which was changed to 6.5 and 5.5 to show the effect of earthquakes of lesser magnitudes. After the analysis is complete, the results can be viewed by selecting from a variety of options from the "Results" menu (Figure 5.24). Each selection opens a table with the corresponding data, and the data can be added to the map by highlighting a column and clicking the "Map" button. Choosing the "Summary Reports" option will allow HAZUS-MH to generate summary reports for any of the selected menu items. These reports are helpful because they summarize the analysis results by study region, rather than individual census tract. 


\begin{tabular}{|c|c|}
\hline Results Insert Selection Tools Help & \\
\hline Ground Motion or Ground Failure & Gontours or Ground Failure Maps \\
\hline General Building Stock & \multirow{8}{*}{$\begin{array}{l}\text { By Building Type } \\
\text { By Count } \\
\text { By Square Footage }\end{array}$} \\
\hline Essential Facilities & \\
\hline Military Installations & \\
\hline User-Defined Structure Inventory & \\
\hline Advanced Engineering Building Model (AEBM) & \\
\hline Iransportation Systems & \\
\hline Uيtility Systems & \\
\hline Inundation & \\
\hline Fire Following Earthquake & \multirow{3}{*}{$\begin{array}{l}\text { By Qccupancy } \\
\text { By Building Type } \\
\text { By General Building Type }\end{array}$} \\
\hline Debris & \\
\hline Gasualties & \\
\hline Shelter & \\
\hline Building Economic Loss & \multirow{4}{*}{$\begin{array}{l}\text { Direct Économic Loss } \\
\text { Building Loss By Damage State }\end{array}$} \\
\hline Indirect Economic Loss & \\
\hline 3rd Party Models & \\
\hline Summary Reports... & \\
\hline
\end{tabular}

\section{Figure 5.24: Results Menu Options}

\subsection{Shelter Suitability}

The model created to determine schools that would be suitable shelters took several characteristics into account. The first two were the school's vicinities to fire zones and major roads, which might be used as evacuation routes. The major roads were selected out of the roads layer and a one-half mile buffer was created around the roads. A onehalf mile buffer was also created around the fire zones. The schools within the buffered fire zones were erased, and the schools layer was clipped to only contain those within one- half mile of the major roads (Figure 5.25). 


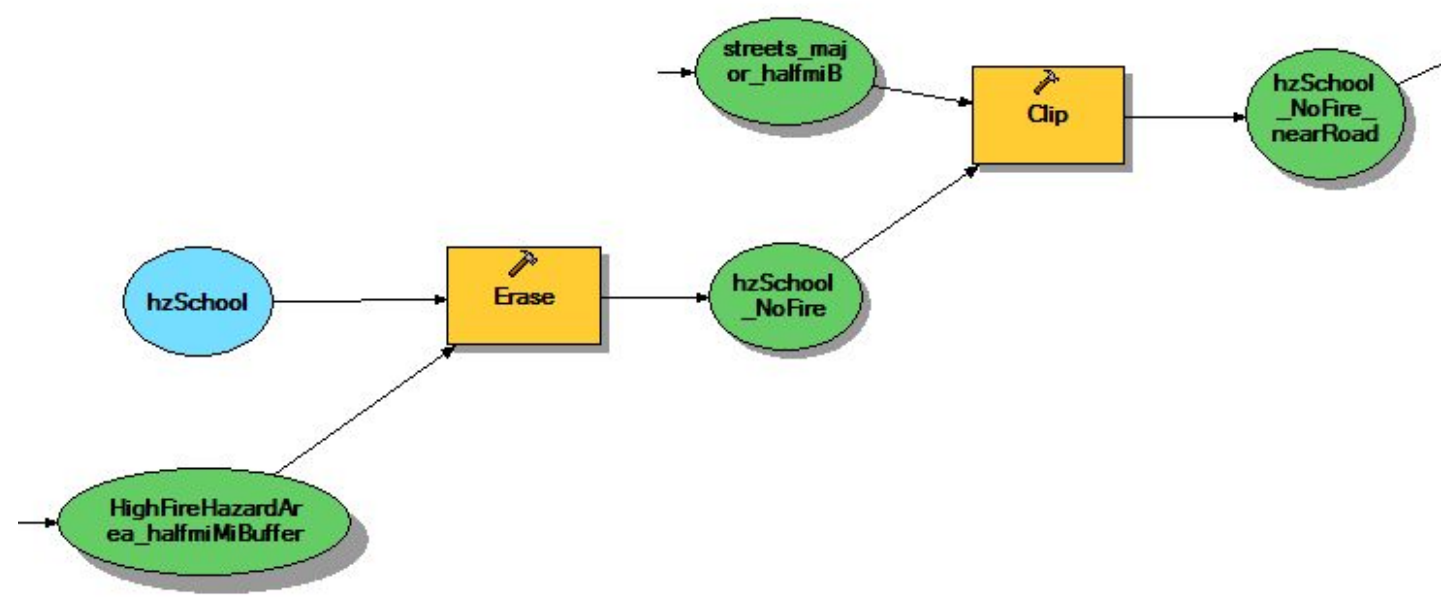

Figure 5.25: School Selection Based on Fire Zones and Major Roads

Schools were then selected based on their vicinity to census blocks with the highest shelter requirements (Figure 5.26). The shelter requirements were extracted from a HAZUS-MH results table. For this model, the blocks with more than 20 people needing shelter were selected, but this parameter can be changed by the client. The remaining census blocks were buffered by one-half mile and the schools within the buffer area were clipped out. The private schools were then deleted, leaving a list of schools owned by the Redlands Unified School District that can act as emergency shelters based on the criteria described above. All of the buffers used in this model have a distance parameter than can be changed as needed to alter the results.

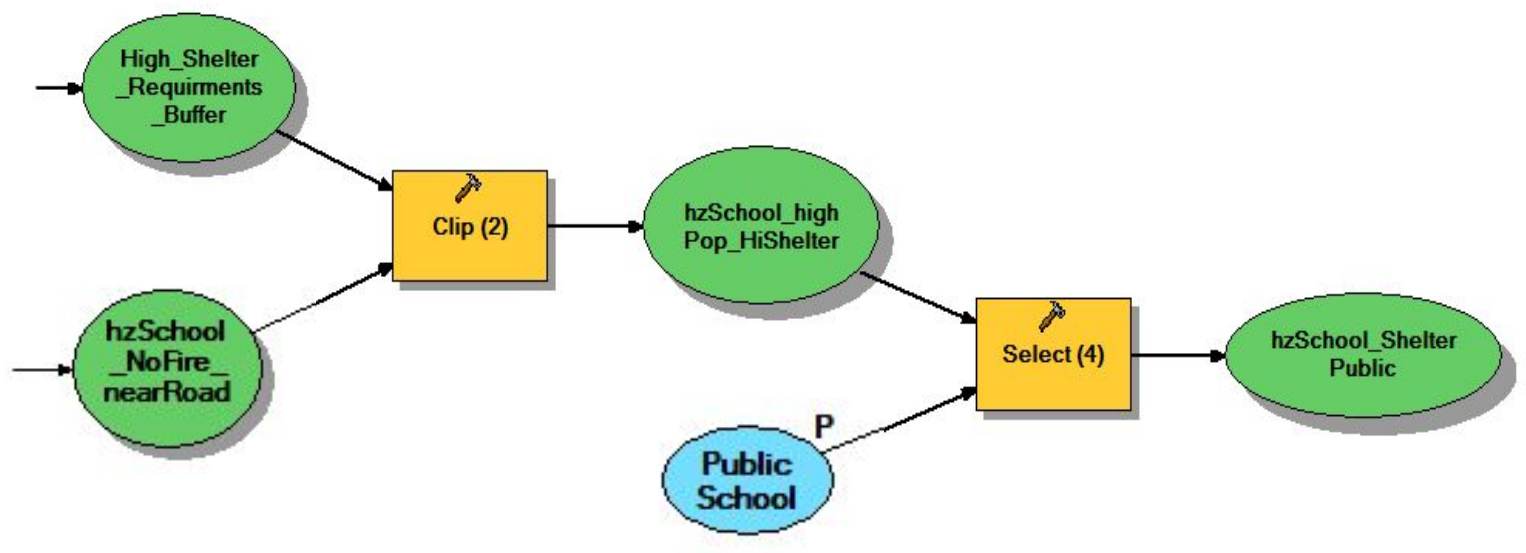

Figure 5.26: Selecting Public Schools near High Shelter Requirements

\subsection{Summary}

This chapter discussed the implementation stages of the project. It detailed the steps followed to disaggregate the census data, and the process of replacing the study area census tracts with census blocks in the HAZUS-MH geodatabases. It also discussed how 
to run an earthquake scenario in HAZUS-MH once the geodatabases have been updated. Lastly, the model created to determine which schools would most likely be suitable shelters was explained. The next chapter will discuss the census disaggregation implementation results, how the addition of census blocks improved the HAZUS-MH analysis, and results from running the HAZUS-MH model. 


\section{Chapter 6 - Results and Analysis}

This chapter explains the sacrifices made to run HAZUS-MH with blocks instead of tracts, as well as the benefits achieved. The results from three scenario earthquakes and how the city can use these in mitigation efforts are discussed. The model to determine suitable shelters and how it could be improved is also discussed.

\subsection{HAZUS-MH Tract Replacement}

There are 25 census tracts in the study area for this project. Because these tracts are fairly large, and were misrepresenting the damage distribution in the area, they were removed and replaced by 2204 census blocks (Figure 6.1). These represented the population distribution and thus the damage distribution much more accurately.
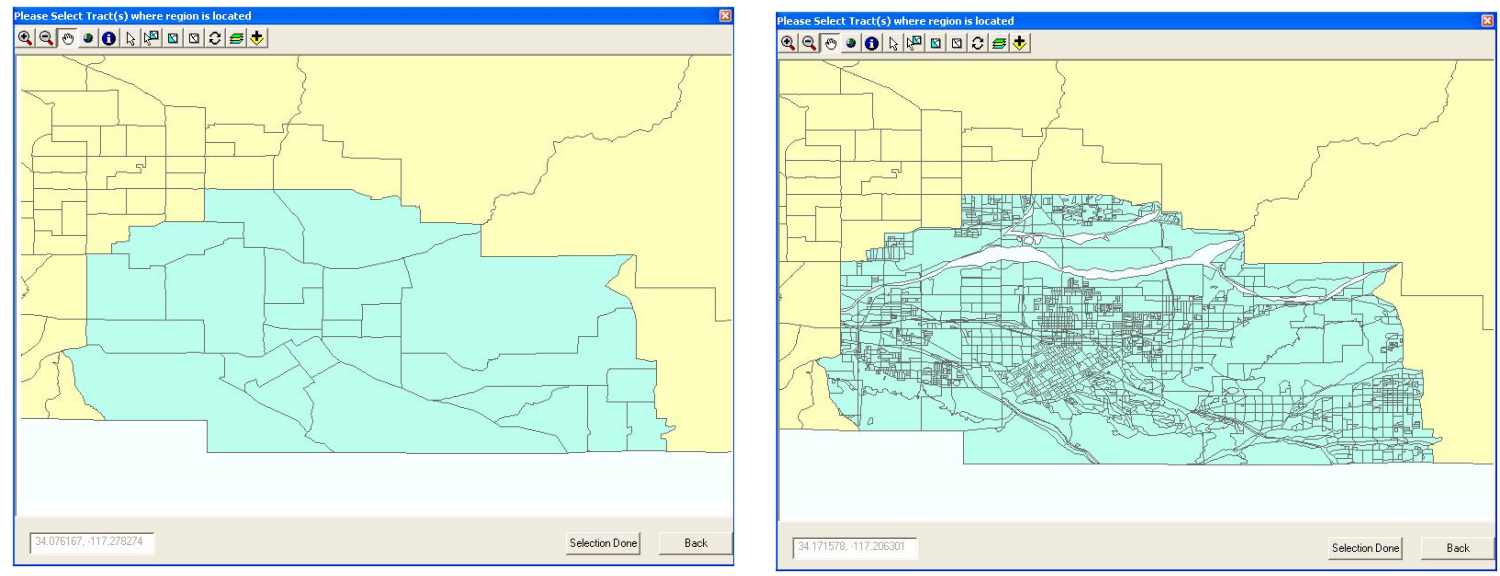

\section{Figure 6.1: Study Area Differences}

The average number of blocks per tract was 88 , with the highest number of blocks making up a tract being 214 and the lowest being 27 . This meant the population was broken into much smaller groups, so earthquake damage was more specific to the area, and less general as in the original tracts (Figure 6.2). 

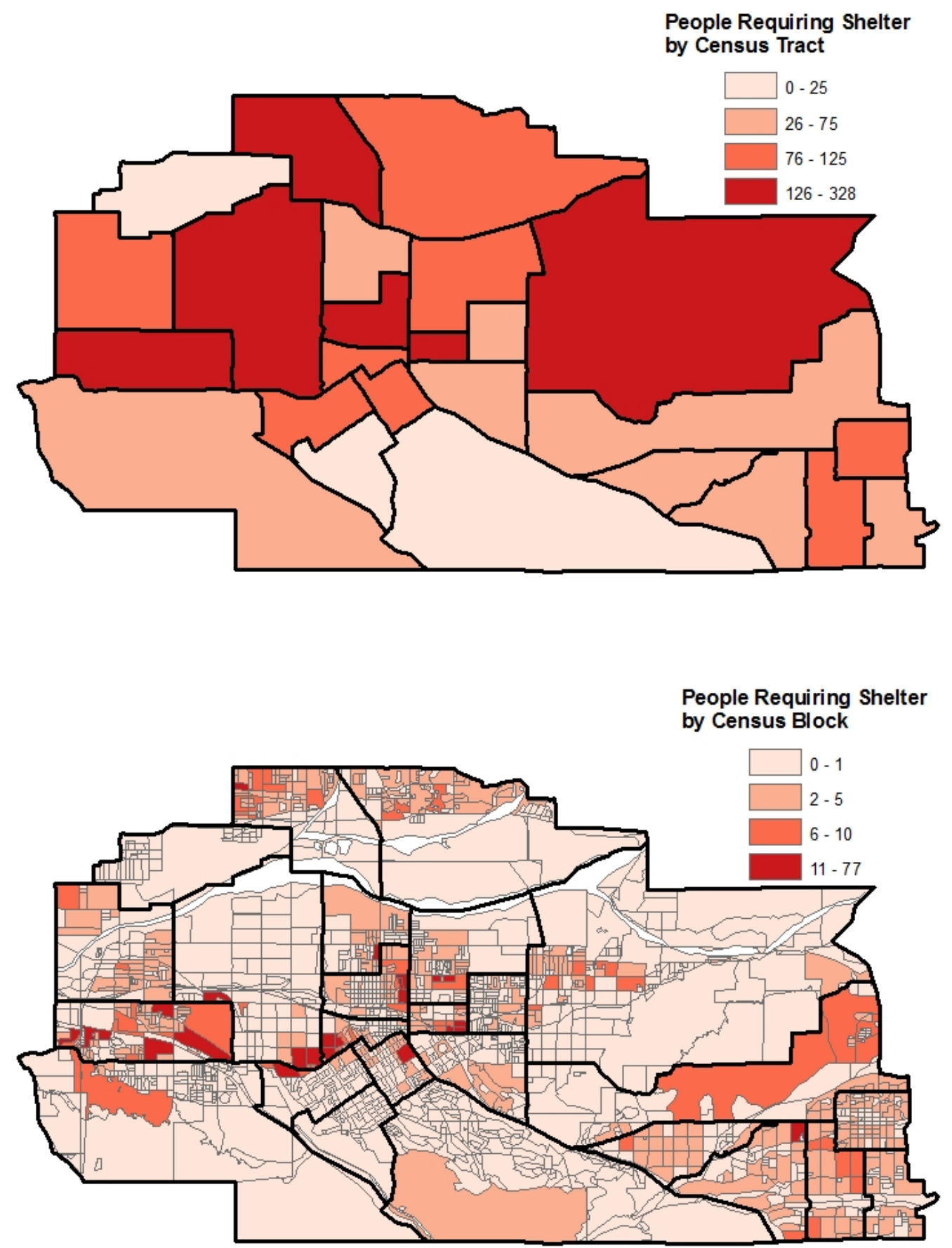

Figure 6.2: Comparison of Shelter Requirements by Census Tracts and Blocks

Figure 6.3 shows the distribution of shelter requirements within a specific tract. HAZUS-MH predicts that the tract as whole will have 133 people requiring shelter. It does not, however, specify where in the tract these people will be located. By using blocks, this number can be broken down into specific areas. As seen in the figure, the 
lower right hand corner of the tract contains the majority of the people requiring shelter. 88 people requiring shelter are located in the blocks in the lower corner; this is over $66 \%$ of the total shelter requirements for the tract. This shows that the tract level does not provide an appropriate distribution of damage for the study area. This helps the City of Redlands determine where there will be the most damage, and allows their mitigation efforts to be more focused on specific areas.

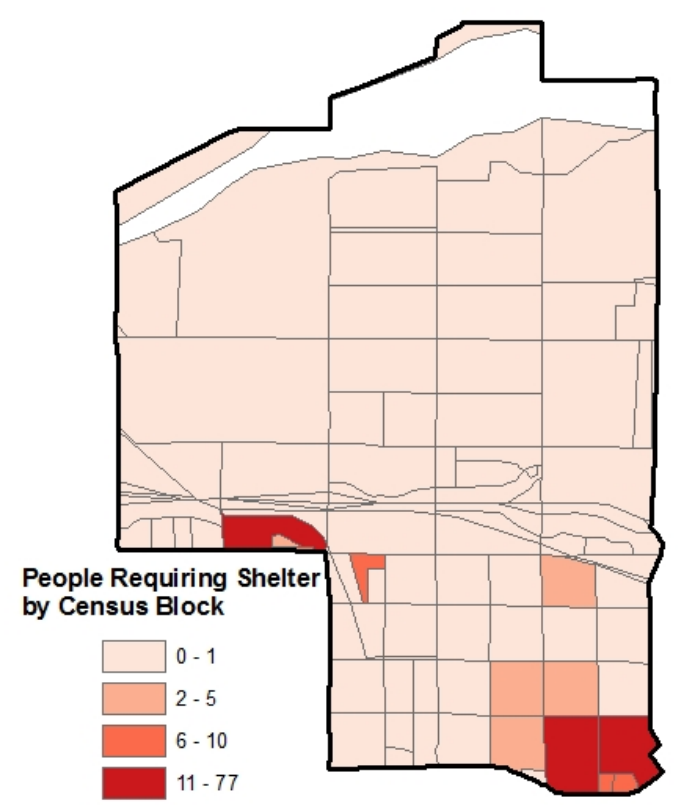

Figure 6.3: Shelter Requirements for Specific Tract

Along with the benefits gained by using census blocks, there were also some sacrifices made. Each block had to be numbered with an eleven-digit "tract" number to be added to HAZUS-MH. This caused the loss of the original block numbers within the HAZUS-MH geodatabases. The blocks can be extracted from HAZUS-MH and joined to a feature class created which contains the original census block numbers, as well as the new HAZUS-MH tract numbers. The databases now only use blocks within the study area; for a study region to be defined at the original tract level, all the HAZUS-MH geodatabases would have to be replaced by the originals. The analysis processing time was significantly affected by changing the aggregation level. This was expected because of the larger database size and level of detail. The analysis only had to determine damage to 24 tracts before; it now had to process 2204 blocks. The total processing time for a scenario was barely over a minute with the original tracts. Processing time for the blocks was now close to thirty minutes. This is not a major problem because thirty minutes is not excessive for a one-time, pre-event risk assessment of the study area.

\subsection{HAZUS-MH Earthquake Model Results}

The HAZUS-MH earthquake model was run with three different scenarios for the blocks, and one scenario was run with the original tracts as a point of comparison. Regardless of the aggregation level, the study area was a total of 97 square miles with a total population 
of 178,732 . There were 62,000 households and 47,000 buildings with an $\$ 11,313$ million dollar total replacement value (Table 11). Residential buildings made up 93\% of the total building stock.

Table 11. Study Area Characteristics

\begin{tabular}{|l|l|}
\hline Study Area & 97 Square Miles \\
\hline Population & 178,732 \\
\hline Households & 62,000 \\
\hline Buildings & 47,000 \\
\hline Building Replacement Cost & $\$ 11,313$ Million \\
\hline
\end{tabular}

The tracts were used to run a scenario of a 7.5 magnitude earthquake on the San Andreas Fault. This same scenario was run using the blocks, as well as 6.5 and 5.5 magnitude earthquakes. The two matching scenarios run on the blocks and tracts returned virtually the same overall results, with the exception of fire damage. The tract-level analysis predicted more ignitions, but less people exposed, and less building damage from the fire. The block-level analysis predicted fewer ignitions, but more than double the population exposed and the building damage. The cause of this is unknown as the data in both sets of geodatabases were consistent with each other. An expert would be required to thoroughly understand the underlying methodology in the fire following earthquake module to determine the cause for the differences. The results from the two 7.5 Magnitude earthquakes are summarized in Table 12.

Table 12. Damage Comparisons for 7.5 Earthquake Across Tracts and Blocks

\begin{tabular}{|c|c|c|c|c|c|c|}
\hline & \multicolumn{3}{|c|}{ Census Tracts } & \multicolumn{3}{|c|}{ Census Blocks } \\
\hline $\begin{array}{l}\text { Total Debris (thousands of } \\
\text { tons) }\end{array}$ & \multicolumn{3}{|c|}{1051} & \multicolumn{3}{|c|}{1052} \\
\hline Displaced Households & \multicolumn{3}{|c|}{3250} & \multicolumn{3}{|c|}{3185} \\
\hline $\begin{array}{l}\text { Resident Requiring Short } \\
\text { Term Shelter }\end{array}$ & \multicolumn{3}{|c|}{2292} & \multicolumn{3}{|c|}{2198} \\
\hline Number of Fire Ignitions & \multicolumn{3}{|c|}{18} & \multicolumn{3}{|c|}{7} \\
\hline Building Value Burned & \multicolumn{3}{|c|}{ \$11 Million } & \multicolumn{3}{|c|}{ \$23 Million } \\
\hline Exposed people (fire) & \multicolumn{3}{|c|}{215} & \multicolumn{3}{|c|}{490} \\
\hline $\begin{array}{l}\text { Total Direct Building } \\
\text { Economic Loss }\end{array}$ & \multicolumn{3}{|c|}{ \$3,108 Million } & \multicolumn{3}{|c|}{$\$ 3,109$ Million } \\
\hline \multirow{2}{*}{ Casualty severity 3} & 2 a.m. & 2 p.m. & 5 p.m. & 2 a.m. & 2 p.m. & 5 p.m. \\
\hline & 24 & 95 & 109 & 22 & 55 & 51 \\
\hline Casualty severity 4 & 44 & 179 & 131 & 40 & 106 & 91 \\
\hline
\end{tabular}

There were three scenario earthquakes run for the study area made up of census blocks. The only differences between these earthquakes were their magnitudes. Each earthquake had the same epicenter and used the default settings applied by HAZUS-MH. As expected, as the magnitude increases, so does the level of damage across the study area (Table 13). Moving the epicenter up and down the fault was experimented with, but 
it had no significant affect on the outcome because the distances were not far enough apart to make a difference in source-to-site distance. This distance is responsible for defining the decrease in ground shaking intensity as the distance from the source increases (FEMA, 2008a).

Table 13. Damage Comparison for Three Different Earthquakes Across Blocks

\begin{tabular}{|c|c|c|c|c|c|c|c|c|c|}
\hline & \multicolumn{3}{|c|}{ 5.5 Magnitude } & \multicolumn{3}{|c|}{ 6.5 Magnitude } & \multicolumn{3}{|c|}{ 7.5 Magnitude } \\
\hline $\begin{array}{l}\text { Total Debris } \\
\text { (thousands of } \\
\text { tons) }\end{array}$ & \multicolumn{3}{|c|}{58} & \multicolumn{3}{|c|}{420} & \multicolumn{3}{|c|}{1053} \\
\hline $\begin{array}{c}\text { Displaced } \\
\text { Households }\end{array}$ & \multicolumn{3}{|c|}{100} & \multicolumn{3}{|c|}{1104} & \multicolumn{3}{|c|}{3185} \\
\hline $\begin{array}{c}\text { Resident } \\
\text { Requiring Short } \\
\text { Term Shelter }\end{array}$ & \multicolumn{3}{|c|}{70} & \multicolumn{3}{|c|}{768} & \multicolumn{3}{|c|}{2198} \\
\hline $\begin{array}{l}\text { Number of Fire } \\
\text { Ignitions }\end{array}$ & \multicolumn{3}{|c|}{4} & \multicolumn{3}{|c|}{6} & \multicolumn{3}{|c|}{7} \\
\hline $\begin{array}{c}\text { Building Value } \\
\text { Burned }\end{array}$ & \multicolumn{3}{|c|}{$\$ 2.5$ Million } & \multicolumn{3}{|c|}{ \$9.8 Million } & \multicolumn{3}{|c|}{ \$23 Million } \\
\hline $\begin{array}{l}\text { Exposed people } \\
\text { (fire) }\end{array}$ & \multicolumn{3}{|c|}{40} & \multicolumn{3}{|c|}{245} & \multicolumn{3}{|c|}{490} \\
\hline $\begin{array}{c}\text { Total Direct } \\
\text { Building } \\
\text { Economic Loss }\end{array}$ & \multicolumn{3}{|c|}{ \$342 Million } & \multicolumn{3}{|c|}{ \$1,463 Million } & \multicolumn{3}{|c|}{ \$3,109 Million } \\
\hline \multirow{2}{*}{$\begin{array}{c}\text { Casualty } 3 \\
\text { (Life Threatening } \\
\text { Injuries) }\end{array}$} & 2a.m. & 2p.m. & 5p.m. & 2a.m. & 2p.m. & 5p.m. & 2a.m. & 2p.m. & 5p.m. \\
\hline & 0 & 0 & 0 & 5 & 10 & 11 & 22 & 55 & 51 \\
\hline $\begin{array}{l}\text { Casualty } 4 \\
\text { (Fatalities) }\end{array}$ & 0 & 1 & 1 & 8 & 20 & 18 & 40 & 106 & 91 \\
\hline $\begin{array}{c}\text { Schools } \\
\text { (Average } \\
\text { Functionality on } \\
\text { Day 1) }\end{array}$ & \multicolumn{3}{|c|}{$69 \%$} & \multicolumn{3}{|c|}{$34 \%$} & \multicolumn{3}{|c|}{$19 \%$} \\
\hline $\begin{array}{c}\text { Hospitals } \\
\text { (Average } \\
\text { Functionality on } \\
\text { Day 1) }\end{array}$ & \multicolumn{3}{|c|}{$90 \%$} & \multicolumn{3}{|c|}{$61 \%$} & \multicolumn{3}{|c|}{$45 \%$} \\
\hline $\begin{array}{c}\text { Fire Station } \\
\text { (Average } \\
\text { Functionality on } \\
\text { Day 1) }\end{array}$ & \multicolumn{3}{|c|}{$74 \%$} & \multicolumn{3}{|c|}{$39 \%$} & \multicolumn{3}{|c|}{$19 \%$} \\
\hline $\begin{array}{c}\text { Police Station } \\
\text { (Average } \\
\text { Functionality on } \\
\text { Day 1) }\end{array}$ & \multicolumn{3}{|c|}{$69 \%$} & \multicolumn{3}{|c|}{$31 \%$} & \multicolumn{3}{|c|}{$14 \%$} \\
\hline
\end{tabular}


Even though the level of damage may change with the varying magnitude, the concentrations of the highest levels of damage are still in the same areas (Figure 6.4). The areas with the majority of damage would most likely change if the earthquake was moved to the San Jacinto fault on the south side of the study area. Running multiple scenarios showed that there are vulnerable neighborhoods within the study area. This allows disaster management officials to pinpoint where they should focus their mitigation efforts and community preparedness initiatives. 

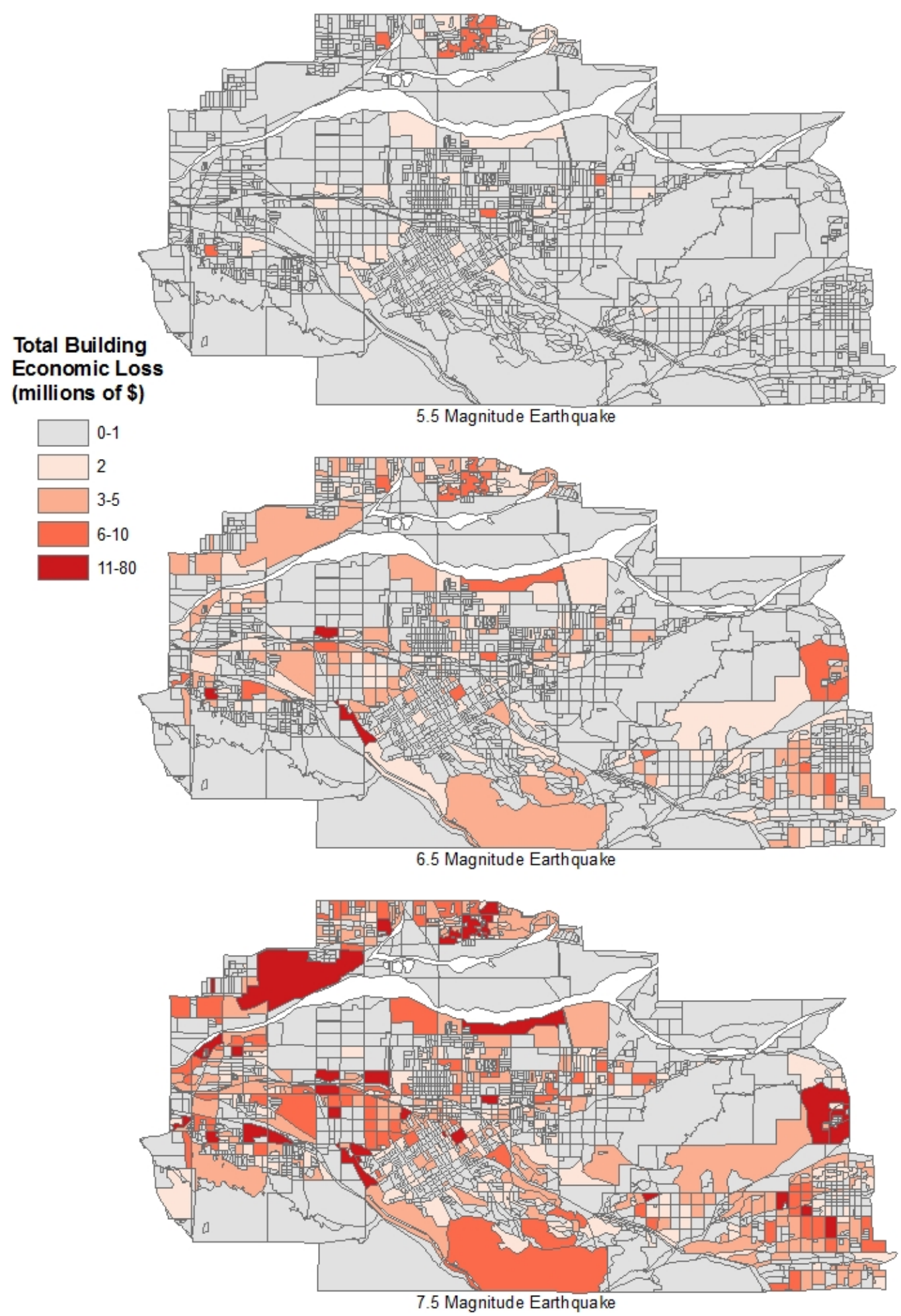

Figure 6.4: Total Building Economic Losses per Census Block for Three Scenario Earthquakes 


\subsection{Shelter Suitability Model Results}

The model created to determine schools that were suitable to act as shelters narrowed the list of 55 schools in the study area down to six. There were 45 left after the schools within the fire zone buffer were erased, and 40 left after schools outside the major roads buffer were removed. Schools within a half mile of census blocks with the highest predicted shelter needs brought the list down the 13. The private schools were removed from this list, leaving only six schools owned by the Redlands Unified School District which met all the other requirements.

The structural suitability was not used in the model because it appeared that it would have eliminated every school. The structural suitability was based on the functionality of each school on day one after an earthquake, as estimated by HAZUS-MH. If these predictions are correct, then a 7.5 earthquake will leave the best school only $32.6 \%$ functional on the first day. The school's functionality shows a distinct pattern related to the distance from the source of the earthquake (Figure 6.5). The further away a school is from the source, the less damage a school incurs during an earthquake. The magnitude of the earthquake determines just how much each school is affected. As the magnitude increases, the worst damage extends further into the study area. The schools remaining after running the geoprocessing model all fall in the center of the study area, which puts them in the middle range of functionality. In the 7.5 earthquake, the functionality of these schools ranged from $17 \%$ to $22 \%$. In the 6.5 earthquake the range is $32 \%$ to $39 \%$ and in the 5.5 earthquake, the functionality ranged from $60 \%$ to $72 \%$. The percentages are not very reassuring that any school will be structurally suitable to be an earthquake shelter. The city should explore other options for emergency shelters. 


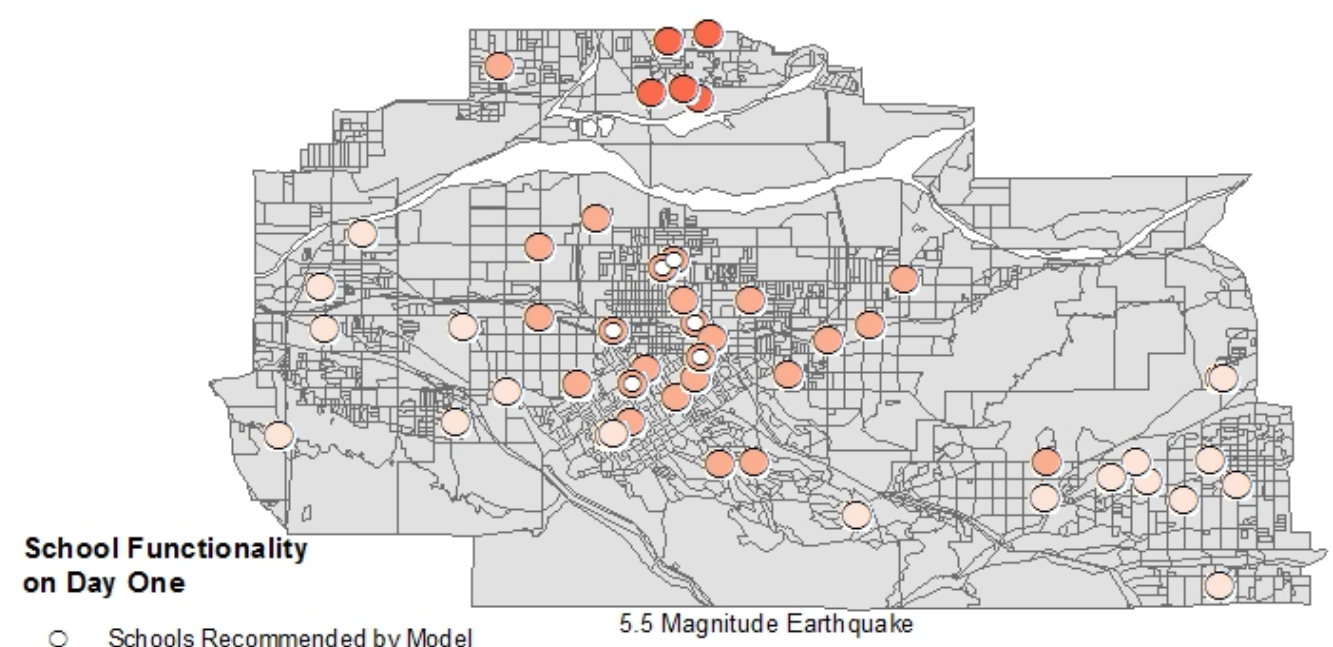

- Schools Recommended by Model 5.5 Magnitude Earthquake
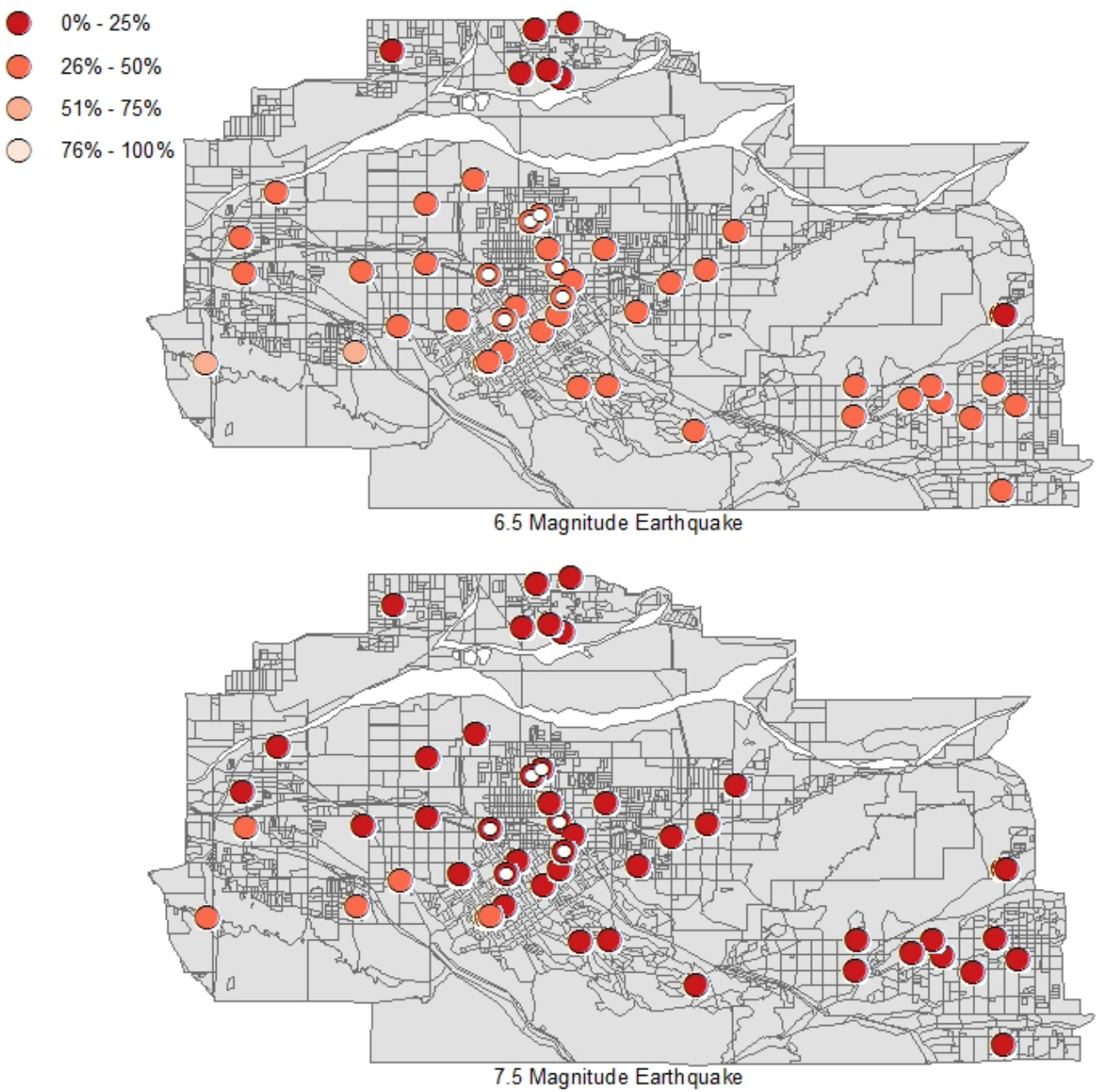

Figure 6.5: Schools Functionality on Day One of Three Earthquake Scenarios 


\subsection{Summary}

This chapter discussed the results of using census blocks as the aggregation level in HAZUS-MH and how the software performance was affected by doing so. The estimated damage to the study area based on three scenario earthquakes was discussed. The damage increased as the magnitude increased, but the concentration of the highest levels of damage were still in the same areas. The shelter suitability model was described and issues with the structural functionality from HAZUS-MH were explained. Five schools were determined by the model to be suitable based on their proximity to major roads, high risk fire zones, and blocks with the high shelter requirements. The structural suitability was not used in this model because it may have eliminated all possible shelters. The next chapter will summarize this report, including requirements, methods, and results. It will also discuss possible future work that could be done to expand this project 


\section{Chapter 7 - Conclusions and Future Work}

This chapter discusses how the client's expectations for the HAZUS-MH software were met and how future work might expand on this project.

\subsection{Conclusions}

The main purpose of the project was to provide the client with a working version of the HAZUS-MH software with altered geodatabases. The accompanying geodatabases were manipulated to use a census block aggregation level. This was accomplished by first updating the census data with the 2008 Business Analyst demographics and then manipulating the HAZUS-MH geodatabases to use the census block data. A model was also created to assist the client in choosing schools that can act as suitable shelters. The following functional requirements were fulfilled for the client:

- HAZUS-MH will be fully functional after modifications are made to the geodatabases.

- The Client should be able to duplicate analyst's efforts by means of extensive documentation.

The client can now utilize the HAZUS-MH software to understand the effects a severe earthquake may have on the study area at the census block level. The client can also repeat the process, if needed, by using the documentation provided. The successful completion of this project makes it possible for city officials and the disaster management team to focus their mitigation and preparedness efforts on specific neighborhoods that will be most affected when a catastrophic event occurs.

\subsection{Future Work}

\subsubsection{Census Tract Replacement}

This project altered the geodatabases the HAZUS-MH software uses to aggregate data for the user-defined study area. The smallest aggregation level available in the earthquake model is the census tract. The census tract feature classes were modified to actually use census blocks within the project study area. This was done by removing the original tracts and replacing them with the census blocks. The census blocks were given unique eleven-digit IDs so the software could process the blocks as tracts. Another approach to accomplish this would be to actually alter the programming behind HAZUS-MH to override the aggregation level restrictions. This has been accomplished by the State of Wyoming through a contract with PBS\&J, the consulting firm awarded the contract to develop the HAZUS-MH applications and update the hazard and inventory databases under supervision from the National Institute of Buildings Sciences. This would allow both the tracts and blocks data to be retained so study regions could be defined at either aggregation level without having to replace the geodatabases.

\subsubsection{Enhancing HAZUS-MH with User-Supplied Data}

The loss estimates predicted by HAZUS-MH can be significantly improved by updating the default databases and parameters with user-supplied data. Level one analysis only 
uses the default databases built into the software. One soil condition is used for the entire study region, and liquefaction and landsliding effects are completely ignored. Indirect economic impacts are calculated based on a general economy that may not accurately portray the study area. Enhanced results are only as good as the data put into HAZUSMH. The City of Redlands data, at this point, are neither complete nor accurate enough to enhance the HAZUS-MH databases. The HAZUS-MH User Manual lists the following enhancements to the default inventory that could increase the accuracy of analysis results:

- "Development of maps of soil conditions affecting ground shaking, liquefaction and landsliding potential. These maps would be used for evaluation of the effects of these local conditions upon damage and losses.

- Use of locally available data or estimates concerning the square footage of buildings in different occupancy classes.

- Use of local expertise to modify, primarily by judgment, the databases concerning percentages of model building types associated with different occupancy classes.

- Preparation of a detailed inventory for all essential facilities.

- Collection of detailed inventory and cost data to improve evaluation of losses and lack of function in various transportation and utility lifelines.

- Use of locally available data concerning construction costs or other economic parameters.

- Collections of data, such as number of fire trucks, for evaluation of the probable extent of areas affected by fires.

- Development of inundation maps.

- Gathering of information concerning high potential loss facilities and facilities housing hazardous materials.

- Synthesis of data for modeling the economy of the study region used in calculation of indirect economic impacts." (FEMA, 2008b, p. 33)

Compiling this data would take a considerable amount of effort, and be extremely time consuming, but it would greatly increase the results of the analysis, and therefore, increase the effectiveness of the disaster management team.

\subsection{Shelter Suitability Model Enhancement}

The first way the model could be enhanced was mentioned in the previous section. If there was a more complete dataset for schools, other characteristics could be considered in the model. These include square footage of a school, which could help determine how many people each school could potentially shelter. The square footage, along with other attributes, like building type and design level, would also enhance the HAZUS-MH results so structural suitability would be more useful. Individual buildings that make up a school campus could also be input into HAZUS-MH, so the results would be more specific. HAZUS-MH assumes that each school is only one building, so the damage to the school is grouped together. It could be determined which school building would most likely act as the actual shelter, such as the gym or the cafeteria. Specifics attributes could be obtained about these buildings which, in turn, would allow for more accurate predictions of how the building will likely withstand an earthquake.

Another possible enhancement would be the use of a location-allocation tool, available in ArcInfo Workstation. The shelter capacity of the school and the number of 
people that might seek shelter would be required. Location-allocation is the process of determining the best possible location of a facility so that it is the most accessible to the population. This concept is used in retail to find ideal locations for stores that are accessible by the largest number of potential consumers. It is also used in emergency services, like determining a location for a new fire station so that households are reached within a certain time period. Location-allocation tools could be used to locate shelters where they will be the most accessible to the people who will need them.

\subsection{Summary}

This chapter summarized how the results of the project met the clients requirements, including delivering a working version of HAZUS-MH at the census block aggregation level for the defined study area. The possible extensions to the work completed were discussed, including supplying HAZUS-MH with detailed local inventory for more accurate analysis results. This would give the city of Redlands more reliable estimates of how a severe earthquake might affect the area. 


\section{Works Cited}

Amdahl, G. (2001). Disaster Response: GIS for Public Safety. Redlands, CA, USA: ESRI.

Bausch, D. (2003). HAZUS: FEMA's GIS-BASED risk assessment tool. Geospatial Information \& Technology Association .

Bausch, D., \& Hansen, R. (2009). A GIS-Based Methodology for Exporting the Hazards U.S. (HAZUS) Earthquake Model for Global Applications. Retrieved December 6, 2009, from Use HAZUS: http://www.usehazus.com/docs/gis_global_hazus.pdf

Chong, J.-R. (2009, January 24). Study finds troubling pattern of Southern California quakes. Retrieved January 27, 2009, from Los Angeles Times:

http://www.latimes.com/news/local/la-me-fault-quakes242009jan24,0,7734479.story

ESRI. (1999). GIS for Emergency Management. Retrieved October 3, 2009, from http://www.esri.com/library/whitepapers/pdfs/emermgmt.pdf

ESRI. (2008, July). ESRI Demographic Update Methodology: 2008/2013. Retrieved November 7, 2009, from

http://www.esri.com/library/whitepapers/pdfs/demographic-update-methodology2008.pdf

ESRI. (2009). ESRI Data: Updated Demographics. Retrieved December 6, 2009, from

ESRI Business Analyst: http://www.esri.com/data/esri_data/pdfs/2009-esriupdated-demographics-data-list.pdf

FEMA. (2005, January). HAZUS Annual Progress and Utilization Report for Fiscal Year 2004. Retrieved December 6, 2009, from HAZUS: FEMA's Methodology for Estimating Potential Losses from Disasters:

http://www.fema.gov/pdf/plan/prevent/hazus/dl_hazus04.pdf

FEMA. (2008, December). Dec 08 Hot Zone. Retrieved October 3, 2009, from HAZUS Hot Zone Newsletter: http://www.usehazus.com/uploads/main/HAZUS_newsletter_dec_08_06_opt.pdf

FEMA. (2008a). HAZUS-MH MR3 Earthquake Model Technical Manual. [Technical Manual that accompanies computer software]. Washington, D.C.

FEMA. (2008b). HAZUS-MH MR3 Earthquake Model User Manual. [User Manual that accompanies computer software].Washington, D.C.

FEMA. (2009a). Risk Map - Powered by HAZUS. Retrieved October 3, 2009, from HAZUS-MH Natural Hazard Loss Estimation: http://proceedings.esri.com/library/userconf/feduc09/papers/berman_esri_fed_uc_ 2009.pdf

FEMA. (2009b, August 28). FEMA: HAZUS. Retrieved January 27, 2009, from http://www.fema.gov/plan/prevent/hazus/

FEMA. (2009c, May). May 09 Hot Zone. Retrieved October 3, 2009, from HAZUS Hot Zone Newsletter: http://www.usehazus.com/uploads/main/May_09_Hot_Zone.pdf

Greene, R. (2002). Confronting Catastrophe: A GIS Handbook. Redlands, CA, USA: ESRI.

Hawaii State Department of Defense. (2005, February). Earthquake Hazards and Estimated Losses in the County of Hawaii. Retrieved February 6, 2009, from 
National Earthquake Hazards Reduction Program Resources:

http://www.nehrp.gov/resources/index.htm

Huyck, C. K., Castner, L. E., Bouabid, J., \& Eguchi, T. R. (2002). A Comprehensive Seismic Vulnerability and Loss Evaluation of the State of South Carolina Using Hazus: Part V Lifelines, Essential Facilities, and Hazardous Materials Sites. 7th National US Conference on Earthquake Engineering. Boston.

Jones, M. L., Cox, D., Bernkopf, R., Goltz, J., Hudnut, K., Mileti, D., et al. (2008). The ShakeOut Scenario. Retrieved February 7, 2009, from USGS Earthquake Hazards Program: http://pubs.usgs.gov/of/2008/1150/

Kar, B., \& Hodgson, M. E. (2008). A GIS-Based Model to Determine Site Suitability of Emergency Evacuation Shelters. Transactions in GIS , 12 (2), 227-248.

Lynch, D. K., \& Cole, B. M. (2009). San Andreas Fault Map - Zoom In on the Fault! Retrieved February 20, 2009, from Geology.com: http://geology.com/sanandreas-fault/

National Institute of Building Sciences. (2001, June 1). HAZUS99 - SR1 VALIDATION. Retrieved February 7, 2009, from HAZUS-Multihazard Loss Estimation Methodology: http://www.nibs.org/hazusweb/overview/pubs.php

National Institute of Building Sciences. (2002, April). A Guide to Using HAZUS for Mitigation. Retrieved February 7, 2009, from HAZUS-Multihazard Loss Estimation Methodology Publications: http://www.nibs.org/hazusweb/overview/pubs.php

Schneider, P. J. (1999). HAZUS, a GIS-Based Multihazard Loss Estimation Software Program. Nineteenth Annual ESRI User Conference. San Diego: ESRI.

U.S. Census Bureau. (2009, July 14). American Fact Finder Help. Retrieved October 2, 2009, from U.S. Census Bureau American Fact Finder: http://factfinder.census.gov/home/en/epss/glossary_c.html

Whitman, R. V., \& Lagorio, H. J. (n.d.). The FEMA-NIBS Methodology for Earthquake Loss Estimation. Retrieved February 7, 2009, from HAZUS-Multihazard Loss Estimation Methodology Publications: http://www.nibs.org/hazusweb/overview/pubs.php 


\section{Appendix A. Summary of HAZUS-MH Inventory Databases (Earthquake Module)}

\section{General Building Stock}

Occupancy Square Footage

Building Type- Occupancy

Essential Facilities

Medical Care Facilities

Emergency Operation Centers

Schools

\section{High Potential Loss Facilities}

Dams

Nuclear Power Facilities

Military Installations

Transportation System

Highway Segments

Highway Bridges

Highway Tunnels

Railway Track Segments

Railway Bridges

Railway Tunnels

Railway Facilities

Light Rail Track Segments

Light Rail Bridges

Light Rail Tunnels

Light Rail Facilities

Bus Facilities

Ports and Harbors Facilities

Ferry Facilities

Airports Facilities

Airports Runways

\section{Utility System}

Potable Water Pipeline Segments

Potable Water Facilities

Potable Water Distribution Lines

Waste Water Pipeline Segments

Waste Water Facilities

Waste Water Distribution Lines 
Oil Pipelines Segments

Oil Systems Facilities

Natural Gas Pipelines Segments

Natural Gas Facilities

Natural Gas Distribution Lines

Electric Power Facilities

Electric Power Distribution Lines

Communication Facilities

Communication Distribution Cables

Hazardous Materials Facilities

Population Inventory

(FEMA, 2008b) 


\section{Appendix B. ESRI Business Analyst Demographics Fields}

$\begin{array}{ll}\text { TOTPOP_CY } & \text { 2008 Total Population } \\ \text { GQPOP_CY } & \text { 2008 Group Quarters Population } \\ \text { TOTHH_CY } & \text { 2008 Total Households } \\ \text { OWNER_CY } & \text { 2008 Owner Occupied Housing Units } \\ \text { RENTER_CY } & \text { 2008 Renter Occupied Housing Units } \\ \text { VACANT_CY } & \text { 2008 Vacant Housing Units } \\ \text { MALES_CY } & \text { 2008 Male Population } \\ \text { MALEU5_CY } & \text { 2008 Male Population 0-4 } \\ \text { MALE5_CY } & \text { 2008 Male Population 5-9 } \\ \text { MALE10_CY } & \text { 2008 Male Population 10-14 } \\ \text { MALE15_CY } & \text { 2008 Male Population 15-19 } \\ \text { MALE20_CY } & \text { 2008 Male Population 20-24 } \\ \text { MALE25_CY } & \text { 2008 Male Population 25-29 } \\ \text { MALE30_CY } & \text { 2008 Male Population 30-34 } \\ \text { MALE35_CY } & \text { 2008 Male Population 35-39 } \\ \text { MALE40_CY } & \text { 2008 Male Population 40-44 } \\ \text { MALE45_CY } & \text { 2008 Male Population 45-49 } \\ \text { MALE50_CY } & \text { 2008 Male Population 50-54 } \\ \text { MALE55_CY } & \text { 2008 Male Population 55-59 } \\ \text { MALE60_CY } & \text { 2008 Male Population 60-64 } \\ \text { MALE65_CY } & \text { 2008 Male Population 65-69 } \\ \text { MALE70_CY } & \text { 2008 Male Population 70-74 } \\ \text { MALE75_CY } & \text { 2008 Male Population 75-79 } \\ \text { MALE80_CY } & \text { 2008 Male Population 80-84 } \\ \text { MALE85_CY } & \text { 2008 Male Population 85+ } \\ \text { FEMALES_CY } & \text { 2008 Female Population } \\ \text { FEMU5_CY } & \text { 2008 Female Population 0-4 } \\ \text { FEM5_CY } & \text { 2008 Female Population 5-9 } \\ \text { FEM10_CY } & \text { 2008 Female Population 10-14 } \\ \text { FEM15_CY } & \text { 2008 Female Population 15-19 } \\ \text { FEM20_CY } & \text { 2008 Female Population 20-24 } \\ \text { FEM25_CY } & \text { 2008 Female Population 25-29 } \\ \text { FEM30_CY } & \text { 2008 Female Population 30-34 } \\ \text { FEM35_CY } & \text { 2008 Female Population 35-39 } \\ \text { FEM40_CY } & \text { 2008 Female Population 40-44 } \\ \text { FEM45_CY } & \text { 2008 Female Population 45-49 } \\ \text { FEM50_CY } & \text { 2008 Female Population 50-54 } \\ \text { FEM55_CY } & \text { 2008 Female Population 55-59 } \\ \text { FEM60_CY } & \text { 2008 Female Population 60-64 } \\ \text { FEM65_CY } & \text { 2008 Female Population 65-69 } \\ \text { FEM70_CY } & \text { 2008 Female Population 70-74 } \\ \text { FEM75_CY } & \text { Female Population 75-79 } \\ \text { FALY_CY } & \end{array}$




\begin{tabular}{|c|c|}
\hline FEM80_CY & 2008 Female Population 80-84 \\
\hline FEM85_CY & 2008 Female Population $85+$ \\
\hline WHITE_CY & 2008 Population of 1 Race: White \\
\hline BLACK_CY & 2008 Population of 1 Race: Black \\
\hline AMERIND_CY & 2008 Population of 1 Race: American Indian/Alaska Native \\
\hline ASIAN_CY & 2008 Population of 1 Race: Asian \\
\hline PACIFIC_CY & 2008 Population of 1 Race: Pacific Islander \\
\hline OTHRACE_CY & 2008 Population of 1 Race: Other Race \\
\hline RACE2UP_CY & 2008 Population of Two or More Races \\
\hline HISPPOP_CY & 2008 Total Hispanic Population \\
\hline HINC0_CY & 2008 Households with Income $<\$ 10000$ \\
\hline HINC10_CY & 2008 Households with Income \$10000-\$14999 \\
\hline HINC15_CY & 2008 Households with Income \$15000-\$19999 \\
\hline HINC20_CY & 2008 Households with Income \$20000-\$24999 \\
\hline HINC25_CY & 2008 Households with Income \$25000-\$29999 \\
\hline HINC30_CY & 2008 Households with Income $\$ 30000-\$ 34999$ \\
\hline HINC35_CY & 2008 Households with Income \$35000-\$39999 \\
\hline HINC40_CY & 2008 Households with Income \$40000-\$44999 \\
\hline HINC45_CY & 2008 Households with Income \$45000-\$49999 \\
\hline HINC50_CY & 2008 Households with Income \$50000-\$59999 \\
\hline HINC60_CY & 2008 Households with Income \$60000-\$74999 \\
\hline HINC75_CY & 2008 Households with Income \$75000-\$99999 \\
\hline HINC100_CY & 2008 Households with Income \$100000-\$124999 \\
\hline HINC125_CY & 2008 Households with Income $\$ 125000-\$ 149999$ \\
\hline HINC150_CY & 2008 Households with Income \$150000-\$199999 \\
\hline HINC200_CY & 2008 Households with Income $\$ 200000-\$ 249999$ \\
\hline HINC250_CY & 2008 Households with Income $\$ 250000-\$ 499999$ \\
\hline HINC500_CY & 2008 Households with Income $\$ 500000+$ \\
\hline ТОТРОРО0 & 2000 Total Population \\
\hline GQPOP00 & 2000 Pop in Group Quarters \\
\hline TOTHН00 & 2000 Total Households \\
\hline OWNEROCCOO & 2000 Owner Occupied HUs \\
\hline RENTROCCOO & 2000 Renter Occupied HUs \\
\hline $\begin{array}{l}\text { VACANTHU00 } \\
\text { (ESRI, 2009) }\end{array}$ & 2000 Vacant HUs 2000 Vacant Housing Units \\
\hline
\end{tabular}




\section{Appendix C. Census Disaggregation Field Map and Calculations}

\begin{tabular}{|c|c|c|}
\hline HAZUS-MH fields & 2008 Field Names & Calculation \\
\hline Population & BlockPop2008 & $\begin{array}{l}\text { [CensusBlocks.Population] } * \\
\text { [CensusBlocks.PopGrowthRatio] }\end{array}$ \\
\hline Households & BlockHH2008 & $\begin{array}{l}\text { [CensusBlocks.Households] }{ }^{*} \\
\text { [CensusBlocks.HHGrowthRatio] }\end{array}$ \\
\hline GroupQuarters & BlockGQ2008 & $\begin{array}{l}\text { [CensusBlocks.GroupQuarters] } \\
\text { [CensusBlocks.GQGrowthRatio] }\end{array}$ \\
\hline MalesLess 16 & MaleLess16_2008 & $\begin{array}{l}\text { ([CensusBlockGrps.MALEU5_CY]+ } \\
\text { [CensusBlockGrps.MALE5_CY] + } \\
\text { [CensusBlockGrps.MALE10_CY])* } \\
\text { [CensusBlocks.BlkGrpRatio] }\end{array}$ \\
\hline Male16to65 & Male16to65_2008 & $\begin{array}{l}\text { ([CensusBlockGrps.MALE15_CY] + } \\
\text { [CensusBlockGrps.MALE20_CY] + } \\
\text { [CensusBlockGrps.MALE25_CY] + } \\
\text { [CensusBlockGrps.MALE30_CY] + } \\
\text { [CensusBlockGrps.MALE35_CY] + } \\
\text { [CensusBlockGrps.MALE40_CY] + } \\
\text { [CensusBlockGrps.MALE45_CY] + } \\
\text { [CensusBlockGrps.MALE50_CY] + } \\
\text { [CensusBlockGrps.MALE55_CY] + } \\
\text { [CensusBlockGrps.MALE60_CY] }{ }^{*} \\
\text { [CensusBlocks.BlkGrpRatio] }\end{array}$ \\
\hline MaleOver65 & MaleOver65_2008 & $\begin{array}{l}\text { [CensusBlocks.BlockMale2008] - } \\
\text { [CensusBlocks.MaleLess16_2008] - } \\
\text { [CensusBlocks.Male16to65_2008] }\end{array}$ \\
\hline FemaleLess16 & FemaleLess16_2008 & $\begin{array}{l}\text { ( [CensusBlockGrps.FEM5_CY] + } \\
\text { [CensusBlockGrps.FEM10_CY] } \\
+[\text { CensusBlockGrps.FEMU5_CY])* } \\
\text { [CensusBlocks.BlkGrpRatio] }\end{array}$ \\
\hline Female16to65 & Female16to65_2008 & $\begin{array}{l}\text { ( [CensusBlockGrps.FEM15_CY] + } \\
\text { [CensusBlockGrps.FEM20_CY] + } \\
\text { [CensusBlockGrps.FEM25_CY] + } \\
\text { [CensusBlockGrps.FEM30_CY] + } \\
\text { [CensusBlockGrps.FEM35_CY] + } \\
\text { [CensusBlockGrps.FEM40_CY] + } \\
\text { [CensusBlockGrps.FEM45_CY] + } \\
\text { [CensusBlockGrps.FEM50_CY] + } \\
\text { [CensusBlockGrps.FEM55_CY] + } \\
\text { [CensusBlockGrps.FEM60_CY]) * } \\
\text { [CensusBlocks.BlkGrpRatio] }\end{array}$ \\
\hline FemaleOver65 & FemaleOver65_2008 & $\begin{array}{l}\text { [CensusBlocks.BlockFemale2008] - } \\
\text { [CensusBlocks.Female16to65_2008] - }\end{array}$ \\
\hline
\end{tabular}




\begin{tabular}{|c|c|c|}
\hline & & [CensusBlocks.FemaleLess16_2008] \\
\hline MalePopulation & BlockMale2008 & $\begin{array}{l}\text { [CensusBlocks.BlockPop2008] * } \\
\text { [CensusBlocks.BlockMaleRatio] }\end{array}$ \\
\hline FemalePopulation & BlockFemale2008 & $\begin{array}{l}\text { [CensusBlocks.BlockPop2008] * } \\
\text { [CensusBlocks.BlockFemaleRatio] }\end{array}$ \\
\hline White & White2008 & $\begin{array}{l}\text { [CensusBlockGrps.WHITE_CY] * } \\
\text { [CensusBlocks.BlkGrpRatio] }\end{array}$ \\
\hline Black & Black2008 & $\begin{array}{l}\text { [CensusBlockGrps.BLACK_CY] * } \\
\text { [CensusBlocks.BlkGrpRatio] }\end{array}$ \\
\hline NativeAmerican & NativeAm2008 & $\begin{array}{l}\text { [CensusBlockGrps.AMERIND_CY] * } \\
\text { [CensusBlocks.BlkGrpRatio] }\end{array}$ \\
\hline Asian & Asian2008 & $\begin{array}{l}\text { [CensusBlockGrps.ASIAN_CY] * } \\
\text { [CensusBlocks.BlkGrpRatio] }\end{array}$ \\
\hline Hispanic & Hispanic2008 & $\begin{array}{l}\text { [CensusBlocks.BlkGrpRatio] * } \\
\text { [CensusBlockGrps.HISPPOP_CY] }\end{array}$ \\
\hline PacificIslander & PacIsland2008 & $\begin{array}{l}\text { [CensusBlockGrps.PACIFIC_CY] * } \\
\text { [CensusBlocks.BlkGrpRatio] }\end{array}$ \\
\hline OtherRaceOnly & OtherRace2008 & $\begin{array}{l}\text { [CensusBlocks.BlockPop2008] - } \\
\text { [CensusBlocks.White2008] - } \\
\text { [CensusBlocks.Black2008] - } \\
\text { [CensusBlocks.NativeAm2008] - } \\
\text { [CensusBlocks.Asian2008] - } \\
\text { [CensusBlocks.PacIsland2008] }\end{array}$ \\
\hline IncLess 10 & HHIncLess10_2008 & $\begin{array}{l}\text { [CensusBlockGrps.HINC0_CY]* } \\
\text { [CensusBlocks.BlkGrpHHRatio] }\end{array}$ \\
\hline Inc10to20 & HHInc10to20_2008 & $\begin{array}{l}\text { ([CensusBlockGrps.HINC10_CY] + } \\
\text { [CensusBlockGrps.HINC15_CY] }{ }^{*} \\
\text { [CensusBlocks.BlkGrpHHRatio] }\end{array}$ \\
\hline Inc20to30 & HHInc20to30_2008 & $\begin{array}{l}\text { ([CensusBlockGrps.HINC20_CY] + } \\
\text { [CensusBlockGrps.HINC25_CY] ) } \\
\text { [CensusBlocks.BlkGrpHHRatio] }\end{array}$ \\
\hline Inc30to40 & HHInc30to40_2008 & $\begin{array}{l}\text { ([CensusBlockGrps.HINC30_CY] + } \\
\text { [CensusBlockGrps.HINC35_CY] ) } \\
\text { [CensusBlocks.BlkGrpHHRatio] }\end{array}$ \\
\hline Inc40to50 & HHInc40to50_2008 & $\begin{array}{l}\text { ([CensusBlockGrps.HINC40_CY] + } \\
\text { [CensusBlockGrps.HINC45_CY] ) } \\
\text { [CensusBlocks.BlkGrpHHRatio] }\end{array}$ \\
\hline Inc50to60 & HHInc50to60_2008 & $\begin{array}{l}\text { [CensusBlockGrps.HINC50_CY] * } \\
\text { [CensusBlocks.BlkGrpHHRatio] }\end{array}$ \\
\hline Inc60to75 & HHInc60to75_2008 & $\begin{array}{l}\text { ([CensusBlockGrps.HINC60_CY] * } \\
\text { [CensusBlocks.BlkGrpHHRatio] }\end{array}$ \\
\hline Inc75to100 & HHInc75to100_2008 & $\begin{array}{l}\text { [CensusBlockGrps.HINC75_CY] } * \\
\text { [CensusBlocks.BlkGrpHHRatio] }\end{array}$ \\
\hline IncOver100 & HHIncOver100_2008 & $\begin{array}{l}\text { [CensusBlocks.BlockHH2008] - } \\
\text { [CensusBlocks.HHIncLess10_2008] - } \\
\text { [CensusBlocks.HHInc10to20_2008] - }\end{array}$ \\
\hline
\end{tabular}




\begin{tabular}{|c|c|c|}
\hline & & $\begin{array}{l}\text { [CensusBlocks.HHInc20to30_2008] - } \\
\text { [CensusBlocks.HHInc30to40_2008] - } \\
\text { [CensusBlocks.HHInc40to50_2008] - } \\
\text { [CensusBlocks.HHInc50to60_2008] - } \\
\text { [CensusBlocks.HHInc60to75_2008] - } \\
\text { [CensusBlocks.HHInc75to100_2008] }\end{array}$ \\
\hline ResidDay & ResidDay_2008 & $\begin{array}{l}\text { [CensusBlocks.BlockPop2008] }{ }^{*} \\
\text { [CensusBlocks.ResidDayRatio] }\end{array}$ \\
\hline ResidNight & ResidNight_2008 & $\begin{array}{l}\text { [CensusBlocks.BlockPop2008] } * \\
\text { [CensusBlocks.ResidNightRatio] }\end{array}$ \\
\hline WorkingCom & WorkingCom_2008 & $\begin{array}{l}\text { [CensusBlocks.BlockPop2008]* } \\
\text { [CensusBlocks.WorkingComRatio] }\end{array}$ \\
\hline WorkingInd & WorkingInd_2008 & $\begin{array}{l}\text { [CensusBlocks.BlockPop2008] * } \\
\text { [CensusBlocks.WorkingIndRatio] }\end{array}$ \\
\hline OwnerSingleUnits & OwnerSingleUnits_2008 & $\begin{array}{l}\text { [CensusBlocks.OwnerSingleUnits] }{ }^{*} \\
\text { [CensusBlocks.OwnerBlkGrpRatio] }\end{array}$ \\
\hline OwnerMultiUnits & OwnerMultiUnits_2008 & $\begin{array}{l}\text { [CensusBlocks.OwnerMultUnits] }{ }^{*} \\
\text { [CensusBlocks.OwnerBlkGrpRatio] }\end{array}$ \\
\hline OwnerMultiStructs & OwnerMultiStructs_2008 & $\begin{array}{l}\text { [CensusBlocks.OwnerMultStructs] }{ }^{*} \\
\text { [CensusBlocks.OwnerBlkGrpRatio] }\end{array}$ \\
\hline OwnerMHs & OwnerMHs_2008 & $\begin{array}{l}\text { [CensusBlocks.OnwerMHs] }{ }^{*} \\
\text { [CensusBlocks.OwnerBlkGrpRatio] }\end{array}$ \\
\hline RenterSingleUnits & RenterSingleUnits_2008 & $\begin{array}{l}\text { [CensusBlocks.RenterSingleUnits] } \\
\text { [CensusBlocks.OwnerBlkGrpRatio] }\end{array}$ \\
\hline RenterMultiUnits & RenterMultiUnits_2008 & $\begin{array}{l}\text { [CensusBlocks.RenterMultUnits] } \\
\text { [CensusBlocks.RenterBlkGrpRatio] }\end{array}$ \\
\hline RenterMultiStructs & RenterMultiStructs_2008 & $\begin{array}{l}\text { [CensusBlocks.RenterMultStructs] }{ }^{*} \\
\text { [CensusBlocks.RenterBlkGrpRatio] }\end{array}$ \\
\hline RenterMHs & RenterMHs_2008 & $\begin{array}{l}\text { [CensusBlocks.RenterMHs] }{ }^{*} \\
\text { [CensusBlocks.RenterBlkGrpRatio] }\end{array}$ \\
\hline VacantSingleUnits & VacantSingleUnits_2008 & $\begin{array}{l}\text { [CensusBlocks.VacantSingleUnits] } \\
\text { [CensusBlocks.VacantBlkGrpRatio] }\end{array}$ \\
\hline VacantMultiUnits & VacantMultiUnits_2008 & $\begin{array}{l}\text { [CensusBlocks.VacantMultUnits] }{ }^{*} \\
\text { [CensusBlocks.VacantBlkGrpRatio] }\end{array}$ \\
\hline VacantMultiStructs & VacantMultiStructs_2008 & $\begin{array}{l}\text { [CensusBlocks.VacantMultStructs] } \\
\text { [CensusBlocks.VacantBlkGrpRatio] }\end{array}$ \\
\hline VacantMHs & VacantMHs_2008 & $\begin{array}{l}\text { [CensusBlocks.VacantMHs] * } \\
\text { [CensusBlocks.VacantBlkGrpRatio] }\end{array}$ \\
\hline
\end{tabular}

